\title{
Identification and Interaction Analysis of Molecular Markers in Pancreatic Ductal Adenocarcinoma by Integrated Bioinformatics Analysis and Molecular Docking Experiments
}

Basavaraj Vastrad $^{1}$, Chanabasayya Vastrad ${ }^{* 2}$, Anandkumar Tengli ${ }^{3}$

1. Department of Biochemistry, Basaveshwar College of Pharmacy, Gadag, Karnataka 582103, India.

2. Biostatistics and Bioinformatics, Chanabasava Nilaya, Bharthinagar, Dharwad, Karanataka 580001, India.

3. Department of Pharmaceutical Chemistry, JSS College of Pharmacy, Mysuru and JSS Academy of Higher Education \& Research, Mysuru- 570015, Karnataka, India.

* Chanabasayya Vastrad channu.vastrad@gmail.com

Ph: +919480073398

Chanabasava Nilaya, Bharthinagar,

Dharwad 580001 , Karanataka, India 
medRxiv preprint doi: https://doi.org/10.1101/2020.12.20.20248601; this version posted December 23, 2020. The copyright holder for this

\begin{abstract}
The current investigation aimed to mine therapeutic molecular targets that play an key part in the advancement of pancreatic ductal adenocarcinoma (PDAC). The expression profiling by high throughput sequencing dataset profile GSE133684 dataset was downloaded from the Gene Expression Omnibus (GEO) database. Limma package of $\mathrm{R}$ was used to identify differentially expressed genes (DEGs). Functional enrichment analysis of DEGs were performed. Protein-protein interaction (PPI) networks of the DEGs were constructed. An integrated gene regulatory network was built including DEGs, microRNAs (miRNAs), and transcription factors. Furthermore, consistent hub genes were further validated. Molecular docking experiment was conducted. A total of 463 DEGs (232 up regulated and 231 down regulated genes) were identified between very early PDAC and normal control samples. The results of Functional enrichment analysis revealed that the DEGs were significantly enriched in vesicle organization, secretory vesicle, protein dimerization activity, lymphocyte activation, cell surface, transferase activity, transferring phosphorus-containing groups, hemostasis and adaptive immune system. The PPI network and gene regulatory network of up regulated genes and down regulated genes were established, and hub genes were identified. The expression of hub genes (CCNB1, FHL2, HLA-DPA1 and TUBB1) were also validated to be differentially expressed among PDAC and normal control samples. Molecular docking experiment predicted the novel inhibitory molecules for CCNB1 and FHL2. The identification of hub genes in PDAC enhances our understanding of the molecular mechanisms underlying the progression of this disease. These genes may be potential diagnostic biomarkers and/or therapeutic molecular targets in patients with PDAC.
\end{abstract}

Keywords: pancreatic ductal adenocarcinoma; bioinformatics analysis; biomarker; enrichment analysis; differentially expressed genes 
medRxiv preprint doi: https://doi.org/10.1101/2020.12.20.20248601; this version posted December 23, 2020. The copyright holder for this

\section{Introduction}

Pancreatic ductal adenocarcinoma (PDAC) is one of the most prevalent cancers in the world and primary tumor of the pancreas [1]. PDAC is a global burden ranking 15 th in terms of incidence and fourth in terms of mortality [2]. Despite new developments in multimodal therapy its overall 5-year survival rate remains less than $8 \%$ [3]. PDAC treatment commonly includes surgery, radiation, chemotherapy and immunotherapy [4]. However, PDAC remains common and malignant due to recurrence and metastasis, and ultimately key cause of PDAC associated death [5]. Therefore, there is a vital need to advance new diagnostic strategies and therapeutic agents to upgrade the prognosis of patients with PDAC.

The molecular mechanisms of PDAC tumorigenesis and development remain imprecise. It is therefore key to identify novel genes and pathways that are linked with PDAC tumorigenesis and patient prognosis, which may not only help to illuminate the underlying molecular mechanisms involved, but also to disclose novel diagnostic markers and therapeutic targets. Oji et al [6] demonstrated that the over expression of WT1 is linked with prognosis in patients with PDAC. A previous investigation reported that phosphoinositide 3-kinase signaling pathway is linked with development of PDAC [7]. Expression profiling by high throughput sequencing can promptly uncover gene expression on a global basis and are specially useful in identifying for differentially expressed genes (DEGs) [8]. A huge amount of data has been generated through the use of microarrays and the majority of such data has been deposited and saved in public databases. Previous investigations concerning PDAC gene expression profiling have diagnosed hundreds of DEGs [9].

The aim of this investigation was to identify hub genes and pathways in PDAC using bioinformatics methods. Our investigation contributes predictable biomarkers for early detection and prognosis, as well as effective drug targets for treating PDAC.

\section{Materials and methods}

\section{Sequencing data}


medRxiv preprint doi: https://doi.org/10.1101/2020.12.20.20248601; this version posted December 23, 2020. The copyright holder for this preprint (which was not certified by peer review) is the author/funder, who has granted medRxiv a license to display the preprint in perpetuity. All rights reserved. No reuse allowed without permission.

PDAC expression profiling by high throughput sequencing dataset in this investigation was downloaded from the GEO database (https://www.ncbi.nlm.nih.gov/gds/) [10]. The DEGs were considered by 1 independent PDAC dataset, GSE133684 [11] with 284 PDAC and 117 normal samples. The GSE133684 expression profiling by high throughput sequencing data was based on the GPL20795 HiSeq X Ten (Homo sapiens) platform..

\section{Identification of DEGs}

The Limma package of $\mathrm{R}$ language were used to normalize and convert the raw data to expression profiles [12]. The limma package of $\mathrm{R}$ language was used for DEGs between PDAC and normal control samples [12]. The P-value was adjusted by the Benjamini-Hochberg method [13]. An adjusted P-value $<0.05$ and $\mid \log 2$ fold change (FC) $\mid>1$ were considered as threshold values for DEGs identification. The ggplot2 package and gplots package of $\mathrm{R}$ language was used to generate volcano plot and heat map. The identified DEGs were preserved for further bioinformatics analysis.

\section{GO analysis and pathway enrichment analysis of DEGs}

The GO repository (http://geneontology.org/) [14] consists of a massive set of annotation terms and is generally used for annotating genes and identifying the distinctive biological aspects for expression profiling by high throughput sequencing data. The REACTOME database (https://reactome.org/) [15] contains data on known genes and their biochemical functions and is used for identifying functional and metabolic pathways. By performing the GO and REACTOME enrichment analysis at the functional level, we can boost a better understanding of the roles of these DEGs in the induction and in the advancement of PDAC. The ToppGene (ToppFun) (https://toppgene.cchmc.org/enrichment.jsp) [16] is an online resource that add tools for functional annotation and bioinformatics analysis. Both GO categories and REACTOME pathway enrichment analysis were implemented using ToppGene to inform the functions of these DEGs. $\mathrm{P}<0.05$ was considered to indicate a statistically significant difference.

\section{Protein-protein interaction (PPI) network construction and module analysis}


medRxiv preprint doi: https://doi.org/10.1101/2020.12.20.20248601; this version posted December 23, 2020. The copyright holder for this

The online database IID interactome (http://iid.ophid.utoronto.ca//) [17] was used to construct a PPI network of the proteins encoded by DEGs. Then, Cytoscape software (Version 3.8.1) [18] was applied to perform protein interaction association network analysis and analyze the interaction correlation of the candidate proteins encoded by the DEGs in PDAC. Next, the Network Analyzer Cytoscape plug-in was applied to calculate node degree [19], betweenness centrality [20], stress centrality [21], closeness centrality [22]. Finally, the PEWCC1 (http://apps.cytoscape.org/apps/PEWCC1) [23] module for Cytoscape was used to collect the significant modules in the PPI network complex.

\section{Construction of miRNA-DEG regulatory network}

The miRNet database (https://www.mirnet.ca/) [24] is a database, containing miRNAs involved in various diseases. The miRNAs related to PDAC were searched from miRNet database. Through getting the intersection of the miRNAs and the DEGs, the miRNA-DEG regulatory relationships were selected. Finally, miRNA-DEG regulatory network was built using Cytoscape software.

\section{Construction of TF-DEG regulatory network}

The NetworkAnalyst database (https://www.networkanalyst.ca/) [25] is a database, containing TFs involved in various diseases. The TFs related to PDAC were searched from TF database. Through getting the intersection of the TFs $s$ and the DEGs, the TF-DEG regulatory relationships were selected. Finally, TFs -DEG regulatory network was built using Cytoscape software.

\section{Hub genes validation}

After hub genes identified from expression profiling by high throughput sequencing dataset, UALCAN (http://ualcan.path.uab.edu/analysis.html) [26] was used to validate the selected up regulated and down regulated hub genes. UALCAN is an online tool for gene expression analysis between PDAC and normal data from The Cancer Genome Atlas (TCGA). It adds data such as gene expression, tumor staging, and survival period for PDAC. cBioPortal is an online platform (http://www.cbioportal.org) [27] for gene alteration of hub genes analysis from TCGA. Human protein atlas is an online database (HPA, WwW.proteinatlas.org) [28] for protein expression analysis between PDAC and 
medRxiv preprint doi: https://doi.org/10.1101/2020.12.20.20248601; this version posted December 23, 2020. The copyright holder for this

normal data from TCGA. TIMER is an online platform (https://cistrome.shinyapps.io/timer/) [29] for immune infiltration analysis from TCGA. To explore diagnostic biomarkers of PDAC, we used the above hub genes as candidates to find their diagnostic value based on generalized linear model (GLM) [30]. The pROC in R was used for Receiver operating characteristic (ROC) curve analysis [30]. In brief, half of the samples ( $\mathrm{PDAC}=142$, controls $=59$ ) were aimlessly distributed as the training set and remaining data were used as the test set, which were used to set up a model. An ROC curve analysis was tested to calculate the specificity and sensitivity of the GLM prediction model. The area under the curve (AUC) was figure out to determine the diagnostic efficiency of the classifier.

\section{RT-PCR analysis}

TRI Reagent ${ }^{\circledR}$ (Sigma, USA) was used to extract total RNA from the culture cells of PDAC (CRL-2549TM) and normal (CRL-2989 ${ }^{\mathrm{TM}}$ ) according to the manufacturer's protocol. Reverse transcription cDNA kit (Thermo Fisher Scientific, Waltham, MA, USA) and random primers were used to synthesize cDNA. Quantitative real-time PCR (qRT-PCR) was conducted on the 7 Flex realtime PCR system (Thermo Fisher Scientific, Waltham, MA, USA). The reaction guideline included a denaturation program $\left(5 \mathrm{~min}\right.$ at $\left.95{ }^{\circ} \mathrm{C}\right)$, followed by an amplification and quantification program over 40 cycles $\left(15 \mathrm{~s}\right.$ at $95^{\circ} \mathrm{C}$ and $45 \mathrm{~s}$ at $65^{\circ} \mathrm{C}$ ). Each sample was tested in triplicates. Table 1 depicts the primer sequences of hub genes. The expression level was resolved as a ratio between the hub genes and the internal control $\beta$-actin in the same mRNA sample, and determined by the comparative CT method [31]. Levels of CCNB1, FHL2, HLA-DPA1 and TUBB1 expression were determined by the $2^{-\Delta \Delta \mathrm{Ct}}$ method.

\section{Molecular docking experiment}

The module SYBYL-X 2.0 perpetual software were used for Surflex-Docking of the designed molecules. The molecules were sketched by using ChemDraw Software and imported and saved in sdf. format using openbabel free software. The protein structures of CyclinB1 (CCNB1) its co-crystallisedprotein of PDB code 4Y72, 5H0V and Four and half LIM domains 2 (FHL2) its NMR structure of proteins 2D8Z and 2EHE was retrieved from Protein Data Bank [32-34]. Together 
medRxiv preprint doi: https://doi.org/10.1101/2020.12.20.20248601; this version posted December 23, 2020. The copyright holder for this

with the TRIPOS force field, GasteigerHuckel $(\mathrm{GH})$ charges were added to all designed derivatives for the structure optimization process.In addition, energy minimization was carried outusing MMFF94s and MMFF94 algorithm process. Protein processing was carried out after the incorporation of protein. The cocrystallized ligand and all water molecules were removed from the crystal structure; more hydrogens were added and the side chain was set. TRIPOS force field was used for the minimization of structure. The compounds' interaction efficiency with the receptor was represented by the Surflex-Dock score in kcal / mol units. The interaction between the protein and the ligand, the best pose was incorporated into the molecular area. The visualisation of ligand interaction with receptor is done by using discovery studio visualizer.

\section{Results}

\section{Identification of DEGs}

We analyzed the DEGs of GSE133684 by using the limma package. We used $\mathrm{p} \square<\square 0.05$ and $|\log \mathrm{FC}| \square \geq \square 1$ as the cutoff criteria. We screened 463 DEGs, including 232 up regulated genes and 231 down regulated genes in PDAC samples compared with normal control samples and are listed in Table 2. We identified all the DEGs which were shown in the above volcano map according to the value of $|\log F C|$ is shown in Fig. 1 and then displayed the DEGs on a heatmap is shown in Fig. 2.

\section{GO analysis and pathway enrichment analysis of DEGs}

To symbolize the function of the DEGs and to identify important candidate pathways, GO functional enrichment analysis and REACTOME pathway enrichment analysis were performed. The results of GO categories analysis including biological processes (BP), cellular components (CC) and molecular functions (MF) are listed in Table 3. Firstly, the up regulated genes were annotated with the BP category, including vesicle organization and secretion, whereas the down regulated genes were annotated with the GO terms, including lymphocyte activation and regulation of cell death. Secondly, the up regulated genes were annotated with the GO terms of the CC category, namely secretory vesicle and whole membrane, whereas the down regulated genes were annotated with the GO terms, including cell surface and intrinsic component of plasma membrane. 
medRxiv preprint doi: https://doi.org/10.1101/2020.12.20.20248601; this version posted December 23, 2020. The copyright holder for this

Thirdly, the up regulated genes were annotated with the GO terms of the MF category, such as protein dimerization activity and signaling receptor binding, whereas the down regulated genes were annotated with the GO terms, including transferase activity, transferring phosphorus-containing groups and drug binding. As shown in Table 4, the significantly enriched REACTOME pathways of the up regulated genes with $\mathrm{P}<0.05$ were hemostasis and cell cycle, whereas down regulated genes with $\mathrm{P}<0.05$ were adaptive immune system and transmembrane transport of small molecules.

\section{Protein-protein interaction (PPI) network construction and module analysis}

After all the DEGs were uploaded to the online IID interactome database, the PPI network with 6188 nodes and 13153 edges was constructed using the Cytoscape software (Fig. 3A). Hub DEGs with the node degree, betweenness centrality, stress centrality and closeness centrality were obtained and are listed in Table 5. Among them, CCNB1 and FHL2 were the major up regulated genes, while HLADPA1 and TUBB1 were the major down regulated genes. Then, two significant module that fulfilled the cut-off criteria, namely, PEWCC1 scores $>3$ and number of nodes $>5$, was screened (Fig. 3B and Fig. 3C). The FGB, FGA, FGG, EEF1A1, RPL13A, ITGA4, RPL27A, RPL23A and RPL10 genes were identified in these modules. GO analysis of these genes showed that they were annotated with vesicle organization, regulation of cell death and lymphocyte activation. In addition, the REACTOME enrichment analysis suggested that these genes were mainly involved in hemostasis, innate immune system, disease and adaptive immune system.

\section{Construction of miRNA-DEG regulatory network}

The regulatory network of miRNA-DEG and predicted targets is presented in Fig. 4A. Notably, MAP1B targeted 202 miRNAs, including hsa-mir-4461; CCNB1 targeted 94 miRNAs, including hsa-mir-3928-3p; AHNAK targeted 256 miRNAs, including hsa-mir-2682-5p; KMT2D targeted 209 miRNAs, including hsa-mir1202 and top 20 are listed in Table 6. As a group, a total of 257 of the 463 DEGs were contained in the miRNA-DEG regulatory network.

\section{Construction of TF-DEG regulatory network}


medRxiv preprint doi: https://doi.org/10.1101/2020.12.20.20248601; this version posted December 23, 2020. The copyright holder for this

The regulatory network of TF-DEG and predicted targets is presented in Fig. 4B. Notably, EZH2 targeted 45 TFs, including SOX2; TPM1 targeted 40 TFs, including MYC; AHNAK targeted 58 TFs, including KLF4, TXNIP targeted 51 TFs, including TP63 and top 20 are listed in Table 6. As a group, a total of 259 of the 463 DEGs were contained in the TF-DEG regulatory network.

\section{Hub genes validation}

All of the hub genes were validated in TCGA data. Hub genes contributed to the survival period in patients with PDAC, we analyzed the overall survival (OS) for each hub gene by UALCAN (Fig. 5). The results showed that the high expression of CCNB1 and FHL2 mRNA level were associated with the worse OS in patients with PDAC, while low expression of HLA-DPA1 and TUBB1 mRNA level were associated with the worse OS in patients with PDAC. As shown in Fig. 6, the expression of the up regulated hub genes CCNB1 and FHL2 in PDAC were significantly elevated compared with normal, while expression of the down regulated hub genes HLA-DPA1 and TUBB1 in PDAC were significantly decreased compared with normal. The expression of each hub gene in PDAC patients was analyzed according to the individual cancer stage. As shown in Fig. 7, the expression of CCNB1 and FHL2 were higher in patients with all individual cancer stages than that in normal, which revealed that these up regulated hub genes might be associated with tumor progression positively, where as the expression of HLA-DPA1 and TUBB1 were lower in patients with all individual cancer stages than that in normal, which revealed that these down regulated hub genes might be associated with tumor progression positively. We used cBioportal tool to explore the specific mutation of hub genes in PDAC dataset with 184 samples. From the OncoPrint, percentages of alterations in CCNB1, FHL2, HLA-DPA1 and TUBB1 genes among lung cancer ranged from $0 \%$ to $2.3 \%$ in individual genes (CCNB1, 0\%; FHL2, 0.6\%; HLA-DPA1, 2.3\%; TUBB1, 2.3\%) and is shown in Fig. 8. In addition, we used the 'HPA' to examine the protein expression levels of CCNB1 and FHL2, and observed that the protein expression levels of the these hub genes were noticeably up regulated in PDAC compared with normal tissues, whereas protein expression levels of HLA-DPA1 and TUBB1, and observed that the protein expression levels of the these hub genes were noticeably down regulated in PDAC compared with normal tissues (Fig. 9). The association of CCNB1, FHL2, HLADPA1 and TUBB1 expression level with immune infiltration abundance in PDAC 
medRxiv preprint doi: https://doi.org/10.1101/2020.12.20.20248601; this version posted December 23, 2020. The copyright holder for this

was evaluated using TIMER database. CCNB1 and FHL2 expression were negatively correlated with infiltration degree of $\mathrm{B}$ cells, CD8+ $\mathrm{T}$ cells, macrophage, neutrophil, and dendritic cells, where as HLA-DPA1 and TUBB1 were positively correlated with infiltration degree of $\mathrm{B}$ cells, CD8+ $\mathrm{T}$ cells, macrophage, neutrophil, and dendritic cells and is shown in Fig. 10. As these 4 genes are prominently expressed in PDAC, we performed a ROC curve analysis to evaluate their sensitivity and specificity for the diagnosis of PDAC. As shown in Fig. 11, CCNB1, FHL2, HLA-DPA1 and TUBB1 achieved an AUC value of $>0.70$, demonstrating that these genes have high sensitivity and specificity for PDAC diagnosis. The results suggested that CCNB1, FHL2, HLA-DPA1 and TUBB1 can be used as biomarkers for the diagnosis of PDAC.

\section{RT-PCR analysis}

Next, in order to verify the results of previous bioinformatics analysis, the gene expression levels of CCNB1, FHL2, HLA-DPA1 and TUBB1 were detected by RT-PCR. As shown in Fig 12, CCNB1 and FHL2 mRNA expression levels were significantly up regulated in the PDAC compared to normal, and HLA-DPA1 and TUBB1 mRNA level were down regulated compared to normal, which was consistent with the results of bioinformatics analysis.

\section{Molecular docking experiment}

The docking simulation was performed in the present study to recognize the active site conformation andsignificant interactions, which are responsible for complex stability with ligand receptor. Novel molecules containing alkylating group and purine heterocyclic ring were designed and performed docking studies using Sybyl X 2.1 drug design software. Molecules containing alkylating group is designed due to non-specific alkylation of physiologically important groupings and purine heterocyclic ring is incorporated due to structural similarity of purine derivatives and to compete for the synthesis of proteins. The proteins which are over expressed in pancreatic duct adenocarcinoma are selected for docking studies. The two proteins of each over expressedcyclin B1 (CCNB1)its co-crystallised protein of PDB code 4Y72, 5H0V and Four and half LIM domains 2 (FHL2) of NMR structure of proteins $2 \mathrm{D} 8 \mathrm{Z}$ and $2 \mathrm{EHE}$ were selected for docking. The investigation of designed molecules was performed to identify the potential molecule. The most 
medRxiv preprint doi: https://doi.org/10.1101/2020.12.20.20248601; this version posted December 23, 2020. The copyright holder for this

of the designed molecules obtained $\mathrm{C}$-score greater than 5 and are active having the c-score greater than 5 are said to be an active, among total of 48 designed molecules few molecules have excellent good binding energy (C-score) greater than 8 respectively. Few of the designed molecules IM $11 \&$ PU 42, shown good binding score of $7.83 \& 8.57$ and the molecules IM 13, TZ 23, TZ 27, TZ 37, PU 41, PU 43 \& PU 49 have good binding score 8.013, 8.523, 8.235, 8.800, 10.338, $10.891 \& 9.411$ with CCNB1 PDB code $1 \mathrm{H} 0 \mathrm{~V}$ and $4 \mathrm{Y} 72$ respectively and are shown in Fig. 13. Molecules of IM 09, IM 10, IM \& 18 shown good binding score of 7.14, $7.75 \& 7.80$ and the molecules IM 8 and TZ 24 with binding score 6.24 and 6.32 with FHL2 of PDB code 2D8Z and 2EQQ respectively, the values are depicted in Table 7. The molecule IM 8has highest binding score its interaction with protein $1 \mathrm{H} 0 \mathrm{~V}$ and hydrogen bonding and other bonding interactions with amino acids are depicted by 3D and 2D shown in Fig. 14 and Fig. 15.

\section{Discussion}

Due to the high heterogeneity of PDAC, PDAC was still a disease with high rates of pervasiveness and fatality. With surgery as the main, the other treatments including radiotherapy, chemotherapy, targeted therapy, and gene therapy as a additive to the finite treatment measures of PDAC, the 5-year survival rate was still less than $8 \%$ [35]. Therefore, the early diagnosis and effective treatment of PDAC is crucially required, which may be achieved via the identification of the DEGs between PDAC and normal control, and by considerate the underlying molecular mechanism. Microarray and high throughput sequencing analysis can screen a massive number of genes in the human genome for farther functional analysis, and can be extensively used to screen biomarkers for early diagnosis and unique therapeutic targets. Therefore, they may help the diagnosis of PDAC in the early stages and the advancement of targeted treatment, thus developing prognosis.

The current investigation systematically applied integrated bioinformatics methods to identify novel biomarkers that serve roles in the advancement PDAC. The data extracted from the GEO dataset contained 31 pairs of lung cancer and normal samples. A total of 232 up regulated and 231 down regulated genes in PDAC, when compared with normal control samples, were identified using bioinformatics analysis, indicating that the incidence and advancement of PDAC. The results of the DEGs may provide potential biomarkers for the diagnosis of 
medRxiv preprint doi: https://doi.org/10.1101/2020.12.20.20248601; this version posted December 23, 2020. The copyright holder for this preprint (which was not certified by peer review) is the author/funder, who has granted medRxiv a license to display the preprint in perpetuity. All rights reserved. No reuse allowed without permission.

PDAC. DAP (death associated protein) [36], KRT8 [37], IGFBP2 [38], KRT19 [39], CD44 [40], AHNAK (AHNAK nucleoprotein) [41] and BTG1 [42] are a noticeable factors in the PDAC progression. Wang et al [43] reported that KIF2C induces proliferation, migration, and invasion in gastric cancer patients through the MAPK signaling pathway, but this gene might be associated with development of PDAC. DBN1 expression was significantly increased in breast cancer [44], but this gene might be liable for development of PDAC. MAP1B was reported to lung cancer progression [45], but this gene may be key for advancement of PDAC. BNIP3L down regulation was required to develop breast and ovarian cancer [46], but this down regulation of gene might be involved in progression of PDAC. Yen et al [47] reported that ITGA4 was expressed in oral cancer, but this gene might be novel biomarker for PDAC. Tomsic et al. [48] showed that mutation in SRRM2 was associated with progression of thyroid carcinoma, but alteration in this gene might be key factor for advancement of PDAC. Recent studies have shown that down regulation of IL7R is associated with progression of esophageal squamous cell carcinoma [49], but this gene might be involved in pathogenesis of PDAC. Lee et al [50] found that reduced expression of the HLA-DRA is key factor for development of colorectal cancer, but this gene might be linked with advancement of PDAC. Liu et al. [51] reported that the absence of SESN3 linked with development of hepatocellular carcinoma, but this gene might be associated with progression of PDAC.

Then, GO and REACTOME pathway analyses were used to investigate the interactions of these DEGs. Increasing evidence shows that LAPTM4B [52], CEACAM6 [53], SERPINE2 [54] and VNN1 [55], SPHK1 [56], HRG (histidine rich glycoprotein) [57], VEGFC (vascular endothelial growth factor C) [58], ANXA3 [59], APOA2 [60], LCN2 [61], TIMP1 [62], CD63 [63], CD151 [64], MAL2 [65], ARNTL2 [66], PKD2 [67], E2F1 [68], MMP1 [69], CCR7 [70], NOTCH2 [71], BTLA (B and T lymphocyte associated) [72], TFRC (transferrin receptor) [73], CD4 [74], ATM (ATM serine/threonine kinase) [75], LEF1 [76], CSF1R [77], CTSB (cathepsin B) [78], DUSP2 [79] and NR4A1 [80] are closely associated with progression of PDAC. PTGER3 [81] and MAGI2 [82] are linked with angiogenesis, chemoresistance, cell proliferation and migration in ovary cancer, but these genes might be liable for growth PDAC. Hoagland et al [83] demonstrated that HP (haptoglobin) expression was responsible for progression of 
medRxiv preprint doi: https://doi.org/10.1101/2020.12.20.20248601; this version posted December 23, 2020. The copyright holder for this preprint (which was not certified by peer review) is the author/funder, who has granted medRxiv a license to display the preprint in perpetuity. All rights reserved. No reuse allowed without permission.

lung cancer, but this gene might be involved in PDAC progression. FGA (fibrinogen alpha chain) was demonstrated to be a lung cancer susceptibility gene through activation of integrin-AKT signaling pathway [84], but this gene might be liable for progression of PDAC. Repetto et al [85] investigated the importance of FGB (fibrinogen beta chain) in the pathogenesis of gastric carcinoma, but this gene might be responsible for progression of PDAC. PLA2G4A [86], FGG (fibrinogen gamma chain) [87] and TYMS (thymidylatesynthetase) [88] have been demonstrated to be up regulated in cancer, but these genes might be liable for progression of PDAC. RAB32 [89], SEPTIN4 [90], TPM2 [91], ACOT7 [92], PRTFDC1 [93], CABLES1 [94], HLA-DMB [95], PTPRC (protein tyrosine phosphatase receptor type C) [96], CD5 [97], CD6 [97], MS4A1 [98], CD22 [99], CD27 [100], MRC2 [101], CLEC2D [102], EEF1A1 [103] and APOB (apolipoprotein B) [104] played a predominant role in the cancer progression, but these genes might be associated with development of PDAC. Jung et al [105] found that SMPD1 stimulates the drug resistance in colorectal cancer, but this gene might be linked with development of PDAC. Liu et al. [106], Yang et al [107], Song et al [108], Seachrist et al [109], Zhu et al [110], Wu et al [111], Wang et al [112], Yi et al [113], Lan et al [114] and Appert-Collin et al [115] revealed that PADI4, MAOB (monoamine oxidase B), TRPC6, BCL11A, CXCR5, TCF7, POU2F2, SLC4A1, STK17B and LRP1 were associated with cancer cell invasion, but these genes might be liable for progression of PDAC. Kairouz et al [116], Diez-Bello et al [117], Xue et al [118], Abo-Elfadl et al [119], Li et al [120] and Zhao et al [121] reported that GRB14, TRPC6, ZFPM2, TNFRSF13B, ADAM19 and PIK3IP1enhance the cancer cell proliferation, but this gene might be involved in advancement of PDAC. Leite et al [122], Feng et al [123], Wang et al [124], Zhong et al [125], Yokoyama-Mashima et al [126], Guo et al [127], Lawson et al [128] and Wang et al [129] demonstrated that low levels of HLA-DPA1, FGL2, CBLB (Cbl proto-oncogene B), NCKAP1L, DYRK2, OGT (O-linked Nacetylglucosamine (GlcNAc) transferase), CAMK1D and RNF213 are linked with progression of cancer, but these genes might be essential for progression of PDAC. Polymorphic genes such as RORA (RAR related orphan receptor A) [130], IGF2R [131] and ZBTB20 [132] are contribute to progression of cancer, but these genes might be crucial for advancement of PDAC. Hope et al. [133] identified that the VCAN (versican) was central role in immune cell infiltration in cancer, but this gene may be associated with immune cell infiltration in PDAC. 
medRxiv preprint doi: https://doi.org/10.1101/2020.12.20.20248601; this version posted December 23, 2020. The copyright holder for this

Construction of PPI network and modules of DEGs may be helpful for understanding the relationship of developmental PDAC. Bai et al [134] reported that CCNB1 plays a positive role in proliferation of cancer cells, but this gene might be involved in development of PDAC. FHL2 [135] and RPL10 [136] are associated with progression of PDAC. Further investigation is required in order to clarify the underlying biological mechanisms of novel biomarkers HLA-DPA1, TUBB1, RPL13A, RPL27A and RPL23A on PDAC.

The miRNA-DEG regulatory network and TF-DEG regulatory network were constructed to explore the molecular mechanism of PDAC. The EZH2 [137], KMT2D [138], TXNIP (thioredoxin interacting protein) [139], TP63 [140], SOX2 [141], MYC [142] and KLF4 [143] genes are associated with PDAC. TPM1 [144] and hsa-mir-1202 [145] have been associated with cancer risk, but these genes and miRNAs might be responsible for progression of PDAC. Hsa-mir-4461, hsa-mir3928-3p and hsa-mir-2682-5p might be considered as novel biomarkers for progression of PDAC.

In conclusion, we aim to identify DEGs by bioinformatics analysis to find the potential biomarkers which may be involved in the advancement of PDAC. The investigation contributes a set of useful DEGs for future studies into molecular mechanisms and biomarkers of PDAC. And the application of data mining and integration is accessible for prediction of PDAC advancement. Nevertheless, further molecular biological analyses are recommended to certify the function of the DEGs in PDAC.

\section{Conflict of interest}

The authors declare that they have no conflict of interest.

\section{Ethical approval}

This article does not contain any studies with human participants or animals performed by any of the authors.

\section{Informed consent}

No informed consent because this study does not contain human or animals participants. 


\section{Availability of data and materials}

The datasets supporting the conclusions of this article are available in the GEO (Gene Expression Omnibus) (https://www.ncbi.nlm.nih.gov/geo/) repository. [(GSE133684) (https://www.ncbi.nlm.nih.gov/geo/query/acc.cgi?acc=GSE133684]

\section{Consent for publication}

Not applicable.

\section{Competing interests}

The authors declare that they have no competing interests.

\section{Authors}

Basavaraj Vastrad

Chanabasayya Vastrad

Anandkumar Tengli

\section{Acknowledgement}

I thank Shenglin Huang, Fudan University, Shanghai, China, very much, the author who deposited their microarray dataset, GSE133684, into the public GEO database.

\section{Author Contributions}

Basavaraj Vastrad - Writing original draft, and review and editing Anandkumar Tengli - Writing original draft and investigation

Chanabasayya Vastrad - Software and investigation

\section{References}

1. Thiruvengadam, S.S.; Chuang, J.; Huang, R.; Girotra, M.; Park, W.G. Chronic pancreatitis changes in high-risk individuals for pancreatic ductal adenocarcinoma. Gastrointest. Endosc 2019,89,842-851.e1. doi:10.1016/j.gie.2018.08.029 
medRxiv preprint doi: https://doi.org/10.1101/2020.12.20.20248601; this version posted December 23, 2020. The copyright holder for this preprint (which was not certified by peer review) is the author/funder, who has granted medRxiv a license to display the preprint in perpetuity. All rights reserved. No reuse allowed without permission.

2. Al-Hawary, M.M.; Kaza, R.K.; Azar, S.F.; Ruma, J.A.; Francis, I.R. Mimics of pancreatic ductal adenocarcinoma. Cancer. Imaging 2013,13,342-349. doi:10.1102/1470-7330.2013.9012

3. Siegel, R.L.; Miller, K.D.; Jemal, A. Cancer statistics, 2018. CA. Cancer. J. Clin 2018,68,7-30. doi:10.3322/caac. 21442

4. Adamska, A.; Domenichini, A.; Falasca, M. Pancreatic Ductal Adenocarcinoma: Current and Evolving Therapies. Int. J. Mol. Sci 2017,18,1338. doi:10.3390/ijms 18071338

5. Tsuchiya, N.; Matsuyama, R.; Murakami, T.; Yabushita, Y.; Sawada, Y.U, Kumamoto, T.; Endo, I. Risk Factors Associated With Early Recurrence of Borderline Resectable Pancreatic Ductal Adenocarcinoma After Neoadjuvant Chemoradiation Therapy and Curative Resection. Anticancer. Res 2019,39,4431-4440. doi:10.21873/anticanres.13615

6. Oji, Y.; Nakamori, S.; Fujikawa, M.; Nakatsuka, S.; Yokota, A.; Tatsumi, N.; Abeno, S.; Ikeba, A.; Takashima, S.; Tsujie, M.; et al. Overexpression of the Wilms' tumor gene WT1 in pancreatic ductal adenocarcinoma. Cancer. Sci. 2004,95,583-587. doi:10.1111/j.1349-7006.2004.tb02490.x

7. Murthy, D.; Attri, K.S.; Singh, P.K. Phosphoinositide 3-Kinase Signaling Pathway in Pancreatic Ductal Adenocarcinoma Progression, Pathogenesis, and Therapeutics. Front. Physiol 2018,9,335. doi:10.3389/fphys.2018.00335

8. Reddy, R.R.S, Ramanujam, M.V. High Throughput Sequencing-Based Approaches for Gene Expression Analysis. Methods. Mol. Biol 2018,1783,299-323. doi:10.1007/978-1-4939-7834-2_15

9. Gu, Y.; Feng, Q.; Liu, H.; Zhou, Q.; Hu, A.; Yamaguchi, T.; Xia, S.; Kobayashi, H. Bioinformatic evidences and analysis of putative biomarkers in pancreatic ductal adenocarcinoma. Heliyon 2019,5,e02378. doi:10.1016/j.heliyon.2019.e02378

10.Clough, E.; Barrett, T. The Gene Expression Omnibus Database. Methods. Mol. Biol 2016,1418,93 $\square$ 110. doi:10.1007/978-1-4939-3578-9_5

11.Yu, S.; Li, Y.; Liao, Z.; Wang, Z.; Wang, Z.; Li, Y.; Qian, L.; Zhao, J.; Zong, H.; Kang, B.; et al. Plasma extracellular vesicle long RNA profiling identifies a diagnostic signature for the detection of pancreatic ductal adenocarcinoma. Gut 2020,69,540-550. doi:10.1136/gutjnl-2019-318860 
medRxiv preprint doi: https://doi.org/10.1101/2020.12.20.20248601; this version posted December 23, 2020. The copyright holder for this

12.Ritchie, M.E.; Phipson, B.; Wu, D.; Hu, Y.; Law, C.W.; Shi, W.; Smyth, G.K. limma powers differential expression analyses for RNA-sequencing and microarray studies. Nucleic. Acids. Res 2015,43,e47. doi:10.1093/nar/gkv007

13.Ferreira, J.A. The Benjamini-Hochberg method in the case of discrete test statistics. Int. J. Biostat 2007,3. doi:10.2202/1557-4679.1065

14.Thomas, P.D. The Gene Ontology and the Meaning of Biological Function. Methods. Mol. Biol 2017,1446,15 $\square$ 24. doi:10.1007/978-1-4939-3743-1_2

15.Fabregat, A.; Jupe, S.; Matthews, L.; Sidiropoulos, K.; Gillespie, M.; Garapati, P.; Haw, R.; Jassal, B.; Korninger, F.; May, B.; et al. The Reactome Pathway Knowledgebase. Nucleic. Acids. Res 2018,46,D649D655. doi:10.1093/nar/gkx1132

16.Chen, J.; Bardes, E.E.; Aronow, B.J.; Jegga, A.G. ToppGene Suite for gene list enrichment analysis and candidate gene prioritization. Nucleic. Acids. Res 2009,37,W305-W311. doi:10.1093/nar/gkp427

17.Kotlyar, M.; Pastrello, C.; Malik, Z.; Jurisica, I. IID 2018 update: contextspecific physical protein-protein interactions in human, model organisms and domesticated species. Nucleic. Acids. Res 2019,47,D581-D589. doi:10.1093/nar/gky1037

18.Shannon, P.; Markiel, A.; Ozier, O.; Baliga, N.S, Wang, J.T.; Ramage, D.; Amin, N.; Schwikowski, B.; Ideker, T. Cytoscape: a software environment for integrated models of biomolecular interaction networks. Genome. Res 2003,13(,2498-2504. doi:10.1101/gr.1239303

19.Przulj, N.; Wigle, D.A.; Jurisica, I. Functional topology in a network of protein interactions. Bioinformatics doi:10.1093/bioinformatics/btg415

20.Nguyen, T.P.; Liu, W.C.; Jordán, F. Inferring pleiotropy by network analysis: linked diseases in the human PPI network. BMC. Syst. Biol 2011,5,179. doi:10.1186/1752-0509-5-179

21.Shi, Z.; Zhang, B. Fast network centrality analysis using GPUs. BMC. Bioinformatics 2011,12,149. doi:10.1186/1471-2105-12-149

22.Fadhal, E.; Gamieldien, J.; Mwambene, E.C. Protein interaction networks as metric spaces: a novel perspective on distribution of hubs. BMC. Syst. Biol 2014,8,6. doi:10.1186/1752-0509-8-6 
medRxiv preprint doi: https://doi.org/10.1101/2020.12.20.20248601; this version posted December 23, 2020. The copyright holder for this

23.Zaki, N.; Efimov, D.; Berengueres, J. Protein complex detection using interaction reliability assessment and weighted clustering coefficient. BMC. Bioinformatics 2013,14,163. doi:10.1186/1471-2105-14-163

24.Fan, Y.; Xia, J miRNet-Functional Analysis and Visual Exploration of miRNA-Target Interactions in a Network Context. Methods. Mol. Biol 2018,1819,215-233. doi:10.1007/978-1-4939-8618-7_10

25.Zhou, G.; Soufan, O.; Ewald, J.; Hancock, R.E.W.; Basu, N.; Xia, J. NetworkAnalyst 3.0: a visual analytics platform for comprehensive gene expression profiling and meta-analysis. Nucleic. Acids. Res 2019,47,W234W241. doi:10.1093/nar/gkz240

26. Chandrashekar, D.S.; Bashel, B.; Balasubramanya, S.A.H.; Creighton, C.J: Ponce-Rodriguez, I.; Chakravarthi, B.V.S.K.; Varambally, S. UALCAN: A Portal for Facilitating Tumor Subgroup Gene Expression and Survival Analyses. Neoplasia 2017,19,649-658. doi:10.1016/j.neo.2017.05.002

27.Gao, J.; Aksoy, B.A.; Dogrusoz, U.; Dresdner, G.; Gross, B.; Sumer, S.O.; Sun, Y.; Jacobsen, A.; Sinha R.; Larsson E.; et al. Integrative analysis of complex cancer genomics and clinical profiles using the cBioPortal. Sci Signal. 2013,6,pl1. doi:10.1126/scisignal.2004088

28.Uhlen, M.; Oksvold, P.; Fagerberg, L.; Lundberg, E.; Jonasson, K.; Forsberg, M.; Zwahlen, M.; Kampf, C.; Wester, K.; Hober, S.; et al. Towards a knowledge-based Human Protein Atlas. Nat. Biotechnol 2010,28,1248-1250. doi:10.1038/nbt1210-1248

29.Li, T.; Fan, J.; Wang, B.; Traugh, N.; Chen Q.; Liu J.S.; Li B.; Liu X.S. TIMER: A Web Server for Comprehensive Analysis of Tumor-Infiltrating Immune Cells. Cancer. Res 2017,77,e108-e110. doi:10.1158/00085472.CAN-17-0307

30.Robin, X.; Turck, N.; Hainard, A.; Tiberti, N.; Lisacek, F.; Sanchez, J.C.; Müller, M. pROC: an open-source package for $\mathrm{R}$ and $\mathrm{S}+$ to analyze and compare ROC curves. BMC. Bioinformatics 2011,12,77. doi:10.1186/14712105-12-77

31.Livak, K.J.; Schmittgen, T.D. Analysis of relative gene expression data using real-time quantitative PCR and the 2(-Delta Delta C(T)) Method. Methods 2001,25,402-408. doi:10.1006/meth.2001.1262

32.El-Saadi M.W.; Williams-Hart T.; Salvatore B.A.; Mahdavian E. Use of insilico assays to characterize the ADMET profile and identify potential 
therapeutic targets of fusarochromanone, a novel anti-cancer agent. In. Silico. Pharmacol 2015,3,6. doi:10.1186/s40203-015-0010-5

33.Li, J.; Ma, X.; Liu, C.; Li, H.; Zhuang, J.; Gao, C.; Zhou, C.; Liu, L.; Wang, K.; Sun C. Exploring the Mechanism of Danshen against Myelofibrosis by Network Pharmacology and Molecular Docking. Evid. Based. Complement. Alternat. Med. 2018,2018,8363295. doi:10.1155/2018/8363295

34.Ruddarraju, R.R.; Murugulla, A.C.; Kotla, R.; Tirumalasetty, M.C.B.; Wudayagiri, R.; Donthabakthuni, S.; Maroju, R. Design, synthesis, anticancer activity and docking studies of theophylline containing 1,2,3triazoles with variant amide derivatives. Medchemcomm 2016,8,176-183. doi:10.1039/c6md00479b

35.Moffitt, R.A.; Marayati, R.; Flate, E.L.; Volmar, K.E.; Loeza, S.G.; Hoadley, K.A.; Rashid, N.U.; Williams, L.A.; Eaton, S.C.; Chung, A.H.; et al. Virtual microdissection identifies distinct tumor- and stroma-specific subtypes of pancreatic ductal adenocarcinoma. Nat. Genet 2015,47,11681178. doi:10.1038/ng.3398

36.Dansranjavin, T.; Möbius, C.; Tannapfel, A.; Bartels, M.; Wittekind, C.; Hauss, J.; Witzigmann, H. E-cadherin and DAP kinase in pancreatic adenocarcinoma and corresponding lymph node metastases. Oncol. Rep 2006,15,1125-1131.

37.Treiber, M.; Schulz, H.U.; Landt, O.; Drenth, J.P.; Castellani, C.; Real, F.X.; Akar, N.; Ammann, R.W.; Bargetzi, M.; Bhatia, E.; et al. Keratin 8 sequence variants in patients with pancreatitis and pancreatic cancer. J. Mol. Med (Berl) 2006,84,1015-1022. doi:10.1007/s00109-006-0096-7

38.Liu, H.; Li, L.; Chen, H.; Kong, R.; Pan, S.; Hu, J.; Wang, Y.; Li, Y.; Sun B. Silencing IGFBP-2 decreases pancreatic cancer metastasis and enhances chemotherapeutic sensitivity. Oncotarget 2017,8,61674-61686. doi:10.18632/oncotarget.18669

39.Yao, H.; Yang, Z.; Liu, Z.; Miao, X.; Yang, L.; Li, D.; Zou, Q.; Yuan, Y. Glypican-3 and KRT19 are markers associating with metastasis and poor prognosis of pancreatic ductal adenocarcinoma. Cancer. Biomark 2016,17,397-404. doi:10.3233/CBM-160655

40.Huynh, D.L.; Koh, H.; Chandimali, N.; Zhang, J.J.; Kim, N.; Kang, T.Y.; Ghosh, M.; Gera, M.; Park, Y.H.; Kwon, T.; et al. BRM270 Inhibits the Proliferation of CD44 Positive Pancreatic Ductal Adenocarcinoma Cells via 
medRxiv preprint doi: https://doi.org/10.1101/2020.12.20.20248601; this version posted December 23, 2020. The copyright holder for this

Downregulation of Sonic Hedgehog Signaling. Evid. Based. Complement Alternat. Med. 2019,2019,8620469. doi:10.1155/2019/8620469

41.Zhang, Z.; Liu, X.; Huang, R.; Liu, X.; Liang, Z.; Liu, T. Upregulation of nucleoprotein AHNAK is associated with poor outcome of pancreatic ductal adenocarcinoma prognosis via mediating epithelial-mesenchymal transition. J. Cancer 2019,10,3860-3870. doi:10.7150/jca.31291

42.Huang, Y.; Zheng, J.; Tan, T.; Song, L.; Huang, S.; Zhang, Y.; Lin, L.; Liu, J.; Zheng P.; Chen X.; et al. BTG1 low expression in pancreatic ductal adenocarcinoma is associated with a poorer prognosis. Int. J. Biol. Markers. 2018,33,189-194. doi:10.5301/ijbm.5000310

43.Wang, P.B.; Chen, Y.; Ding, G.R.; Du, H.W.; Fan, H.Y. Keratin 18 induces proliferation, migration, and invasion in gastric cancer via the MAPK signalling pathway. Clin. Exp. Pharmacol. Physiol. 2020,10.1111/14401681.13401. doi:10.1111/1440-1681.13401

44.Alfarsi, L.H.; El Ansari, R.; Masisi, B.K.; Parks, R.; Mohammed, O.J.; Ellis, I.O.; Rakha, E.A.; Green, A.R. Integrated Analysis of Key Differentially Expressed Genes Identifies DBN1 as a Predictive Marker of Response to Endocrine Therapy in Luminal Breast Cancer. Cancers. (Basel). 2020,12,1549. doi:10.3390/cancers12061549

45.Tessema, M.; Yingling, C.M.; Picchi, M.A.; Wu, G.; Liu, Y.; Weissfeld, J.L.; Siegfried, J.M.; Tesfaigzi, Y.; Belinsky, S.A. Epigenetic Repression of CCDC37 and MAP1B Links Chronic Obstructive Pulmonary Disease to Lung Cancer. J. Thorac. Oncol 2015,10,1181-1188. doi:10.1097/JTO.0000000000000592

46.Lai, J.; Flanagan, J.; Phillips, W.A.; Chenevix-Trench, G.; Arnold, J. Analysis of the candidate 8p21 tumour suppressor, BNIP3L, in breast and ovarian cancer. Br. J. Cancer 2003,88,270-276. doi:10.1038/sj.bjc.6600674 47.Yen, C.Y.; Huang, C.Y.; Hou, M.F.; Yang, Y.H.; Chang, C.H.; Huang, H.W.; Chen, C.H.; Chang, H.W. Evaluating the performance of fibronectin 1 (FN1), integrin $\alpha 4 \beta 1$ (ITGA4), syndecan-2 (SDC2), and glycoprotein CD44 as the potential biomarkers of oral squamous cell carcinoma (OSCC). Biomarkers 2013,18,63-72. doi:10.3109/1354750X.2012.737025

48.Tomsic, J.; He, H.; Akagi, K.; Liyanarachchi, S.; Pan, Q.; Bertani, B.; Nagy, R.; Symer, D.E.; Blencowe, B.J.; de la Chapelle, A. A germline mutation in 
SRRM2, a splicing factor gene, is implicated in papillary thyroid carcinoma predisposition. Sci. Rep 2015,5,10566. doi:10.1038/srep10566

49.Kim, M.J.; Choi, S.K.; Hong, S.H.; Eun, J.W.; Nam, S.W.; Han, J.W.; You, J.S. Oncogenic IL7R is downregulated by histone deacetylase inhibitor in esophageal squamous cell carcinoma via modulation of acetylated FOXO1. Int. J. Oncol 2018,53,395-403. doi:10.3892/ijo.2018.4392

50.Lee, J.; Li, L.; Gretz, N.; Gebert, J.; Dihlmann, S. Absent in Melanoma 2 (AIM2) is an important mediator of interferon-dependent and -independent HLA-DRA and HLA-DRB gene expression in colorectal cancers. Oncogene 2012,31,1242-1253. doi:10.1038/onc.2011.320

51.Liu, Y.; Kim, H.G.; Dong, E.; Dong, C.; Huang, M.; Liu, Y.; Liangpunsakul, S, Dong, X.C. Sesn3 deficiency promotes carcinogen-induced hepatocellular carcinoma via regulation of the hedgehog pathway. Biochim. Biophys. Acta. Mol. Basis. Dis 2019,1865,2685-2693. doi:10.1016/j.bbadis.2019.07.011

52. Yang, Z.; Senninger, N.; Flammang, I.; Ye, Q.; Dhayat, S.A. Clinical impact of circulating LAPTM4B-35 in pancreatic ductal adenocarcinoma. $J$. Cancer. Res. Clin. Oncol 2019,145,1165-1178. doi:10.1007/s00432-01902863-w

53.Pandey, R.; Zhou, M.; Islam, S.; Chen, B.; Barker, N.K.; Langlais, P.; Srivastava, A.; Luo, M.; Cooke, L.S.; Weterings, E.; et al. Carcinoembryonic antigen cell adhesion molecule 6 (CEACAM6) in Pancreatic Ductal Adenocarcinoma (PDA): An integrative analysis of a novel therapeutic target. Sci. Rep 2019,9,18347. doi:10.1038/s41598-019$54545-9$

54.Neesse, A.; Wagner, M.; Ellenrieder, V.; Bachem, M.; Gress, T.M.; Buchholz, M. Pancreatic stellate cells potentiate proinvasive effects of SERPINE2 expression in pancreatic cancer xenograft tumors. Pancreatology 2007,7,380-385. doi:10.1159/000107400

55.Kang, M.; Qin, W.; Buya, M.; Dong, X.; Zheng, W.; Lu, W.; Chen, J.; Guo, Q.; Wu, Y. VNN1, a potential biomarker for pancreatic cancer-associated new-onset diabetes, aggravates paraneoplastic islet dysfunction by increasing oxidative stress. Cancer. Lett 2016,373,241-250. doi:10.1016/j.canlet.2015.12.031

56.Li, J.; Wu, H.; Li, W.; Yin, L.; Guo, S.; Xu, X.; Ouyang, Y.; Zhao, Z.; Liu, S.; Tian, Y.; et al Downregulated miR-506 expression facilitates pancreatic 
cancer progression and chemoresistance via SPHK1/Akt/NF- $\mathrm{B}$ signaling. Oncogene 2016,35,5501-5514. doi:10.1038/onc.2016.90

57.Chen, X.L.; Xie, K.X.; Yang, Z.L.; Yuan, L.W. Expression of FXR and HRG and their clinicopathological significance in benign and malignant pancreatic lesions. Int. J. Clin. Exp. Pathol 2019,12,2111-2120.

58.Guo, J.; Lou, W.; Ji, Y.; Zhang, S. Effect of CCR7, CXCR4 and VEGF-C on the lymph node metastasis of human pancreatic ductal adenocarcinoma. Oncol. Lett 2013,5,1572-1578. doi:10.3892/ol.2013.1261

59.Wan, Y.C.E.; Liu, J.; Zhu, L.; Kang, T.Z.E.; Zhu, X.; Lis, J.; Ishibashi, T.; Danko, C.G.; Wang, X.; Chan, K.M. The H2BG53D oncohistone directly upregulates ANXA3 transcription and enhances cell migration in pancreatic ductal adenocarcinoma. Signal. Transduct. Target. Ther 2020,5,106. doi:10.1038/s41392-020-00219-2

60.Sato, Y.; Kobayashi, T.; Nishiumi, S.; Okada, A.; Fujita, T.; Sanuki, T.; Kobayashi, M.; Asahara, M.; Adachi, M.; Sakai, A.; et al. Prospective Study Using Plasma Apolipoprotein A2-Isoforms to Screen for High-Risk Status of Pancreatic Cancer. Cancers (Basel) 2020,12,E2625. doi:10.3390/cancers12092625

61.Gumpper, K.; Dangel, A.W.; Pita-Grisanti, V.; Krishna, S.G.; Lara, L.F.; Mace, T.; Papachristou, G.I.; Conwell, D.L.; Hart, P.A.; Cruz-Monserrate, Z. Lipocalin-2 expression and function in pancreatic diseases. Pancreatology 2020,20,419-424. doi:10.1016/j.pan.2020.01.002

62.D'Costa, Z.; Jones, K.; Azad, A.; van Stiphout, R.; Lim, S.Y.; Gomes, A.L.; Kinchesh, P.; Smart, S.C.; Gillies McKenna, W.; Buffa, F.M.; et al. Gemcitabine-Induced TIMP1 Attenuates Therapy Response and Promotes Tumor Growth and Liver Metastasis in Pancreatic Cancer. Cancer. Res. 2017,77,5952-5962. doi:10.1158/0008-5472.CAN-16-2833

63.Buscail, E.; Chauvet, A.; Quincy, P.; Degrandi, O.; Buscail, C.; Lamrissi, I.; Moranvillier, I.; Caumont, C.; Verdon, S.; Brisson, A.; et al. CD63-GPC1Positive Exosomes Coupled with CA19-9 Offer Good Diagnostic Potential for Resectable Pancreatic Ductal Adenocarcinoma. Transl. Oncol 2019,12,1395-1403. doi:10.1016/j.tranon.2019.07.009

64.Zhu, G.H.; Huang, C.; Qiu, Z.J.; Liu, J.; Zhang, Z.H.; Zhao, N.; Feng, Z.Z.; Lv, X.H. Expression and prognostic significance of CD151, c-Met, and 
integrin alpha3/alpha6 in pancreatic ductal adenocarcinoma. Dig. Dis. Sci 2011,56,1090-1098. doi:10.1007/s10620-010-1416-x

65.Eguchi, D.; Ohuchida, K.; Kozono, S.; Ikenaga, N.; Shindo, K.; Cui, L.; Fujiwara, K.; Akagawa, S.; Ohtsuka, T.; Takahata, S.; et al. MAL2 expression predicts distant metastasis and short survival in pancreatic cancer. Surgery 2013,154,573-582. doi:10.1016/j.surg.2013.03.010

66.Wang, Z.; Liu, T.; Xue, W.; Fang, Y.; Chen, X.; Xu, L.; Zhang, L.; Guan, K.; Pan, J.; Zheng, L.; et al. ARNTL2 promotes pancreatic ductal adenocarcinoma progression through TGF/BETA pathway and is regulated by miR-26a-5p. Cell. Death. Dis 2020,11,692. doi:10.1038/s41419-02002839-6

67. Yuan, J.; Rozengurt, E. PKD, PKD2, and p38 MAPK mediate Hsp27 serine82 phosphorylation induced by neurotensin in pancreatic cancer PANC-1 cells. J. Cell. Biochem 2008,103,648-662. doi:10.1002/jcb.21439

68.Schild, C.; Wirth, M.; Reichert, M.; Schmid, R.M.; Saur, D.; Schneider, G.; $\mathrm{PI} 3 \mathrm{~K}$ signaling maintains c-myc expression to regulate transcription of E2F1 in pancreatic cancer cells. Mol. Carcinog 2009,48,1149-1158. doi:10.1002/mc.2056

69.Chen, Y.; Peng, S.; Cen, H.; Lin, Y.; Huang, C.; Chen, Y.; Shan, H.; Su, Y.; Zeng, L. MicroRNA hsa-miR-623 directly suppresses MMP1 and attenuates IL-8-induced metastasis in pancreatic cancer. Int. J. Oncol 2019,55,142156. doi:10.3892/ijo.2019.4803

70.Wang, L.; Zhao, X.Y.; Zhu, J.S.; Chen, N.W.; Fan, H.N.; Yang, W.; Guo, J.H. CCR7 regulates ANO6 to promote migration of pancreatic ductal adenocarcinoma cells via the ERK signaling pathway. Oncol. Lett 2018,16,2599-2605. doi:10.3892/ol.2018.8962

71.Mazur, P.K.; Einwächter, H.; Lee, M.; Sipos, B.; Nakhai, H.; Rad, R.; Zimber-Strobl, U.; Strobl, L.J.; Radtke, F.; Klöppel, G.; et al. Notch2 is required for progression of pancreatic intraepithelial neoplasia and development of pancreatic ductal adenocarcinoma. Proc. Natl. Acad. Sci. U. S. A. 2010,107,13438-13443. doi:10.1073/pnas.1002423107

72.Bian, B.; Fanale, D.; Dusetti, N.; Roque, J.; Pastor, S.; Chretien, A.S.; Incorvaia, L.; Russo, A.; Olive, D.; Iovanna, J.; et al. Prognostic significance of circulating PD-1, PD-L1, pan-BTN3As, BTN3A1 and BTLA in patients 
medRxiv preprint doi: https://doi.org/10.1101/2020.12.20.20248601; this version posted December 23, 2020. The copyright holder for this

with pancreatic adenocarcinoma. Oncoimmunology 2019,8,e1561120. doi:10.1080/2162402X.2018.1561120

73.Ryschich, E.; Huszty, G.; Knaebel, H.P.; Hartel, M.; Büchler, M.W.; Schmidt, J. Transferrin receptor is a marker of malignant phenotype in human pancreatic cancer and in neuroendocrine carcinoma of the pancreas. Eur. J. Cancer 2004,40,1418-1422. doi:10.1016/j.ejca.2004.01.036

74.Sonntag, K.; Hashimoto, H.; Eyrich, M.; Menzel, M.; Schubach, M.; Döcker, D.; Battke, F.; Courage, C.; Lambertz, H.; Handgretinger, R.; et al. Immune monitoring and TCR sequencing of CD4 $\mathrm{T}$ cells in a long term responsive patient with metastasized pancreatic ductal carcinoma treated with individualized, neoepitope-derived multipeptide vaccines: a case report. J. Transl. Med 2018,16,23. doi:10.1186/s12967-018-1382-1

75.Hutchings, D.; Jiang, Z.; Skaro, M.; Weiss, M.J.; Wolfgang, C.L.; Makary, M.A.; He, J.; Cameron, J.L.; Zheng, L.; Klimstra, D.S.; et al Histomorphology of pancreatic cancer in patients with inherited ATM serine/threonine kinase pathogenic variants. Mod. Pathol 2019,32,18061813. doi:10.1038/s41379-019-0317-6

76.Singhi, A.D.; Lilo, M.; Hruban, R.H.; Cressman, K.L.; Fuhrer, K.; Seethala, R.R. Overexpression of lymphoid enhancer-binding factor 1 (LEF1) in solidpseudopapillary neoplasms of the pancreas. Mod. Pathol 2014,27,13551363. doi:10.1038/modpathol.2014.40

77.Zhu, Y.; Knolhoff, B.L.; Meyer, M.A.; Nywening, T.M.; West, B.L.; Luo, J.; Wang-Gillam, A.; Goedegebuure, S.P.; Linehan, D.C.; DeNardo, D.G. CSF1/CSF1R blockade reprograms tumor-infiltrating macrophages and improves response to T-cell checkpoint immunotherapy in pancreatic cancer models. Cancer. Res 2014,74,5057-5069. doi:10.1158/0008-5472.CAN-133723

78.Dumartin, L.; Whiteman, H.J.; Weeks, M.E.; Hariharan, D.; Dmitrovic, B.; Iacobuzio-Donahue, C.A.; Brentnall, T.A.; Bronner, M.P.; Feakins, R.M.; Timms, J.F.; et al AGR2 is a novel surface antigen that promotes the dissemination of pancreatic cancer cells through regulation of cathepsins B and D. Cancer. Res 2011,71,7091-7102. doi:10.1158/0008-5472.CAN-111367

79.Wang, C.A.; Chang, I.H.; Hou, P.C.; Tai, Y.J.; Li, W.N.; Hsu, P.L.; Wu, S.R.; Chiu, W.T.; Li, C.F.; Shan, Y.S.; et al. DUSP2 regulates extracellular 
medRxiv preprint doi: https://doi.org/10.1101/2020.12.20.20248601; this version posted December 23, 2020. The copyright holder for this

vesicle-VEGF-C secretion and pancreatic cancer early dissemination. $J$. Extracell. Vesicles 2020,9,1746529. doi:10.1080/20013078.2020.1746529

80.Yoon, K.; Lee, S.O.; Cho, S.D.; Kim, K.; Khan, S.; Safe ,S. Activation of nuclear TR3 (NR4A1) by a diindolylmethane analog induces apoptosis and proapoptotic genes in pancreatic cancer cells and tumors. Carcinogenesis 2011,32,836-842. doi:10.1093/carcin/bgr040

81.Rodriguez-Aguayo, C.; Bayraktar, E.; Ivan, C.; Aslan, B.; Mai, J.; He, G.; Mangala, L.S.; Jiang, D.; Nagaraja, A.S.; Ozpolat, B.; et al. PTGER3 induces ovary tumorigenesis and confers resistance to cisplatin therapy through up-regulation Ras-MAPK/Erk-ETS1-ELK1/CFTR1 axis. EBioMedicine 2019,40,290-304. doi:10.1016/j.ebiom.2018.11.045

82.Chang, H.; Zhang, X.; Li, B.; Meng, X. MAGI2-AS3 suppresses MYC signaling to inhibit cell proliferation and migration in ovarian cancer through targeting miR-525-5p/MXD1 axis. Cancer. Med 2020,9,6377-6386. doi:10.1002/cam4.3126

83.Hoagland, L.F.; Campa, M.J.; Gottlin, E.B.; Herndon, J.E.; Patz, E.F. Haptoglobin and posttranslational glycan-modified derivatives as serum biomarkers for the diagnosis of nonsmall cell lung cancer. Cancer 2007,110,2260-2268. doi:10.1002/cncr.23049

84.Wang, M.; Zhang, G.; Zhang, Y.; Cui, X.; Wang, S.; Gao, S.; Wang, Y.; Liu, Y.; Bae, J.H.; Yang, W.H.; et al. Fibrinogen Alpha Chain Knockout Promotes Tumor Growth and Metastasis through Integrin-AKT Signaling Pathway in Lung Cancer. Mol. Cancer. Res 2020,18,943-954. doi:10.1158/1541-7786.MCR-19-1033

85.Repetto, O.; Maiero, S.; Magris, R.; Miolo, G.; Cozzi, M.R.; Steffan, A.; Canzonieri, V.; Cannizzaro, R.; De Re, V. Quantitative Proteomic Approach Targeted to Fibrinogen $\beta$ Chain in Tissue Gastric Carcinoma. Int. J. Mol. Sci 2018,19,759. doi:10.3390/ijms19030759

86.Bazhan, D.; Khaniani, M.S. Supplementation with omega fatty acids increases the mRNA expression level of PLA2G4A in patients with gastric cancer. J. Gastrointest. Oncol 2018,9,1176-1183. doi:10.21037/jgo.2018.08.12

87.Duan, S.; Gong, B.; Wang, P.; Huang, H.; Luo, L.; Liu, F. Novel prognostic biomarkers of gastric cancer based on gene expression microarray: 
medRxiv preprint doi: https://doi.org/10.1101/2020.12.20.20248601; this version posted December 23, 2020. The copyright holder for this

COL12A1, GSTA3, FGA and FGG. Mol. Med. Rep 2018,18,3727-3736. doi:10.3892/mmr.2018.9368

88.Lee, S.W.; Chen, T.J.; Lin, L.C.; Li, C.F.; Chen, L.T.; Hsing, C.H.; Hsu, H.P.; Tsai, C.J.; Huang, H.Y.; Shiue, Y.L. Overexpression of thymidylate synthetase confers an independent prognostic indicator in nasopharyngeal carcinoma. Exp. Mol. Pathol 2013,95,83-90. doi:10.1016/j.yexmp.2013.05.006

89.Shibata, D.; Mori, Y.; Cai, K.; Zhang, L.; Yin, J.; Elahi, A.; Hamelin, R.; Wong, Y.F.; Lo, W.K.; Chung T.K.; et al. RAB32 hypermethylation and microsatellite instability in gastric and endometrial adenocarcinomas. Int. J. Cancer 2006,119,801-806. doi:10.1002/ijc. 21912

90.Zhao, X.; Feng, H.; Wang, Y.; Wu, Y.; Guo, Q.; Feng, Y.; Ma, M.; Guo, W.; Song, X.; Zhang, Y.; et al. Septin4 promotes cell death in human colon cancer cells by interacting with BAX. Int. J. Biol. Sci 2020,16,1917-1928. doi:10.7150/ijbs.44429

91.Zhang, J.; Zhang, J.; Xu, S.; Zhang, X.; Wang, P.; Wu, H.; Xia, B.; Zhang, G.; Lei, B.; Wan, L.; et al. Hypoxia-Induced TPM2 Methylation is Associated with Chemoresistance and Poor Prognosis in Breast Cancer. Cell. Physiol. Biochem 2018,45,692-705. doi:10.1159/000487162

92.Feng, H.; Liu, X. Interaction between ACOT7 and LncRNA NMRAL2P via Methylation Regulates Gastric Cancer Progression. Yonsei. Med. J 2020,61,471-481. doi:10.3349/ymj.2020.61.6.471

93.Suzuki, E.; Imoto, I.; Pimkhaokham, A.; Nakagawa, T.; Kamata, N.; Kozaki, K.I.; Amagasa, T.; Inazawa, J. PRTFDC1, a possible tumor-suppressor gene, is frequently silenced in oral squamous-cell carcinomas by aberrant promoter hypermethylation. Oncogene 2007,26,7921-7932. doi:10.1038/sj.onc.1210589

94.Sakamoto, H.; Friel, A.M.; Wood, A.W.; Guo, L.; Ilic, A.; Seiden, M.V.; Chung, D.C.; Lynch, M.P.; Serikawa, T.; Munro, E.; et al. Mechanisms of Cables 1 gene inactivation in human ovarian cancer development. Cancer. Biol. Ther 2008,7,180-188. doi:10.4161/cbt.7.2.5253

95.Callahan, M.J.; Nagymanyoki, Z.; Bonome, T.; Johnson, M.E.; Litkouhi, B.; Sullivan, E.H.; Hirsch, M.S.; Matulonis, U.A.; Liu, J.; Birrer, M.J.; et al. Increased HLA-DMB expression in the tumor epithelium is associated with increased CTL infiltration and improved prognosis in advanced-stage serous 
medRxiv preprint doi: https://doi.org/10.1101/2020.12.20.20248601; this version posted December 23, 2020. The copyright holder for this

ovarian cancer. Clin. Cancer. Res 2008,14,7667-7673. doi:10.1158/10780432.CCR-08-0479

96.Wu, Y.; Han, J.; Vladimirovna, K.E.; Zhang, S.; Lv, W.; Zhang, Y.; Jamaspishvili, E.; Sun, J.; Fang, Q.; Meng, J.; et al. Upregulation Of Protein Tyrosine Phosphatase Receptor Type C Associates To The Combination Of Hashimoto's Thyroiditis And Papillary Thyroid Carcinoma And Is Predictive Of A Poor Prognosis. Onco. Targets. Ther 2019,12,8479-8489. doi:10.2147/OTT.S226426

97.Moreno-Manuel, A.; Jantus-Lewintre, E.; Simões, I.; Aranda, F.; CalabuigFariñas, S.; Carreras, E.; Zúñiga, S.; Saenger, Y.; Rosell, R.; Camps, C.; et al. CD5 and CD6 as immunoregulatory biomarkers in non-small cell lung cancer. Transl. Lung. Cancer. Res 2020,9,1074-1083. doi:10.21037/tlcr-19445

98.Wright, C.M.; Savarimuthu Francis, S.M.; Tan, M.E.; Martins, M.U.; Winterford, C.; Davidson, M.R.; Duhig, E.E.; Clarke, B.E.; Hayward, N.K.; et al. MS4A1 dysregulation in asbestos-related lung squamous cell carcinoma is due to CD20 stromal lymphocyte expression. PLoS. One 2012,7,e34943. doi:10.1371/journal.pone.0034943

99.Tuscano, J.M.; Kato, J.; Pearson, D.; Xiong, C.; Newell, L.; Ma, Y.; Gandara, D.R.; O'Donnell, R.T. CD22 antigen is broadly expressed on lung cancer cells and is a target for antibody-based therapy. Cancer. Res 2012,72,5556-5565. doi:10.1158/0008-5472.CAN-12-0173

100. Nielsen, J.S.; Sahota, R.A.; Milne, K.; Kost, S.E.; Nesslinger, N.J.; Watson, P.H.; Nelson, B.H. CD20+ tumor-infiltrating lymphocytes have an atypical CD27- memory phenotype and together with CD8+ T cells promote favorable prognosis in ovarian cancer. Clin. Cancer. Res 2012,18,32813292. doi:10.1158/1078-0432.CCR-12-0234

101. Gai, X.; Tu, K.; Lu, Z.; Zheng, X. MRC2 expression correlates with TGF $\beta 1$ and survival in hepatocellular carcinoma. Int. J. Mol. Sci 2014,15,15011-15025. doi:10.3390/ijms150915011

102. Mathew, S.O.; Chaudhary, P.; Powers, S.B.; Vishwanatha, J.K.; Mathew, P.A. Overexpression of LLT1 (OCIL, CLEC2D) on prostate cancer cells inhibits NK cell-mediated killing through LLT1-NKRP1A (CD161) interaction. 
medRxiv preprint doi: https://doi.org/10.1101/2020.12.20.20248601; this version posted December 23, 2020. The copyright holder for this

103. Joung, E.K.; Kim, J.; Yoon, N.; Maeng, L.S.; Kim, J.H.; Park, S.;

Kang, K.; Kim, J.S.; Ahn, Y.H.; Ko, Y.H.; et al. Expression of EEF1A1 Is Associated with Prognosis of Patients with Colon Adenocarcinoma. J. Clin. Med 2019,8,1903. doi:10.3390/jem8111903

104. Yang, D.D.; Chen, Z.H.; Wang, D.S.; Yu, H.E.; Lu, J.H.; Xu, R.H.;

Zeng, Z.L. Prognostic value of the serum apolipoprotein B to apolipoprotein A-I ratio in metastatic colorectal cancer patients. J. Cancer 2020,11,10631074. doi:10.7150/jca. 3565

105. Jung, J.H.; Taniguchi, K.; Lee, H.M.; Lee, M.Y.; Bandu, R.; Komura,

K.; Lee, K.Y.; Akao, Y.; Kim, K.P. Comparative lipidomics of 5-

Fluorouracil-sensitive and -resistant colorectal cancer cells reveals altered sphingomyelin and ceramide controlled by acid sphingomyelinase (SMPD1). Sci. Rep 2020,10,6124. doi:10.1038/s41598-020-62823-0

106. Liu, M.; Qu, Y.; Teng, X.; Xing, Y.; Li, D.; Li, C.; Cai, L.; PADI4 $\square$ mediated epithelial $\square$ mesenchymal transition in lung cancer cells.

Mol. Med. Rep 2019,19,3087-3094. doi:10.3892/mmr.2019.9968

107. Yang, Y.C.; Chien, M.H.; Lai, T.C.; Su, C.Y.; Jan, Y.H.; Hsiao, M.;

Chen, C.L. Monoamine Oxidase B Expression Correlates with a Poor

Prognosis in Colorectal Cancer Patients and Is Significantly Associated with

Epithelial-to-Mesenchymal Transition-Related Gene Signatures. Int. J. Mol.

Sci 2020,21,2813. doi:10.3390/ijms21082813

108. Song, Y.; Liu, G.; Liu, S.; Chen, R.; Wang, N.; Liu, Z.; Zhang, X.;

Xiao, Z.; Liu, L. Helicobacter pylori upregulates TRPC6 via Wnt/ $\beta$-catenin signaling to promote gastric cancer migration and invasion. Onco. Targets.

Ther 2019,12,5269-5279. doi:10.2147/OTT.S201025

109. Seachrist, D.D.; Hannigan, M.M.; Ingles, N.N.; Webb, B.M.; Weber-

Bonk, K.L.; Yu, P.; Bebek, G.; Singh, S.; Sizemore, S.T.; Varadan, V.; et al.

The transcriptional repressor BCL11A promotes breast cancer metastasis. $J$.

Biol. Chem 2020,295,11707-11719. doi:10.1074/jbc.RA120.014018

110. Zhu, Z.; Zhang, X.; Guo, H.; Fu, L.; Pan, G.; Sun, Y. CXCL13-

CXCR5 axis promotes the growth and invasion of colon cancer cells via PI3K/AKT pathway. Mol. Cell. Biochem 2015,400,287-295. doi:10.1007/s11010-014-2285-y

111. Wu, B.; Chen, M.; Gao, M.; Cong, Y.; Jiang, L.; Wei, J.; Huang, J. Down-regulation of lncTCF7 inhibits cell migration and invasion in 
medRxiv preprint doi: https://doi.org/10.1101/2020.12.20.20248601; this version posted December 23, 2020. The copyright holder for this

colorectal cancer via inhibiting TCF7 expression. Hum. Cell 2019,32,31-40. doi:10.1007/s13577-018-0217-y

112. Wang, S.M.; Tie, J.; Wang, W.L.; Hu, S.J.; Y+in, J.P.; Yi, X.F.; Tian, Z.H.; Zhang, X.Y.; Li, M.B.; Li, Z.S.; et al. POU2F2-oriented network promotes human gastric cancer metastasis. Gut 2016,65,1427-1438. doi:10.1136/gutjnl-2014-308932

113. Yi, T.; Zhou, X.; Sang, K.; Huang, X.; Zhou, J.; Ge, L. Activation of lncRNA lnc-SLC4A1-1 induced by H3K27 acetylation promotes the development of breast cancer via activating CXCL8 and NF-kB pathway. Artif. Cells. Nanomed. Biotechnol 2019,47,3765-3773. doi:10.1080/21691401.2019.1664559

114. Lan, Y.; Han, J.; Wang, Y.; Wang, J.; Yang, G.; Li, K.; Song, R.; Zheng, T.; Liang, Y.; Pan, S.; et al. STK17B promotes carcinogenesis and metastasis via AKT/GSK-3 $\beta /$ Snail signaling in hepatocellular carcinoma. Cell. Death. Dis 2018,9,236. doi:10.1038/s41419-018-0262-1

115. Appert-Collin, A.; Bennasroune, A.; Jeannesson, P.; Terryn, C.; Fuhrmann, G.; Morjani, H.; Dedieu, S. Role of LRP-1 in cancer cell migration in 3-dimensional collagen matrix. Cell. Adh. Migr 2017,11,316326. doi:10.1080/19336918.2016.1215788

116. Kairouz, R.; Parmar, J.; Lyons, R.J.; Swarbrick, A.; Musgrove, E.A.; Daly, R.J. Hormonal regulation of the Grb14 signal modulator and its role in cell cycle progression of MCF-7 human breast cancer cells. J. Cell. Physiol 2005,203,85-93. doi:10.1002/jcp.20199

117. Diez-Bello, R.; Jardin, I.; Lopez, J.J.; El Haouari, M.; Ortega-Vidal, J.; Altarejos, J.; Salido, G.M.; Salido, S.; Rosado, J.A. (-) $\square$ Oleocanthal inhibits proliferation and migration by modulating $\mathrm{Ca} 2+$ entry through TRPC6 in breast cancer cells. Biochim. Biophys. Acta. Mol. Cell. Res. 2019,1866,474-485. doi:10.1016/j.bbamcr.2018.10.010

118. Xue, M.; Tao, W.; Yu, S.; Yan, Z.; Peng, Q.; Jiang, F.; Gao, X. lncRNA ZFPM2-AS1 promotes proliferation via miR-18b-5p/VMA21 axis in lung adenocarcinoma. J. Cell. Biochem 2020,121,313-321. doi:10.1002/jcb.29176

119. Abo-Elfadl, M.T.; Gamal-Eldeen, A.M.; Ismail, M.F.; Shahin, N.N. Silencing of the cytokine receptor TNFRSF13B: A new therapeutic target 
medRxiv preprint doi: https://doi.org/10.1101/2020.12.20.20248601; this version posted December 23, 2020. The copyright holder for this

for triple-negative breast cancer. Cytokine 2020,125,154790. doi:10.1016/j.cyto.2019.154790

120. Li, J.; Xu, X.; Wei, C.; Liu, L.; Wang, T. Long noncoding RNA NORAD regulates lung cancer cell proliferation, apoptosis, migration, and invasion by the miR-30a-5p/ADAM19 axis. Int. J. Clin. Exp. Pathol 2020,13,1-13.

121. Zhao, J.; Cheng, L. Long non-coding RNA CCAT1/miR-148a axis promotes osteosarcoma proliferation and migration through regulating PIK3IP1. Acta. Biochim. Biophys. Sin (Shanghai) 2017,49,503-512. doi:10.1093/abbs/gmx041

122. Leite, F.A.; Lira, R.C.; Fedatto, P.F.; Antonini, S.R.; Martinelli, C.E .; de Castro, M.; Neder, L.; Ramalho, L.N.; Tucci, S.; Mastelaro, M.J.; et al. Low expression of HLA-DRA, HLA-DPA1, and HLA-DPB1 is associated with poor prognosis in pediatric adrenocortical tumors (ACT). Pediatr. Blood. Cancer 2014,61,1940-1948. doi:10.1002/pbc.25118

123. Feng, Y.; Guo, C.; Wang, H.; Zhao, L.; Wang, W.; Wang, T.; Feng, Y.; Yuan, K.; Huang, G. Fibrinogen-Like Protein 2 (FGL2) is a Novel Biomarker for Clinical Prediction of Human Breast Cancer. Med. Sci. Monit 2020,26,e923531. doi:10.12659/MSM.923531

124. Wang, S.; Xu, L.; Che, X.; Li, C.; Xu, L.; Hou, K.; Fan, Y.; Wen, T.; Qu, X.; Liu, Y. E3 ubiquitin ligases Cbl-b and c-Cbl downregulate PD-L1 in EGFR wild-type non-small cell lung cancer. FEBS. Lett 2018,592,621-630. doi:10.1002/1873-3468.12985

125. Zhong, X.P.; Kan, A.; Ling, Y.H.; Lu, L.H.; Mei, J.; Wei, W.; Li,

S.H.; Guo, R.P. NCKAP1 improves patient outcome and inhibits cell growth by enhancing Rb1/p53 activation in hepatocellular carcinoma. Cell. Death. Dis 2019,10,369.. doi:10.1038/s41419-019-1603-4

126. Yokoyama-Mashima, S.; Yogosawa, S.; Kanegae, Y.; Hirooka, S.; Yoshida, S.; Horiuchi, T.; Ohashi, T.; Yanaga, K.; Saruta, M.; Oikawa, T.; et al. Forced expression of DYRK2 exerts anti-tumor effects via apoptotic induction in liver cancer. Cancer. Lett 2019,451,100-109. doi:10.1016/j.canlet.2019.02.046

127. Guo, H.; Zhang, B.; Nairn, A.V.; Nagy, T.; Moremen, K.W.; Buckhaults, P.; Pierce, M. O-Linked N-Acetylglucosamine (O-GlcNAc) Expression Levels Epigenetically Regulate Colon Cancer Tumorigenesis by 
medRxiv preprint doi: https://doi.org/10.1101/2020.12.20.20248601; this version posted December 23, 2020. The copyright holder for this

Affecting the Cancer Stem Cell Compartment via Modulating Expression of Transcriptional Factor MYBL1. J. Biol. Chem 2017,292,4123-4137. doi:10.1074/jbc.M116.763201

128. Lawson, J.; Dickman, C.; MacLellan, S.; Towle, R.; Jabalee, J.; Lam, S.; Garnis, C. Selective secretion of microRNAs from lung cancer cells via extracellular vesicles promotes CAMK1D-mediated tube formation in endothelial cells. Oncotarget 2017,8,83913-83924. doi:10.18632/oncotarget.19996

129. Wang, X.; Ye, M.; Wu.; M.; Fang, H.; Xiao, B.; Xie, L.; Zhu, X. RNF213 suppresses carcinogenesis in glioblastoma by affecting MAPK/JNK signaling pathway. Clin. Transl. Oncol 2020,22,1506-1516. doi:10.1007/s12094-020-02286-x

130. Taheri, M.; Omrani, M.D.; Noroozi, R.; Ghafouri-Fard, S.; Sayad, A. Retinoic acid-related orphan receptor alpha (RORA) variants and risk of breast cancer. Breast. Dis 2017,37,21-25. doi:10.3233/BD-160248

131. Hoyo, C.; Murphy, S.K.; Schildkraut, J.M.; Vidal, A.C.; Skaar, D.; Millikan, R.C.; Galanko, J.; Sandler R.S.; Jirtle R.; Keku T. IGF2R genetic variants, circulating IGF2 concentrations and colon cancer risk in African Americans and Whites. Dis. Markers 2012,32,133-141. doi:10.3233/DMA2011-0865

132. Bai, F.; Xiao, K. Prediction of gastric cancer risk: association between ZBTB20 genetic variance and gastric cancer risk in Chinese Han population. Biosci. Rep 2020,40,BSR20202102. doi:10.1042/BSR20202102

133. Hope, C.; Emmerich, P.B, Papadas, A.; Pagenkopf, A.; Matkowskyj, K.A.; Van De Hey, D.R.; Payne, S.N.; Clipson, L.; Callander, N.S.; Hematti, P.; et al. Versican-Derived Matrikines Regulate Batf3-Dendritic Cell Differentiation and Promote $\mathrm{T}$ Cell Infiltration in Colorectal Cancer. $J$. Immunol 2017,199,1933-1941. doi:10.4049/jimmunol.1700529

134. Bai, X.; Wang, W.; Zhao, P.; Wen, J.; Guo, X.; Shen, T.; Shen, J.; Yang, X. LncRNA CRNDE acts as an oncogene in cervical cancer through sponging miR-183 to regulate CCNB1 expression. Carcinogenesis 2020,41,111-121. doi:10.1093/carcin/bgz166

135. Zienert, E.; Eke, I.; Aust, D.; Cordes, N. LIM-only protein FHL2 critically determines survival and radioresistance of pancreatic cancer cells. Cancer. Lett 2015,364,17-24. doi:10.1016/j.canlet.2015.04.019 
136. Yang, J.; Chen, Z.; Liu, N.; Chen, Y. Ribosomal protein L10 in mitochondria serves as a regulator for ROS level in pancreatic cancer cells. Redox Biol 2018,19,158-165. doi:10.1016/j.redox.2018.08.016

137. Xie, F.; Huang, Q.; Wang, C.; Chen, S.; Liu, C.; Lin, X.; Lv, X.; Wang, C. Downregulation of long noncoding RNA SNHG14 suppresses cell proliferation and invasion by regulating EZH2 in pancreatic ductal adenocarcinoma (PDAC). Cancer. Biomark 2020,27,357-364. doi:10.3233/CBM-190908

138. Li, S.S.; Jiang, W.L.; Xiao, W.Q.; Li, K.; Zhang, Y.F.; Guo, X.Y.; Dai, Y.Q.; Zhao, Q.Y.; Jiang, M.J.; Lu, Z.J.; et al. KMT2D deficiency enhances the anti-cancer activity of $\mathrm{L} 48 \mathrm{H} 37$ in pancreatic ductal adenocarcinoma. World. J. Gastrointest. Oncol 2019,11,599-621. doi:10.4251/wjgo.v11.i8.599

139. Zhu, G.; Zhou, L.; Liu, H.; Shan, Y.; Zhang, X. MicroRNA-224 Promotes Pancreatic Cancer Cell Proliferation and Migration by Targeting the TXNIP-Mediated HIF1 $\alpha$ Pathway. Cell. Physiol. Biochem 2018,48,1735-1746. doi:10.1159/000492309

140. Zhang, K.D.; Hu, B.; Cen, G.; Yang, Y.H.; Chen, W.W.; Guo, Z.Y.; Wang, X.F.; Zhao, Q.; Qiu, Z.J. MiR-301a transcriptionally activated by HIF-2 $\alpha$ promotes hypoxia-induced epithelial-mesenchymal transition by targeting TP63 in pancreatic cancer. World. J. Gastroenterol 2020,26,23492373. doi:10.3748/wjg.v26.i19.2349

141. Wuebben, E.L.; Wilder, P.J.; Cox, J.L.; Grunkemeyer, J.A.; Caffrey, T.; Hollingsworth, M.A.; Rizzino, A. SOX2 functions as a molecular rheostat to control the growth, tumorigenicity and drug responses of pancreatic ductal adenocarcinoma cells. Oncotarget 2016,7,34890-34906. doi:10.18632/oncotarget.8994

142. Muthalagu, N.; Monteverde, T.; Raffo-Iraolagoitia, X.; Wiesheu, R.; Whyte, D.; Hedley, A.; Laing, S.; Kruspig, B.; Upstill-Goddard R.; Shaw R.; et al. Repression of the Type I Interferon Pathway Underlies MYC- and KRAS-Dependent Evasion of NK and B Cells in Pancreatic Ductal Adenocarcinoma. Cancer. Discov 2020,10,872-887. doi:10.1158/21598290.CD-19-0620

143. Wang, Z.; Chen, Y.; Lin, Y.; Wang, X.; Cui, X.; Zhang, Z.; Xian, G.; Qin, C. Novel crosstalk between KLF4 and ZEB1 regulates gemcitabine 
medRxiv preprint doi: https://doi.org/10.1101/2020.12.20.20248601; this version posted December 23, 2020. The copyright holder for this preprint (which was not certified by peer review) is the author/funder, who has granted medRxiv a license to display the preprint in perpetuity.

All rights reserved. No reuse allowed without permission.

resistance in pancreatic ductal adenocarcinoma. Int. J. Oncol 2017,51,12391248. doi:10.3892/ijo.2017.4099

144. Hu, L.; Fang, L.; Zhang, Z.P.; Yan, Z.L. TPM1 is a Novel Predictive Biomarker for Gastric Cancer Diagnosis and Prognosis. Clin Lab. 2020,66,10.7754/Clin.Lab.2019.190235. doi:10.7754/Clin.Lab.2019.190235 145. Chen, H.; Fan, Y.; Xu, W.; Chen, J.; Meng, Y.; Fang, D.; Wang, J. Exploration of miR-1202 and miR-196a in human endometrial cancer based on high throughout gene screening analysis. Oncol. Rep 2017,37,34933501. doi:10.3892/or.2017.5596

\section{Tables}

Table 1 The sequences of primers for quantitative RT-PCR

\begin{tabular}{ccc}
\hline Genes & Primers & Length of target fragment, bp \\
\hline CCNB1 & F: AATAAGGCGAAGATCAACATGGC & 23 \\
& R: TTTGTTACCAATGTCCCCAAGAG & 23 \\
FHL2 & F: GTACAGACTGCTATTCCAACGAG & 23 \\
& R: GCACTGCATGGCATGTTGTT & 20 \\
HLA-DPA1 & F: ATGCGCCCTGAAGACAGAATG & 20 \\
TUBB1 & R: ACACATGGTCCGCCTTGATG & 19 \\
& F: AACACGGGATCGACTTGGC & 21 \\
\hline
\end{tabular}

F: Forward Primers

R: Reverse Primers

Table 2 The statistical metrics for key differentially expressed genes (DEGs)

\begin{tabular}{|c|c|c|c|c|c|c|}
\hline Gene Symbol & $\log \mathrm{FC}$ & p Value & adj.P.Val & $t$ value & Regulation & Gene Name \\
\hline DAP & 0.729809 & $3.54 \mathrm{E}-14$ & $2.59 \mathrm{E}-11$ & 7.862623 & Up & death associated protein \\
\hline MTRNR2L2 & 1.55786 & 4.87E-14 & $3.22 \mathrm{E}-11$ & 7.816552 & Up & MT-RNR2 like 2 \\
\hline ICA1 & 1.027176 & $1.66 \mathrm{E}-13$ & $9 \mathrm{E}-11$ & 7.636838 & Up & islet cell autoantigen 1 \\
\hline KRT8 & 1.61503 & $6.94 \mathrm{E}-13$ & $3.01 \mathrm{E}-10$ & 7.423576 & Up & $\begin{array}{l}\text { keratin } 8 \\
\text { microtubule associated protein } 1 \text { light }\end{array}$ \\
\hline MAP1LC3B2 & 1.050642 & $1.03 \mathrm{E}-11$ & $3.21 \mathrm{E}-09$ & 7.008711 & Up & chain 3 beta 2 \\
\hline KRT18 & 1.317775 & $1.21 \mathrm{E}-11$ & 3.67E-09 & 6.984018 & Up & keratin 18 \\
\hline DBN1 & 0.680188 & $1.71 \mathrm{E}-11$ & $4.78 \mathrm{E}-09$ & 6.928904 & Up & drebrin 1 \\
\hline MAP1B & 0.804673 & $2.02 \mathrm{E}-11$ & 5.5E-09 & 6.902127 & Up & $\begin{array}{l}\text { microtubule associated protein 1B } \\
\text { insulin like growth factor binding protein }\end{array}$ \\
\hline IGFBP2 & 1.26743 & $2.04 \mathrm{E}-11$ & 5.5E-09 & 6.900692 & Up & 2 \\
\hline KRT19 & 1.682062 & $3.2 \mathrm{E}-11$ & $8.32 \mathrm{E}-09$ & 6.828975 & Up & $\begin{array}{l}\text { keratin } 19 \\
\text { aryl hydrocarbon receptor nuclear }\end{array}$ \\
\hline ARNTL2 & 1.064741 & $3.25 \mathrm{E}-11$ & $8.42 \mathrm{E}-09$ & 6.826429 & Up & translocator like 2 \\
\hline MND1 & 1.050388 & $6.48 \mathrm{E}-11$ & $1.51 \mathrm{E}-08$ & 6.714983 & Up & meiotic nuclear divisions 1 \\
\hline LCN2 & 1.195504 & $1.23 \mathrm{E}-10$ & 2.65E-08 & 6.610378 & Up & lipocalin 2 \\
\hline HP & 1.105468 & $1.98 \mathrm{E}-10$ & 4.01E-08 & 6.531824 & Up & haptoglobin \\
\hline GOLIM4 & 0.730931 & $1.99 \mathrm{E}-10$ & 4.01E-08 & 6.531295 & Up & golgi integral membrane protein 4 \\
\hline
\end{tabular}


medRxiv preprint doi: https://doi.org/10.1101/2020.12.20.20248601; this version posted December 23, 2020. The copyright holder for this preprint (which was not certified by peer review) is the author/funder, who has granted medRxiv a license to display the preprint in perpetuity.

All rights reserved. No reuse allowed without permission.

\begin{tabular}{|c|c|c|c|c|c|c|}
\hline FGB & 1.281458 & $2.04 \mathrm{E}-10$ & 4.09E-08 & 6.526862 & $\mathrm{Up}$ & fibrinogen beta chain \\
\hline TCEAL3 & 0.698058 & $2.11 \mathrm{E}-10$ & 4.19E-08 & 6.521292 & $\mathrm{Up}$ & transcription elongation factor A like 3 \\
\hline H3P47 & 0.806164 & $3.14 \mathrm{E}-10$ & $5.88 \mathrm{E}-08$ & 6.455108 & $\mathrm{Up}$ & H3 histone pseudogene 47 \\
\hline CD27-AS1 & 1.127104 & $3.53 \mathrm{E}-10$ & $6.52 \mathrm{E}-08$ & 6.435648 & $\mathrm{Up}$ & $\begin{array}{l}\text { CD27 antisense RNA 1 } \\
\text { leucine rich single-pass membrane }\end{array}$ \\
\hline LSMEM1 & 1.300595 & $3.94 \mathrm{E}-10$ & 7.16E-08 & 6.417125 & $\mathrm{Up}$ & protein 1 \\
\hline CD63 & 0.638758 & 4.97E-10 & $8.71 \mathrm{E}-08$ & 6.378004 & $\mathrm{Up}$ & CD63 molecule \\
\hline MAOB & 1.081308 & $7.82 \mathrm{E}-10$ & $1.29 \mathrm{E}-07$ & 6.301015 & $\mathrm{Up}$ & monoamine oxidase $\mathrm{B}$ \\
\hline $\begin{array}{c}\text { FGG } \\
\text { LOC10537002 }\end{array}$ & 1.037158 & $8.4 \mathrm{E}-10$ & $1.36 \mathrm{E}-07$ & 6.288927 & $\mathrm{Up}$ & fibrinogen gamma chain \\
\hline 7 & 1.046446 & $1.06 \mathrm{E}-09$ & $1.66 \mathrm{E}-07$ & 6.248715 & $\mathrm{Up}$ & uncharacterized LOC105370027 \\
\hline $\mathrm{H} 2 \mathrm{BC} 17$ & 0.973199 & $1.13 \mathrm{E}-09$ & $1.75 \mathrm{E}-07$ & 6.237457 & $\mathrm{Up}$ & $\begin{array}{l}\text { H2B clustered histone } 17 \\
\text { zinc finger protein, FOG family member }\end{array}$ \\
\hline ZFPM2 & 1.167509 & $1.26 \mathrm{E}-09$ & $1.93 \mathrm{E}-07$ & 6.218913 & $\mathrm{Up}$ & $\begin{array}{c}2 \\
\text { ubiquitin conjugating enzyme E2 Q2 }\end{array}$ \\
\hline UBE2Q2P1 & 0.75226 & $2.34 \mathrm{E}-09$ & $3.3 \mathrm{E}-07$ & 6.111953 & $\mathrm{Up}$ & pseudogene 1 \\
\hline GTF3C6 & 0.66658 & $2.41 \mathrm{E}-09$ & $3.36 \mathrm{E}-07$ & 6.107154 & $\mathrm{Up}$ & general transcription factor IIIC subunit 6 \\
\hline FGA & 1.058162 & $2.56 \mathrm{E}-09$ & $3.52 \mathrm{E}-07$ & 6.096366 & $\mathrm{Up}$ & fibrinogen alpha chain \\
\hline $\mathrm{H} 4 \mathrm{C} 15$ & 0.646131 & $3.44 \mathrm{E}-09$ & 4.5E-07 & 6.044383 & $\mathrm{Up}$ & H4 clustered histone 15 \\
\hline TAX1BP3 & 0.761452 & $3.74 \mathrm{E}-09$ & $4.85 \mathrm{E}-07$ & 6.029641 & $\mathrm{Up}$ & Tax1 binding protein 3 \\
\hline RET & 0.748469 & 4.44E-09 & $5.62 \mathrm{E}-07$ & 5.999495 & $\mathrm{Up}$ & ret proto-oncogene \\
\hline HTATIP2 & 0.696367 & $4.69 \mathrm{E}-09$ & $5.87 \mathrm{E}-07$ & 5.989713 & $\mathrm{Up}$ & HIV-1 Tat interactive protein 2 \\
\hline MCEMP1 & 1.055887 & 7.5E-09 & 8.94E-07 & 5.906144 & $\mathrm{Up}$ & mast cell expressed membrane protein 1 \\
\hline APOB & 0.984349 & $8.66 \mathrm{E}-09$ & $1.02 \mathrm{E}-06$ & 5.88037 & $\mathrm{Up}$ & apolipoprotein B \\
\hline TPM2 & 0.808631 & $9.37 \mathrm{E}-09$ & $1.09 \mathrm{E}-06$ & 5.866037 & $\mathrm{Up}$ & tropomyosin 2 \\
\hline MYL6B & 0.735111 & $9.66 \mathrm{E}-09$ & $1.12 \mathrm{E}-06$ & 5.860685 & $\mathrm{Up}$ & myosin light chain 6B \\
\hline PRELID2 & 1.007003 & $1.01 \mathrm{E}-08$ & $1.16 \mathrm{E}-06$ & 5.851789 & $\mathrm{Up}$ & PRELI domain containing 2 \\
\hline STAC & 0.70663 & $1.08 \mathrm{E}-08$ & $1.24 \mathrm{E}-06$ & 5.839882 & $\mathrm{Up}$ & SH3 and cysteine rich domain \\
\hline $\mathrm{H} 4 \mathrm{C} 14$ & 0.640786 & $1.16 \mathrm{E}-08$ & $1.32 \mathrm{E}-06$ & 5.826872 & $\mathrm{Up}$ & H4 clustered histone 14 \\
\hline KLHDC8B & 0.931058 & $1.17 \mathrm{E}-08$ & $1.32 \mathrm{E}-06$ & 5.825909 & $\mathrm{Up}$ & kelch domain containing $8 \mathrm{~B}$ \\
\hline HRG & 1.25373 & $1.49 \mathrm{E}-08$ & $1.63 \mathrm{E}-06$ & 5.782449 & $\mathrm{Up}$ & $\begin{array}{l}\text { histidine rich glycoprotein } \\
\text { dimethylargininedimethylaminohydrolas }\end{array}$ \\
\hline DDAH1 & 0.960624 & $2.46 \mathrm{E}-08$ & $2.46 \mathrm{E}-06$ & 5.689878 & $\mathrm{Up}$ & e 1 \\
\hline C19orf33 & 1.048033 & $2.73 \mathrm{E}-08$ & $2.69 \mathrm{E}-06$ & 5.670561 & $\mathrm{Up}$ & chromosome 19 open reading frame 33 \\
\hline FAH & 0.995091 & $3.02 \mathrm{E}-08$ & $2.92 \mathrm{E}-06$ & 5.651858 & $\mathrm{Up}$ & $\begin{array}{l}\text { fumarylacetoacetate hydrolase } \\
\text { discoidin, CUB and LCCL domain }\end{array}$ \\
\hline DCBLD2 & 0.939546 & $3.06 \mathrm{E}-08$ & $2.96 \mathrm{E}-06$ & 5.649534 & $\mathrm{Up}$ & $\begin{array}{c}\text { containing } 2 \\
\text { interferon alpha inducible protein } 27 \text { like }\end{array}$ \\
\hline IFI27L2 & 0.822377 & $3.76 \mathrm{E}-08$ & $3.53 \mathrm{E}-06$ & 5.611483 & $\mathrm{Up}$ & 2 \\
\hline PTGES3L & 0.989667 & $3.95 \mathrm{E}-08$ & $3.7 \mathrm{E}-06$ & 5.602037 & $\mathrm{Up}$ & prostaglandin E synthase 3 like \\
\hline TIMP1 & 0.829195 & 4.17E-08 & $3.89 \mathrm{E}-06$ & 5.591888 & $\mathrm{Up}$ & TIMP metallopeptidase inhibitor 1 \\
\hline SNURF & 0.743535 & 4.2E-08 & $3.91 \mathrm{E}-06$ & 5.590685 & $\mathrm{Up}$ & $\begin{array}{l}\text { SNRPN upstream reading frame } \\
\text { CKLF like MARVEL transmembrane }\end{array}$ \\
\hline CMTM2 & 0.918208 & $4.76 \mathrm{E}-08$ & 4.36E-06 & 5.567227 & $\mathrm{Up}$ & domain containing 2 \\
\hline MDK & 0.797135 & $6.31 \mathrm{E}-08$ & $5.6 \mathrm{E}-06$ & 5.513868 & $\mathrm{Up}$ & midkine \\
\hline BCAP31 & 0.771229 & $6.77 \mathrm{E}-08$ & $5.93 \mathrm{E}-06$ & 5.500637 & $\mathrm{Up}$ & B cell receptor associated protein 31 \\
\hline RAB32 & 0.725327 & $7.54 \mathrm{E}-08$ & $6.49 \mathrm{E}-06$ & 5.480174 & $\mathrm{Up}$ & RAB32, member RAS oncogene family \\
\hline $\mathrm{PCP} 2$ & 0.848727 & 7.79E-08 & $6.64 \mathrm{E}-06$ & 5.474068 & $\mathrm{Up}$ & Purkinje cell protein 2 \\
\hline AOPEP & 0.665257 & $9.03 \mathrm{E}-08$ & 7.61E-06 & 5.445854 & $\mathrm{Up}$ & aminopeptidase $\mathrm{O}$ (putative) \\
\hline
\end{tabular}




\begin{tabular}{|c|c|c|c|c|c|c|}
\hline FKBP1B & 1.079675 & $9.08 \mathrm{E}-08$ & 7.64E-06 & 5.444649 & Up & FKBP prolylisomerase $1 \mathrm{~B}$ \\
\hline UBE2C & 0.919203 & $9.19 \mathrm{E}-08$ & 7.7E-06 & 5.442432 & Up & ubiquitin conjugating enzyme $\mathrm{E} 2 \mathrm{C}$ \\
\hline CETN2 & 0.907963 & $9.64 \mathrm{E}-08$ & 7.99E-06 & 5.433373 & Up & $\begin{array}{c}\text { centrin } 2 \\
\text { triggering receptor expressed on myeloid }\end{array}$ \\
\hline TREML3P & 0.736245 & $1.04 \mathrm{E}-07$ & $8.51 \mathrm{E}-06$ & 5.418563 & Up & $\begin{array}{l}\text { cells like 3, pseudogene } \\
\text { colorectal liver metastasis associated }\end{array}$ \\
\hline CLMAT3 & 0.914772 & $1.09 \mathrm{E}-07$ & 8.91E-06 & 5.409301 & Up & $\begin{array}{c}\text { transcript } 3 \\
\text { target of myb1 like } 1 \text { membrane }\end{array}$ \\
\hline TOM1L1 & 1.010788 & $1.25 \mathrm{E}-07$ & $1 \mathrm{E}-05$ & 5.382976 & Up & trafficking protein \\
\hline RABAC1 & 0.685861 & $1.28 \mathrm{E}-07$ & $1.02 \mathrm{E}-05$ & 5.378165 & Up & $\begin{array}{l}\text { Rab acceptor } 1 \\
\text { protein tyrosine phosphatase receptor }\end{array}$ \\
\hline PTPRN & 0.756419 & $1.8 \mathrm{E}-07$ & $1.35 \mathrm{E}-05$ & 5.312969 & Up & type $\mathrm{N}$ \\
\hline CCDC9B & 0.764226 & $1.89 \mathrm{E}-07$ & $1.42 \mathrm{E}-05$ & 5.302684 & Up & coiled-coil domain containing 9B \\
\hline UNC13B & 0.669902 & 2.49E-07 & $1.8 \mathrm{E}-05$ & 5.248667 & Up & unc-13 homolog B \\
\hline APOH & 0.937929 & $2.62 \mathrm{E}-07$ & $1.88 \mathrm{E}-05$ & 5.238638 & Up & $\begin{array}{l}\text { apolipoprotein } \mathrm{H} \\
\text { minichromosome maintenance } 10\end{array}$ \\
\hline MCM10 & 0.778282 & $2.66 \mathrm{E}-07$ & $1.9 \mathrm{E}-05$ & 5.236183 & Up & replication initiation factor \\
\hline $\mathrm{H} 2 \mathrm{BC} 11$ & 0.672283 & $2.8 \mathrm{E}-07$ & $1.98 \mathrm{E}-05$ & 5.226015 & Up & $\begin{array}{l}\mathrm{H} 2 \mathrm{~B} \text { clustered histone } 11 \\
\text { enhancer of zeste } 2 \text { polycomb repressive }\end{array}$ \\
\hline $\mathrm{EZH} 2$ & 0.665264 & $3 \mathrm{E}-07$ & $2.1 \mathrm{E}-05$ & 5.211928 & Up & complex 2 subunit \\
\hline $\mathrm{H} 2 \mathrm{AC} 13$ & 0.672944 & $3.06 \mathrm{E}-07$ & $2.14 \mathrm{E}-05$ & 5.208195 & Up & H2A clustered histone 13 \\
\hline NCBP2L & 0.690397 & $3.18 \mathrm{E}-07$ & $2.2 \mathrm{E}-05$ & 5.200769 & Up & nuclear cap binding protein subunit 2 like \\
\hline CCNB1 & 0.69638 & $3.18 \mathrm{E}-07$ & $2.2 \mathrm{E}-05$ & 5.200386 & Up & cyclin B1 \\
\hline $\begin{array}{c}\text { PKD2 } \\
\text { LOC10013035 }\end{array}$ & 0.747713 & $3.28 \mathrm{E}-07$ & $2.25 \mathrm{E}-05$ & 5.194336 & Up & $\begin{array}{l}\text { polycystin 2, transient receptor potential } \\
\text { cation channel }\end{array}$ \\
\hline 7 & 0.908199 & $3.58 \mathrm{E}-07$ & $2.43 \mathrm{E}-05$ & 5.176869 & Up & uncharacterized LOC100130357 \\
\hline ORM1 & 0.845653 & 4.18E-07 & $2.79 \mathrm{E}-05$ & 5.145905 & Up & $\begin{array}{c}\text { orosomucoid } 1 \\
\text { cerebellar degeneration related protein } 2\end{array}$ \\
\hline CDR2L & 0.75789 & 4.37E-07 & $2.89 \mathrm{E}-05$ & 5.137166 & Up & like \\
\hline $\mathrm{H} 2 \mathrm{AJ}$ & 0.700133 & 4.63E-07 & $3.02 \mathrm{E}-05$ & 5.125431 & Up & H2A.J histone \\
\hline TPM1 & 0.669813 & $4.65 \mathrm{E}-07$ & $3.03 \mathrm{E}-05$ & 5.124861 & Up & tropomyosin 1 \\
\hline ACOT7 & 0.80117 & $5.34 \mathrm{E}-07$ & $3.4 \mathrm{E}-05$ & 5.097055 & Up & $\begin{array}{l}\text { acyl-CoA thioesterase } 7 \\
\text { adaptor related protein complex } 1 \text { subunit }\end{array}$ \\
\hline AP1M2 & 0.962099 & $5.68 \mathrm{E}-07$ & $3.57 \mathrm{E}-05$ & 5.084413 & Up & mu 2 \\
\hline AVEN & 0.668545 & $6.52 \mathrm{E}-07$ & 4.05E-05 & 5.056569 & Up & apoptosis and caspase activation inhibitor \\
\hline DNAH2 & 0.732007 & 7.09E-07 & 4.35E-05 & 5.039399 & Up & $\begin{array}{l}\text { dynein axonemal heavy chain } 2 \\
\text { transient receptor potential cation } \\
\text { channel subfamily } \mathrm{C} \text { member } 2 \\
\text { (pseudogene) }\end{array}$ \\
\hline RND3 & 0.841233 & $7.53 \mathrm{E}-07$ & $4.58 \mathrm{E}-05$ & 5.027115 & Up & $\begin{array}{l}\text { Rho family GTPase } 3 \\
\text { protein phosphatase } 1 \text { regulatory }\end{array}$ \\
\hline PPP1R14A & 0.745833 & $7.86 \mathrm{E}-07$ & $4.75 \mathrm{E}-05$ & 5.018397 & Up & inhibitor subunit $14 \mathrm{~A}$ \\
\hline TGFB3 & 0.835809 & 7.9E-07 & $4.76 \mathrm{E}-05$ & 5.01733 & Up & transforming growth factor beta 3 \\
\hline TPST1 & 0.819069 & 8.34E-07 & 4.99E-05 & 5.006228 & Up & tyrosylproteinsulfotransferase 1 \\
\hline VNN1 & 0.865209 & $1.1 \mathrm{E}-06$ & $6.32 \mathrm{E}-05$ & 4.949468 & Up & vanin 1 \\
\hline MIR1282 & 1.063689 & $1.12 \mathrm{E}-06$ & $6.41 \mathrm{E}-05$ & 4.945828 & Up & microRNA 1282 \\
\hline APOA2 & 0.724038 & $1.23 \mathrm{E}-06$ & 6.93E-05 & 4.92633 & Up & $\begin{array}{l}\text { apolipoprotein A2 } \\
\text { family with sequence similarity } 92\end{array}$ \\
\hline FAM92A & 0.677465 & $1.25 \mathrm{E}-06$ & 7.03E-05 & 4.922308 & Up & $\begin{array}{c}\text { member A } \\
\text { Myb/SANT DNA binding domain }\end{array}$ \\
\hline MSANTD3 & 0.66954 & $1.29 \mathrm{E}-06$ & $7.18 \mathrm{E}-05$ & 4.916615 & Up & containing 3 \\
\hline GRK4 & 0.900233 & $1.37 \mathrm{E}-06$ & $7.55 \mathrm{E}-05$ & 4.904444 & Up & G protein-coupled receptor kinase 4 \\
\hline TSPAN15 & 0.802125 & $1.4 \mathrm{E}-06$ & 7.7E-05 & 4.899117 & Up & tetraspanin 15 \\
\hline
\end{tabular}




\begin{tabular}{|c|c|c|c|c|c|c|}
\hline PTGER3 & 0.731073 & $1.54 \mathrm{E}-06$ & $8.36 \mathrm{E}-05$ & 4.879106 & Up & prostaglandin E receptor 3 \\
\hline MITF & 0.871653 & $1.63 \mathrm{E}-06$ & $8.76 \mathrm{E}-05$ & 4.867297 & Up & melanocyte inducing transcription factor \\
\hline MMP1 & 0.771433 & $1.75 \mathrm{E}-06$ & $9.33 \mathrm{E}-05$ & 4.852725 & Up & $\begin{array}{c}\text { matrix metallopeptidase } 1 \\
\text { mal, } \mathrm{T} \text { cell differentiation protein } 2\end{array}$ \\
\hline MAL2 & 0.749667 & $1.81 \mathrm{E}-06$ & $9.62 \mathrm{E}-05$ & 4.845684 & Up & (gene/pseudogene) \\
\hline $\begin{array}{c}\text { CTPS2 } \\
\text { LOC10192953 }\end{array}$ & 0.67219 & $1.83 \mathrm{E}-06$ & $9.71 \mathrm{E}-05$ & 4.843038 & Up & CTP synthase 2 \\
\hline 8 & 0.711706 & $1.9 \mathrm{E}-06$ & $9.98 \mathrm{E}-05$ & 4.835864 & Up & $\begin{array}{l}\text { uncharacterized LOC101929538 } \\
\text { olfactory receptor family } 2 \text { subfamily B }\end{array}$ \\
\hline OR2B6 & 0.909758 & $1.94 \mathrm{E}-06$ & 0.000102 & 4.831266 & Up & member 6 \\
\hline C20orf96 & 0.740435 & $2.13 \mathrm{E}-06$ & 0.000109 & 4.811175 & Up & chromosome 20 open reading frame 96 \\
\hline $\begin{array}{c}\text { MPZL3 } \\
\text { LOC10192742 }\end{array}$ & 0.734878 & $2.16 \mathrm{E}-06$ & 0.000111 & 4.808022 & Up & myelin protein zero like 3 \\
\hline 0 & 0.734878 & $2.29 \mathrm{E}-06$ & 0.000116 & 4.79601 & Up & uncharacterized LOC101927420 \\
\hline EPDR1 & 0.769808 & $2.47 \mathrm{E}-06$ & 0.000125 & 4.779781 & Up & ependymin related 1 \\
\hline FHL2 & 0.853097 & $2.75 \mathrm{E}-06$ & 0.000137 & 4.756748 & Up & four and a half LIM domains 2 \\
\hline LAPTM4B & 0.92193 & $3.02 \mathrm{E}-06$ & 0.000148 & 4.736673 & Up & lysosomal protein transmembrane 4 beta \\
\hline ARG2 & 1.000424 & $3.03 \mathrm{E}-06$ & 0.000149 & 4.735971 & Up & arginase 2 \\
\hline ADAM22 & 0.710055 & $3.12 \mathrm{E}-06$ & 0.000152 & 4.729888 & Up & ADAM metallopeptidase domain 22 \\
\hline GPC5 & 0.6499 & $3.29 \mathrm{E}-06$ & 0.000159 & 4.718778 & Up & glypican 5 \\
\hline DERA & 0.676038 & $3.31 \mathrm{E}-06$ & 0.000161 & 4.716998 & Up & deoxyribose-phosphate aldolase \\
\hline OXTR & 0.917126 & $3.55 \mathrm{E}-06$ & 0.00017 & 4.70246 & Up & oxytocin receptor \\
\hline PROK2 & 0.789874 & $3.77 \mathrm{E}-06$ & 0.000179 & 4.689155 & Up & prokineticin 2 \\
\hline CNN1 & 0.901951 & $3.81 \mathrm{E}-06$ & 0.00018 & 4.686924 & Up & calponin 1 \\
\hline KRT7 & 0.904375 & 4.03E-06 & 0.000188 & 4.674982 & Up & keratin 7 \\
\hline CENPI & 0.730063 & 4.07E-06 & 0.00019 & 4.672762 & Up & $\begin{array}{l}\text { centromere protein I } \\
\text { long intergenic non-protein coding RNA }\end{array}$ \\
\hline LINC01684 & 0.731662 & 4.19E-06 & 0.000195 & 4.666397 & Up & $\begin{array}{c}1684 \\
\text { potassium calcium-activated channel }\end{array}$ \\
\hline KCNMB1 & 0.752736 & $4.56 \mathrm{E}-06$ & 0.000209 & 4.647801 & Up & subfamily M regulatory beta subunit 1 \\
\hline LACTB2 & 0.695963 & 4.69E-06 & 0.000215 & 4.641781 & Up & lactamase beta 2 \\
\hline BEST3 & 0.711771 & 4.73E-06 & 0.000216 & 4.640144 & Up & bestrophin 3 \\
\hline C5orf30 & 0.731538 & $5.21 \mathrm{E}-06$ & 0.000236 & 4.618767 & Up & chromosome 5 open reading frame 30 \\
\hline SMPD1 & 0.834518 & $5.41 \mathrm{E}-06$ & 0.000244 & 4.610568 & Up & sphingomyelinphosphodiesterase 1 \\
\hline ANO10 & 0.657575 & $5.46 \mathrm{E}-06$ & 0.000246 & 4.608531 & Up & anoctamin 10 \\
\hline GINS1 & 0.706019 & $5.61 \mathrm{E}-06$ & 0.000252 & 4.602785 & Up & $\begin{array}{c}\text { GINS complex subunit } 1 \\
\text { transforming growth factor beta } 1\end{array}$ \\
\hline TGFB1I1 & 0.782636 & 6.07E-06 & 0.000269 & 4.585606 & Up & induced transcript 1 \\
\hline CABLES1 & 0.659259 & $6.29 \mathrm{E}-06$ & 0.000277 & 4.577514 & Up & Cdk5 and Abl enzyme substrate 1 \\
\hline ROBO1 & 0.71818 & 7.03E-06 & 0.000304 & 4.552913 & Up & $\begin{array}{l}\text { roundabout guidance receptor } 1 \\
\text { BUB1 mitotic checkpoint }\end{array}$ \\
\hline BUB1 & 0.667318 & 7.42E-06 & 0.000319 & 4.541048 & Up & serine/threonine kinase \\
\hline FUNDC1 & 0.767386 & $7.66 \mathrm{E}-06$ & 0.000328 & 4.533938 & Up & FUN14 domain containing 1 \\
\hline CRTC3-AS1 & 0.751802 & 7.83E-06 & 0.000334 & 4.529039 & Up & CRTC3 antisense RNA 1 \\
\hline DMC1 & 0.841001 & 7.84E-06 & 0.000334 & 4.528894 & Up & DNA meiotic recombinase 1 \\
\hline ZSCAN16-AS1 & 0.738009 & 8.09E-06 & 0.000344 & 4.521862 & $\mathrm{Up}$ & ZSCAN16 antisense RNA 1 \\
\hline SCARF1 & 0.676906 & 8.39E-06 & 0.000355 & 4.513776 & Up & $\begin{array}{l}\text { scavenger receptor class F member } 1 \\
1 \text {-aminocyclopropane-1-carboxylate }\end{array}$ \\
\hline ACCSL & 0.65649 & $8.65 \mathrm{E}-06$ & 0.000365 & 4.50688 & Up & synthase homolog (inactive) like \\
\hline CXCL3 & 0.778559 & $1.03 \mathrm{E}-05$ & 0.000421 & 4.468754 & Up & C-X-C motif chemokine ligand 3 \\
\hline
\end{tabular}


medRxiv preprint doi: https://doi.org/10.1101/2020.12.20.20248601; this version posted December 23, 2020. The copyright holder for this preprint (which was not certified by peer review) is the author/funder, who has granted medRxiv a license to display the preprint in perpetuity.

All rights reserved. No reuse allowed without permission.

\begin{tabular}{|c|c|c|c|c|c|c|}
\hline LINC00892 & 0.819555 & $1.05 \mathrm{E}-05$ & 0.00043 & 4.462734 & Up & $\begin{array}{l}\text { long intergenic non-protein coding RNA } \\
\qquad 892\end{array}$ \\
\hline RNF208 & 0.841349 & $1.06 \mathrm{E}-05$ & 0.000433 & 4.461088 & Up & ring finger protein 208 \\
\hline EAF2 & 0.668192 & $1.15 \mathrm{E}-05$ & 0.000464 & 4.443023 & Up & ELL associated factor 2 \\
\hline LAMB2 & 0.699363 & $1.16 \mathrm{E}-05$ & 0.000468 & 4.44064 & Up & laminin subunit beta 2 \\
\hline LOXL3 & 0.736971 & $1.19 \mathrm{E}-05$ & 0.000477 & 4.435804 & Up & lysyl oxidase like 3 \\
\hline CEACAM6 & 0.828845 & $1.22 \mathrm{E}-05$ & 0.000489 & 4.429132 & $\mathrm{Up}$ & CEA cell adhesion molecule 6 \\
\hline HPD & 0.801889 & $1.29 \mathrm{E}-05$ & 0.00051 & 4.417691 & $\mathrm{Up}$ & 4-hydroxyphenylpyruvate dioxygenase \\
\hline TMEM67 & 0.706644 & $1.3 \mathrm{E}-05$ & 0.000511 & 4.415933 & $\mathrm{Up}$ & $\begin{array}{l}\text { transmembrane protein } 67 \\
\text { long intergenic non-protein coding RNA }\end{array}$ \\
\hline LINC00534 & 0.991484 & $1.3 \mathrm{E}-05$ & 0.000511 & 4.415737 & Up & 534 \\
\hline TYMS & 0.660517 & $1.31 \mathrm{E}-05$ & 0.000514 & 4.413975 & $\mathrm{Up}$ & thymidylatesynthetase \\
\hline ZGLP1 & 0.781496 & $1.36 \mathrm{E}-05$ & 0.000529 & 4.405803 & Up & zinc finger GATA like protein 1 \\
\hline GNG8 & 0.74057 & $1.51 \mathrm{E}-05$ & 0.000581 & 4.381524 & $\mathrm{Up}$ & G protein subunit gamma 8 \\
\hline MT1X & 0.78313 & $1.59 \mathrm{E}-05$ & 0.000609 & 4.368771 & Up & metallothionein $1 \mathrm{X}$ \\
\hline EVA1B & 0.700855 & $1.71 \mathrm{E}-05$ & 0.000642 & 4.352699 & Up & eva-1 homolog B \\
\hline FRMD3 & 0.658149 & $1.91 \mathrm{E}-05$ & 0.000704 & 4.326801 & $\mathrm{Up}$ & $\begin{array}{l}\text { FERM domain containing } 3 \\
\text { ADAM metallopeptidase with }\end{array}$ \\
\hline ADAMTS1 & 0.710457 & $1.94 \mathrm{E}-05$ & 0.000709 & 4.324203 & $\mathrm{Up}$ & thrombospondin type 1 motif 1 \\
\hline ACTR3B & 0.733415 & $2.06 \mathrm{E}-05$ & 0.00075 & 4.309603 & Up & actin related protein $3 \mathrm{~B}$ \\
\hline METTL22 & 0.69995 & $2.27 \mathrm{E}-05$ & 0.00082 & 4.286931 & $\mathrm{Up}$ & methyltransferase like 22 \\
\hline WASF1 & 0.742178 & $2.34 \mathrm{E}-05$ & 0.000842 & 4.280128 & Up & $\begin{array}{l}\text { WASP family member } 1 \\
\text { long intergenic non-protein coding RNA }\end{array}$ \\
\hline LINC00548 & 0.776323 & 2.51E-05 & 0.000886 & 4.264099 & Up & $\begin{array}{c}548 \\
\text { denticleless E3 ubiquitin protein ligase }\end{array}$ \\
\hline DTL & 0.641962 & $2.52 \mathrm{E}-05$ & 0.00089 & 4.262623 & Up & homolog \\
\hline NT5DC2 & 0.692809 & $2.71 \mathrm{E}-05$ & 0.000939 & 4.245871 & Up & 5'-nucleotidase domain containing 2 \\
\hline VEGFC & 0.669813 & $2.88 \mathrm{E}-05$ & 0.000989 & 4.231356 & Up & $\begin{array}{l}\text { vascular endothelial growth factor } \mathrm{C} \\
\text { membrane associated guanylate kinase, }\end{array}$ \\
\hline MAGI2 & 0.735314 & $2.89 \mathrm{E}-05$ & 0.00099 & 4.230904 & Up & $\begin{array}{l}\text { WW and PDZ domain containing } 2 \\
\text { long intergenic non-protein coding RNA }\end{array}$ \\
\hline LINC00211 & 0.894161 & $2.93 \mathrm{E}-05$ & 0.001001 & 4.227722 & Up & 211 \\
\hline SPHK1 & 0.676802 & 3.04E-05 & 0.001028 & 4.219226 & Up & sphingosine kinase 1 \\
\hline ZNF529-AS1 & 0.661567 & $3.35 \mathrm{E}-05$ & 0.001114 & 4.196168 & Up & $\begin{array}{l}\text { ZNF529 antisense RNA } 1 \\
\text { ADAM metallopeptidase with }\end{array}$ \\
\hline ADAMTS5 & 0.660099 & $3.39 \mathrm{E}-05$ & 0.001123 & 4.193506 & Up & $\begin{array}{l}\text { thrombospondin type } 1 \text { motif } 5 \\
\text { dynein cytoplasmic } 1 \text { intermediate chain }\end{array}$ \\
\hline DYNC1I1 & 0.795012 & 3.39E-05 & 0.001124 & 4.193181 & Up & 1 \\
\hline $\mathrm{CCDC} 3$ & 0.674572 & $3.42 \mathrm{E}-05$ & 0.001131 & 4.191397 & Up & $\begin{array}{l}\text { coiled-coil domain containing } 3 \\
\text { Yip1 interacting factor homolog } \mathrm{B} \text {, }\end{array}$ \\
\hline YIF1B & 0.743761 & $3.43 \mathrm{E}-05$ & 0.001133 & 4.190185 & Up & $\begin{array}{l}\text { membrane trafficking protein } \\
\text { protein kinase cAMP-dependent type I }\end{array}$ \\
\hline PRKAR1B & 0.701104 & $3.54 \mathrm{E}-05$ & 0.001164 & 4.182731 & Up & $\begin{array}{l}\text { regulatory subunit beta } \\
\text { nicotinamide nucleotide }\end{array}$ \\
\hline NMNAT3 & 0.641441 & 4.03E-05 & 0.001305 & 4.151903 & Up & adenylyltransferase 3 \\
\hline TSPAN13 & 0.656865 & 4.05E-05 & 0.00131 & 4.150707 & Up & tetraspanin 13 \\
\hline POLR3G & 0.862253 & 4.19E-05 & 0.001346 & 4.143028 & Up & $\begin{array}{l}\text { RNA polymerase III subunit G } \\
\text { transmembrane protein } 158\end{array}$ \\
\hline TMEM158 & 0.832551 & 4.39E-05 & 0.0014 & 4.131626 & Up & (gene/pseudogene) \\
\hline CYTOR & 0.669042 & 4.41E-05 & 0.001403 & 4.130782 & Up & cytoskeleton regulator RNA \\
\hline FN3K & 0.715739 & 4.44E-05 & 0.001411 & 4.128739 & Up & fructosamine 3 kinase \\
\hline CENPU & 0.685833 & 4.48E-05 & 0.001421 & 4.126825 & Up & centromere protein $\mathrm{U}$ \\
\hline ANXA3 & 0.642891 & $4.52 \mathrm{E}-05$ & 0.001431 & 4.124872 & Up & annexin A3 \\
\hline
\end{tabular}


medRxiv preprint doi: https://doi.org/10.1101/2020.12.20.20248601; this version posted December 23, 2020. The copyright holder for this preprint (which was not certified by peer review) is the author/funder, who has granted medRxiv a license to display the preprint in perpetuity.

All rights reserved. No reuse allowed without permission.

\begin{tabular}{|c|c|c|c|c|c|c|}
\hline PGLYRP1 & 0.743358 & 4.53E-05 & 0.001432 & 4.124178 & Up & $\begin{array}{l}\text { peptidoglycan recognition protein } 1 \\
\text { long intergenic non-protein coding RNA }\end{array}$ \\
\hline LINC00853 & 0.886342 & $4.73 \mathrm{E}-05$ & 0.001482 & 4.113907 & Up & 853 \\
\hline C21 orf58 & 0.673046 & $5 \mathrm{E}-05$ & 0.001552 & 4.10054 & Up & chromosome 21 open reading frame 58 \\
\hline PHACTR3 & 0.768701 & $5.12 \mathrm{E}-05$ & 0.001582 & 4.094798 & Up & $\begin{array}{l}\text { phosphatase and actin regulator } 3 \\
\text { cysteine rich transmembrane module }\end{array}$ \\
\hline CYSTM1 & 0.639491 & $6.02 \mathrm{E}-05$ & 0.001809 & 4.055347 & Up & containing 1 \\
\hline $\mathrm{E} 2 \mathrm{~F} 1$ & 0.689528 & $6.28 \mathrm{E}-05$ & 0.001867 & 4.045197 & Up & E2F transcription factor 1 \\
\hline CTNS & 0.723506 & $6.31 \mathrm{E}-05$ & 0.001876 & 4.043771 & Up & cystinosin, lysosomalcystine transporter \\
\hline $\begin{array}{l}\text { LUZP6 } \\
\text { LY6G6F- }\end{array}$ & 0.784849 & $6.33 \mathrm{E}-05$ & 0.00188 & 4.043183 & Up & leucine zipper protein 6 \\
\hline LY6G6D & 0.697512 & $6.82 \mathrm{E}-05$ & 0.002 & 4.024994 & Up & LY6G6F-LY6G6D readthrough \\
\hline DRC7 & 0.641026 & $6.97 \mathrm{E}-05$ & 0.00203 & 4.019452 & Up & dynein regulatory complex subunit 7 \\
\hline SPINT2 & 0.716213 & 7.44E-05 & 0.002142 & 4.003447 & Up & serine peptidase inhibitor, Kunitz type 2 \\
\hline TST & 0.653129 & $8.57 \mathrm{E}-05$ & 0.002428 & 3.968702 & Up & $\begin{array}{l}\text { thiosulfate sulfurtransferase } \\
\text { phenazine biosynthesis like protein }\end{array}$ \\
\hline PBLD & 0.728909 & $9.82 \mathrm{E}-05$ & 0.002708 & 3.934854 & Up & domain containing \\
\hline COL6A3 & 0.800552 & 0.000106 & 0.002866 & 3.916014 & Up & collagen type VI alpha 3 chain \\
\hline SMYD3 & 0.658545 & 0.00011 & 0.002954 & 3.906774 & Up & SET and MYND domain containing 3 \\
\hline SEPTIN4 & 0.678613 & 0.000113 & 0.003014 & 3.900217 & Up & septin 4 \\
\hline ADAM32 & 0.660263 & 0.000114 & 0.003032 & 3.898284 & Up & $\begin{array}{l}\text { ADAM metallopeptidase domain } 32 \\
\text { alcohol dehydrogenase 1B (class I), beta }\end{array}$ \\
\hline ADH1B & 0.683312 & 0.000115 & 0.003044 & 3.896241 & Up & polypeptide \\
\hline TTLL7 & 0.772356 & 0.000116 & 0.003081 & 3.892908 & Up & tubulin tyrosine ligase like 7 \\
\hline ME1 & 0.679181 & 0.000119 & 0.003134 & 3.887332 & Up & malic enzyme 1 \\
\hline PADI4 & 0.638723 & 0.000119 & 0.00315 & 3.885738 & Up & $\begin{array}{c}\text { peptidyl arginine deiminase } 4 \\
\text { cell death inducing DFFA like effector c }\end{array}$ \\
\hline CIDECP1 & 0.65588 & 0.000123 & 0.003226 & 3.877866 & Up & pseudogene 1 \\
\hline CD151 & 0.680244 & 0.000133 & 0.003439 & 3.859108 & Up & CD151 molecule (Raph blood group) \\
\hline ETV4 & 0.762875 & 0.000137 & 0.003518 & 3.851736 & Up & ETS variant transcription factor 4 \\
\hline MYOM1 & 0.712787 & 0.000141 & 0.003611 & 3.843573 & Up & myomesin 1 \\
\hline TMEFF1 & 0.694055 & 0.000161 & 0.00403 & 3.810035 & Up & MSANTD3-TMEFF1 readthrough \\
\hline GLA & 0.768164 & 0.000169 & 0.004193 & 3.797347 & Up & $\begin{array}{l}\text { galactosidase alpha } \\
\text { thyrotropin releasing hormone degrading }\end{array}$ \\
\hline TRHDE & 0.673175 & 0.000173 & 0.004275 & 3.791127 & Up & \\
\hline СCT6P3 & 0.64622 & 0.000176 & 0.00433 & 3.786849 & Up & pseudogene 3 \\
\hline DNAH14 & 0.67538 & 0.000197 & 0.004737 & 3.757991 & Up & $\begin{array}{c}\text { dynein axonemal heavy chain } 14 \\
\text { pleckstrin homology domain containing }\end{array}$ \\
\hline PLEKHA8P1 & 0.678922 & 0.000198 & 0.004758 & 3.756381 & Up & A8 pseudogene 1 \\
\hline MIR646HG & 0.725938 & 0.0002 & 0.004796 & 3.753511 & Up & $\begin{array}{l}\text { MIR646 host gene } \\
\text { transmembrane protein with EGF like }\end{array}$ \\
\hline TMEFF1 & 0.71416 & 0.000213 & 0.005026 & 3.73756 & Up & and two follistatin like domains 1 \\
\hline DPY19L2 & 0.678632 & 0.000214 & 0.005044 & 3.736377 & Up & $\begin{array}{c}\text { dpy-19 like } 2 \\
\text { ELKS/RAB6-interacting/CAST family }\end{array}$ \\
\hline ERC2 & 0.640215 & 0.000232 & 0.005396 & 3.715528 & Up & member 2 \\
\hline PLA2G4A & 0.672732 & 0.000232 & 0.005396 & 3.715504 & Up & $\begin{array}{l}\text { phospholipase A2 group IVA } \\
\text { zinc finger CCCH-type containing, }\end{array}$ \\
\hline ZC3HAV1L & 0.67853 & 0.000241 & 0.005556 & 3.705049 & Up & antiviral 1 like \\
\hline AQP10 & 0.702387 & 0.000255 & 0.005825 & 3.690433 & Up & $\begin{array}{c}\text { aquaporin } 10 \\
\text { phosphoribosyltransferase domain }\end{array}$ \\
\hline PRTFDC1 & 0.732046 & 0.000266 & 0.006032 & 3.67956 & Up & containing 1 \\
\hline SERPINE2 & 0.708281 & 0.000278 & 0.006263 & 3.667198 & Up & serpin family E member 2 \\
\hline
\end{tabular}


medRxiv preprint doi: https://doi.org/10.1101/2020.12.20.20248601; this version posted December 23, 2020. The copyright holder for this preprint (which was not certified by peer review) is the author/funder, who has granted medRxiv a license to display the preprint in perpetuity.

All rights reserved. No reuse allowed without permission.

\begin{tabular}{|c|c|c|c|c|c|c|}
\hline PRR16 & 0.647548 & 0.000365 & 0.007821 & 3.594668 & Up & proline rich 16 \\
\hline ACER2 & 0.714054 & 0.000441 & 0.009068 & 3.543878 & $\mathrm{Up}$ & alkaline ceramidase 2 \\
\hline THEM5 & 0.68475 & 0.000632 & 0.012136 & 3.44491 & Up & thioesterase superfamily member 5 \\
\hline MS4A3 & 0.669703 & 0.000713 & 0.013422 & 3.41125 & Up & membrane spanning 4-domains A3 \\
\hline CLEC2L & 0.667059 & 0.000745 & 0.013903 & 3.398829 & Up & $\begin{array}{l}\text { C-type lectin domain family } 2 \text { member } \mathrm{L} \\
\text { transient receptor potential cation }\end{array}$ \\
\hline TRPC6 & 0.669122 & 0.000816 & 0.014941 & 3.373194 & $\mathrm{Up}$ & $\begin{array}{c}\text { channel subfamily } \mathrm{C} \text { member } 6 \\
\text { long intergenic non-protein coding RNA }\end{array}$ \\
\hline LINC01089 & 0.641558 & 0.00098 & 0.017284 & 3.320844 & Up & 1089 \\
\hline GRB14 & 0.73252 & 0.001457 & 0.023689 & 3.205476 & $\mathrm{Up}$ & growth factor receptor bound protein 14 \\
\hline MYEOV & 0.66784 & 0.001553 & 0.024891 & 3.186553 & Up & myeloma overexpressed \\
\hline TNNC2 & 0.681795 & 0.001798 & 0.027848 & 3.142855 & Up & troponin $\mathrm{C} 2$, fast skeletal type \\
\hline PLAAT1 & 0.716924 & 0.001991 & 0.030092 & 3.112202 & Up & phospholipase A and acyltransferase 1 \\
\hline INKA2-AS1 & 0.64851 & 0.002272 & 0.033302 & 3.072049 & Up & INKA2 antisense RNA 1 \\
\hline DEFA1 & 0.710406 & 0.002482 & 0.035699 & 3.044927 & Up & defensin alpha 1 \\
\hline LYPLAL1-DT & 0.653678 & 0.00251 & 0.035991 & 3.041436 & Up & LYPLAL1 divergent transcript \\
\hline $\begin{array}{c}\text { G0S2 } \\
\text { LOC10537196 }\end{array}$ & 0.666254 & 0.003148 & 0.04269 & 2.970966 & Up & G0/G1 switch 2 \\
\hline 7 & 0.715866 & 0.00336 & 0.044907 & 2.950485 & $\mathrm{Up}$ & uncharacterized LOC105371967 \\
\hline FBXO7 & -1.02578 & $4.57 \mathrm{E}-31$ & $2.47 \mathrm{E}-26$ & -12.6471 & Down & F-box protein 7 \\
\hline $\mathrm{CD} 44$ & -0.77354 & $1.37 \mathrm{E}-24$ & $3.7 \mathrm{E}-20$ & -10.9533 & Down & CD44 molecule (Indian blood group) \\
\hline BNIP3L & -1.11652 & $7.58 \mathrm{E}-24$ & $1.37 \mathrm{E}-19$ & -10.7506 & Down & BCL2 interacting protein 3 like \\
\hline ITGA4 & -0.7155 & $7.16 \mathrm{E}-22$ & $6.46 \mathrm{E}-18$ & -10.202 & Down & integrin subunit alpha 4 \\
\hline SRRM2 & -0.7545 & $2.82 \mathrm{E}-21$ & $1.74 \mathrm{E}-17$ & -10.0332 & Down & serine/arginine repetitive matrix 2 \\
\hline IL7R & -0.9167 & $3.22 \mathrm{E}-21$ & $1.74 \mathrm{E}-17$ & -10.0169 & Down & $\begin{array}{l}\text { interleukin } 7 \text { receptor } \\
\text { major histocompatibility complex, class }\end{array}$ \\
\hline HLA-DRA & -0.72512 & $6.41 \mathrm{E}-21$ & $2.89 \mathrm{E}-17$ & -9.93149 & Down & II, DR alpha \\
\hline AHNAK & -1.08285 & 1.37E-20 & $5.71 \mathrm{E}-17$ & -9.83691 & Down & AHNAK nucleoprotein \\
\hline SESN3 & -0.83384 & 3.7E-20 & $1.34 \mathrm{E}-16$ & -9.71209 & Down & sestrin 3 \\
\hline BTG1 & -0.67464 & 8.57E-20 & $2.9 \mathrm{E}-16$ & -9.606 & Down & BTG anti-proliferation factor 1 \\
\hline TCF7 & -1.05537 & $9.82 \mathrm{E}-20$ & $3.13 \mathrm{E}-16$ & -9.58878 & Down & $\begin{array}{l}\text { transcription factor } 7 \\
\text { protein tyrosine phosphatase receptor }\end{array}$ \\
\hline PTPRC & -0.79038 & $1.95 \mathrm{E}-19$ & $5.55 \mathrm{E}-16$ & -9.50153 & Down & type C \\
\hline STK17B & -0.6627 & $8.27 \mathrm{E}-19$ & $1.95 \mathrm{E}-15$ & -9.31582 & Down & serine/threonine kinase $17 \mathrm{~b}$ \\
\hline IKZF3 & -0.84512 & $4.27 \mathrm{E}-18$ & $9.64 \mathrm{E}-15$ & -9.10211 & Down & $\begin{array}{c}\text { IKAROS family zinc finger } 3 \\
\text { O-linked N-acetylglucosamine (GlcNAc) }\end{array}$ \\
\hline OGT & -0.85075 & $8.43 \mathrm{E}-18$ & $1.83 \mathrm{E}-14$ & -9.01274 & Down & \\
\hline MALAT1 & -1.15502 & $1.98 \mathrm{E}-17$ & 4.04E-14 & -8.89988 & Down & adenocarcinoma transcript 1 \\
\hline MBNL3 & -0.85006 & $2.01 \mathrm{E}-17$ & 4.04E-14 & -8.89733 & Down & muscleblind like splicing regulator 3 \\
\hline TXNIP & -0.69647 & $3.04 \mathrm{E}-17$ & $5.67 \mathrm{E}-14$ & -8.8425 & Down & thioredoxin interacting protein \\
\hline SLC38A1 & -0.674 & 7.23E-17 & $1.22 \mathrm{E}-13$ & -8.72615 & Down & solute carrier family 38 member 1 \\
\hline NCKAP1L & -0.66777 & $7.45 \mathrm{E}-17$ & $1.22 \mathrm{E}-13$ & -8.72221 & Down & NCK associated protein 1 like \\
\hline PAX5 & -1.15676 & $2.44 \mathrm{E}-16$ & $3.67 \mathrm{E}-13$ & -8.56139 & Down & $\begin{array}{l}\text { paired box } 5 \\
\text { trinucleotide repeat containing adaptor }\end{array}$ \\
\hline TNRC6B & -0.80631 & $3.35 \mathrm{E}-16$ & $4.86 \mathrm{E}-13$ & -8.51801 & Down & $6 \mathrm{~B}$ \\
\hline ATM & -0.65967 & 4.2E-16 & $5.83 \mathrm{E}-13$ & -8.48699 & Down & $\begin{array}{l}\text { ATM serine/threonine kinase } \\
\text { major histocompatibility complex, class }\end{array}$ \\
\hline HLA-DPA1 & -0.67781 & $1.41 \mathrm{E}-15$ & $1.82 \mathrm{E}-12$ & -8.31961 & Down & II, DP alpha 1 \\
\hline FAM102A & -0.76298 & $1.5 \mathrm{E}-15$ & $1.89 \mathrm{E}-12$ & -8.31093 & Down & family with sequence similarity 102 \\
\hline
\end{tabular}


medRxiv preprint doi: https://doi.org/10.1101/2020.12.20.20248601; this version posted December 23, 2020. The copyright holder for this preprint (which was not certified by peer review) is the author/funder, who has granted medRxiv a license to display the preprint in perpetuity.

All rights reserved. No reuse allowed without permission.

\begin{tabular}{|c|c|c|c|c|c|}
\hline DYRK2 & -0.69741 & $1.54 \mathrm{E}-15$ & $1.89 \mathrm{E}-12$ & -8.30769 & Down \\
\hline STRADB & -0.88854 & $2.32 \mathrm{E}-15$ & $2.7 \mathrm{E}-12$ & -8.24996 & Down \\
\hline RNF213 & -0.78696 & $2.36 \mathrm{E}-15$ & $2.7 \mathrm{E}-12$ & -8.2476 & Down \\
\hline RPL10 & -0.68279 & $2.4 \mathrm{E}-15$ & $2.7 \mathrm{E}-12$ & -8.24564 & Down \\
\hline EEF1A1 & -0.93399 & $4.56 \mathrm{E}-15$ & $4.75 \mathrm{E}-12$ & -8.15527 & Down \\
\hline RPL23A & -0.69095 & $5.13 \mathrm{E}-15$ & $5.14 \mathrm{E}-12$ & -8.13875 & Down \\
\hline RPL37 & -0.68343 & $6.21 \mathrm{E}-15$ & $5.9 \mathrm{E}-12$ & -8.11176 & Down \\
\hline HBB & -1.18457 & $1.01 \mathrm{E}-14$ & $9.1 \mathrm{E}-12$ & -8.04285 & Down \\
\hline CAMK4 & -1.1638 & $1.36 \mathrm{E}-14$ & $1.17 \mathrm{E}-11$ & -8.00017 & Down \\
\hline TENT5C & -0.78619 & $1.47 \mathrm{E}-14$ & $1.24 \mathrm{E}-11$ & -7.98892 & Down \\
\hline $\mathrm{BACH} 2$ & -1.06422 & $1.5 \mathrm{E}-14$ & $1.24 \mathrm{E}-11$ & -7.98579 & Down \\
\hline TBCEL & -0.64594 & $1.51 \mathrm{E}-14$ & $1.24 \mathrm{E}-11$ & -7.98482 & Down \\
\hline WDFY4 & -0.99635 & $2.23 \mathrm{E}-14$ & $1.75 \mathrm{E}-11$ & -7.9292 & Down \\
\hline RPL27A & -0.6388 & $2.37 \mathrm{E}-14$ & $1.83 \mathrm{E}-11$ & -7.92052 & Down \\
\hline AAK1 & -0.65765 & $4.11 \mathrm{E}-14$ & $2.89 \mathrm{E}-11$ & -7.8413 & Down \\
\hline MS4A1 & -0.95361 & $4.31 \mathrm{E}-14$ & $2.96 \mathrm{E}-11$ & -7.8342 & Down \\
\hline DCAF12 & -0.7593 & $5.05 \mathrm{E}-14$ & $3.3 \mathrm{E}-11$ & -7.81122 & Down \\
\hline KMT2D & -0.87707 & $5.94 \mathrm{E}-14$ & $3.83 \mathrm{E}-11$ & -7.78757 & Down \\
\hline OPA1 & -0.62121 & $6.75 \mathrm{E}-14$ & $4.3 \mathrm{E}-11$ & -7.76907 & Down \\
\hline CAMK1D & -0.67422 & $1.2 \mathrm{E}-13$ & $6.98 \mathrm{E}-11$ & -7.68504 & Down \\
\hline FAM117B & -0.73486 & $1.2 \mathrm{E}-13$ & $6.98 \mathrm{E}-11$ & -7.68502 & Down \\
\hline BCL11B & -0.71547 & $1.26 \mathrm{E}-13$ & $7.28 \mathrm{E}-11$ & -7.67723 & Down \\
\hline HBA1 & -1.28343 & $1.39 \mathrm{E}-13$ & $7.86 \mathrm{E}-11$ & -7.66283 & Down \\
\hline SEC16A & -0.63051 & $2.06 \mathrm{E}-13$ & $1.07 \mathrm{E}-10$ & -7.60474 & Down \\
\hline NOTCH2 & -1.02848 & $3.2 \mathrm{E}-13$ & $1.62 \mathrm{E}-10$ & -7.53985 & Down \\
\hline SLC25A37 & -0.97321 & $3.22 \mathrm{E}-13$ & $1.62 \mathrm{E}-10$ & -7.53857 & Down \\
\hline BCL9L & -0.7821 & $3.41 \mathrm{E}-13$ & $1.67 \mathrm{E}-10$ & -7.53032 & Down \\
\hline RCAN3 & -0.67723 & $3.62 \mathrm{E}-13$ & $1.75 \mathrm{E}-10$ & -7.52118 & Down \\
\hline RALGPS2 & -0.81589 & $4.58 \mathrm{E}-13$ & $2.08 \mathrm{E}-10$ & -7.48622 & Down \\
\hline SOX6 & -1.09995 & $5.44 \mathrm{E}-13$ & $2.43 \mathrm{E}-10$ & -7.46032 & Down \\
\hline TRANK1 & -0.70118 & $6.86 \mathrm{E}-13$ & $2.99 \mathrm{E}-10$ & -7.4255 & Down \\
\hline IL10RA & -0.80857 & $7.25 \mathrm{E}-13$ & $3.11 \mathrm{E}-10$ & -7.41713 & Down \\
\hline TCP11L2 & -0.85596 & $8.16 \mathrm{E}-13$ & $3.42 \mathrm{E}-10$ & -7.39924 & Down \\
\hline TMC8 & -0.90771 & $8.95 \mathrm{E}-13$ & $3.69 \mathrm{E}-10$ & -7.38532 & Down \\
\hline HBA2 & -1.1918 & $1.49 \mathrm{E}-12$ & $5.84 \mathrm{E}-10$ & -7.30802 & Down \\
\hline ZBTB20 & -0.68652 & $2.37 \mathrm{E}-12$ & $8.9 \mathrm{E}-10$ & -7.23703 & Down \\
\hline CTSB & -0.68749 & $3.44 \mathrm{E}-12$ & $1.27 \mathrm{E}-09$ & -7.17953 & Down \\
\hline NSUN3 & -0.97469 & $3.57 \mathrm{E}-12$ & $1.3 \mathrm{E}-09$ & -7.17397 & Down \\
\hline MARCHF8 & -0.64518 & $4.02 \mathrm{E}-12$ & $1.45 \mathrm{E}-09$ & -7.15528 & Down \\
\hline
\end{tabular}

member A

dual specificity tyrosine phosphorylation regulated kinase 2

STE20 related adaptor beta

ring finger protein 213

ribosomal protein L10

eukaryotic translation elongation factor 1 alpha 1

ribosomal protein L23a

ribosomal protein L37

hemoglobin subunit beta calcium/calmodulin dependent protein kinase IV

terminal nucleotidyltransferase $5 \mathrm{C}$

BTB domain and CNC homolog 2

tubulin folding cofactor $\mathrm{E}$ like

WDFY family member 4

ribosomal protein $\mathrm{L} 27 \mathrm{a}$

AP2 associated kinase 1

membrane spanning 4-domains A1

DDB1 and CUL4 associated factor 12

lysine methyltransferase $2 \mathrm{D}$

OPA1 mitochondrial dynamin like GTPase

calcium/calmodulin dependent protein kinase ID

family with sequence similarity 117 member B

$\mathrm{BAF}$ chromatin remodeling complex subunit BCL11B

hemoglobin subunit alpha 1

SEC16 homolog A, endoplasmic reticulum export factor notch receptor 2

solute carrier family 25 member 37

BCL9 like

RCAN family member 3 Ral GEF with PH domain and SH3 binding motif 2

SRY-box transcription factor 6 tetratricopeptide repeat and ankyrin repeat containing 1

interleukin 10 receptor subunit alpha t-complex 11 like 2

transmembrane channel like 8

hemoglobin subunit alpha 2 zinc finger and BTB domain containing 20 cathepsin B

NOP2/Sun RNA methyltransferase 3 membrane associated ring-CH-type finger 8 
medRxiv preprint doi: https://doi.org/10.1101/2020.12.20.20248601; this version posted December 23, 2020. The copyright holder for this preprint (which was not certified by peer review) is the author/funder, who has granted medRxiv a license to display the preprint in perpetuity. All rights reserved. No reuse allowed without permission.

\begin{tabular}{|c|c|c|c|c|c|c|}
\hline BLK & -0.93113 & 4.45E-12 & $1.6 \mathrm{E}-09$ & -7.13963 & Down & $\begin{array}{l}\text { BLK proto-oncogene, Src family tyrosine } \\
\text { kinase }\end{array}$ \\
\hline LEF1 & -0.72094 & $5.64 \mathrm{E}-12$ & 1.97E-09 & -7.10302 & Down & lymphoid enhancer binding factor 1 \\
\hline TLCD4 & -0.94983 & $5.98 \mathrm{E}-12$ & $2.04 \mathrm{E}-09$ & -7.09373 & Down & TLC domain containing 4 \\
\hline CBLB & -0.62042 & $6.13 \mathrm{E}-12$ & $2.06 \mathrm{E}-09$ & -7.08996 & Down & $\begin{array}{l}\text { Cbl proto-oncogene } \mathrm{B} \\
\text { interferon induced protein with }\end{array}$ \\
\hline IFIT1B & -1.14286 & $7.54 \mathrm{E}-12$ & $2.43 \mathrm{E}-09$ & -7.05769 & Down & tetratricopeptide repeats 1B \\
\hline NLRP1 & -0.70059 & $8.94 \mathrm{E}-12$ & $2.81 \mathrm{E}-09$ & -7.03094 & Down & NLR family pyrin domain containing 1 \\
\hline SORL1 & -0.74274 & $1.46 \mathrm{E}-11$ & 4.32E-09 & -6.95383 & Down & sortilin related receptor 1 \\
\hline IGF2R & -0.81797 & $1.48 \mathrm{E}-11$ & 4.34E-09 & -6.95175 & Down & insulin like growth factor 2 receptor \\
\hline PLEC & -0.76357 & $1.63 \mathrm{E}-11$ & $4.68 \mathrm{E}-09$ & -6.93634 & Down & plectin \\
\hline EEF2 & -0.65473 & $1.63 \mathrm{E}-11$ & 4.68E-09 & -6.93587 & Down & eukaryotic translation elongation factor 2 \\
\hline AFF3 & -0.87612 & $1.65 \mathrm{E}-11$ & 4.71E-09 & -6.93416 & Down & AF4/FMR2 family member 3 \\
\hline YOD1 & -0.88888 & $1.72 \mathrm{E}-11$ & 4.78E-09 & -6.92773 & Down & YOD1 deubiquitinase \\
\hline SFT2D2 & -0.63701 & $2 \mathrm{E}-11$ & 5.49E-09 & -6.90414 & Down & SFT2 domain containing 2 \\
\hline NIBAN3 & -0.99082 & $2.03 \mathrm{E}-11$ & $5.5 \mathrm{E}-09$ & -6.90116 & Down & niban apoptosis regulator 3 \\
\hline POU2F2 & -0.62862 & $2.43 \mathrm{E}-11$ & $6.49 \mathrm{E}-09$ & -6.87264 & Down & $\begin{array}{l}\text { POU class } 2 \text { homeobox } 2 \\
\text { BAF chromatin remodeling complex }\end{array}$ \\
\hline BCL11A & -0.69858 & 3.3E-11 & $8.52 \mathrm{E}-09$ & -6.82374 & Down & subunit BCL11A \\
\hline CLEC17A & -0.81849 & $3.72 \mathrm{E}-11$ & $9.42 \mathrm{E}-09$ & -6.80453 & Down & C-type lectin domain containing 17A \\
\hline $\begin{array}{l}\text { ARL4A } \\
\text { TLCD4- }\end{array}$ & -0.79887 & $3.94 \mathrm{E}-11$ & $9.88 \mathrm{E}-09$ & -6.79545 & Down & ADP ribosylation factor like GTPase 4A \\
\hline RWDD3 & -0.96826 & 4.03E-11 & $1 \mathrm{E}-08$ & -6.79186 & Down & TLCD4-RWDD3 readthrough \\
\hline SCARNA21B & -1.42152 & 4.37E-11 & $1.07 \mathrm{E}-08$ & -6.77868 & Down & small Cajal body-specific RNA 21B \\
\hline RANBP10 & -0.73457 & $5.18 \mathrm{E}-11$ & $1.22 \mathrm{E}-08$ & -6.75141 & Down & RAN binding protein 10 \\
\hline BMF & -0.79975 & $6.24 \mathrm{E}-11$ & $1.46 \mathrm{E}-08$ & -6.72111 & Down & Bc12 modifying factor \\
\hline CLEC2D & -0.68117 & $9.34 \mathrm{E}-11$ & $2.09 \mathrm{E}-08$ & -6.65559 & Down & $\begin{array}{l}\text { C-type lectin domain family } 2 \text { member D } \\
\text { class II major histocompatibility complex }\end{array}$ \\
\hline CIITA & -0.75359 & $1.01 \mathrm{E}-10$ & $2.25 \mathrm{E}-08$ & -6.64292 & Down & transactivator \\
\hline TTN & -1.14193 & $1.17 \mathrm{E}-10$ & $2.57 \mathrm{E}-08$ & -6.61882 & Down & titin \\
\hline SLC4A1 & -1.02319 & $1.56 \mathrm{E}-10$ & 3.25E-08 & -6.57166 & Down & $\begin{array}{c}\text { blood group) } \\
\text { ( }\end{array}$ \\
\hline VSTM2A & -0.78114 & $1.64 \mathrm{E}-10$ & $3.41 \mathrm{E}-08$ & -6.56331 & Down & containing $2 \mathrm{~A}$ \\
\hline FGL2 & -0.65079 & $1.81 \mathrm{E}-10$ & 3.71E-08 & -6.54693 & Down & fibrinogen like 2 \\
\hline RORA & -0.65858 & $1.96 \mathrm{E}-10$ & 3.99E-08 & -6.53369 & Down & RAR related orphan receptor A \\
\hline TNFRSF13C & -0.91687 & $2.97 \mathrm{E}-10$ & $5.64 \mathrm{E}-08$ & -6.46456 & Down & TNF receptor superfamily member $13 \mathrm{C}$ \\
\hline EP400 & -0.66759 & $3.19 \mathrm{E}-10$ & $5.96 \mathrm{E}-08$ & -6.45231 & Down & E1A binding protein $\mathrm{p} 400$ \\
\hline PER1 & -0.85447 & $3.87 \mathrm{E}-10$ & 7.05E-08 & -6.42021 & Down & period circadian regulator 1 \\
\hline MPEG1 & -0.67212 & $5.39 \mathrm{E}-10$ & $9.42 \mathrm{E}-08$ & -6.3641 & Down & $\begin{array}{l}\text { macrophage expressed } 1 \\
\text { alpha-1,3-mannosyl-glycoprotein 4-beta- }\end{array}$ \\
\hline MGAT4A & -0.65772 & $5.49 \mathrm{E}-10$ & $9.55 \mathrm{E}-08$ & -6.36127 & Down & $\mathrm{N}$-acetylglucosaminyltransferase A \\
\hline OSBPL10 & -0.76921 & $6.1 \mathrm{E}-10$ & $1.04 \mathrm{E}-07$ & -6.34334 & Down & oxysterol binding protein like 10 \\
\hline SLC2A1 & -1.01788 & $6.65 \mathrm{E}-10$ & $1.13 \mathrm{E}-07$ & -6.32861 & Down & solute carrier family 2 member 1 \\
\hline PLAGL2 & -0.65128 & $7.62 \mathrm{E}-10$ & $1.27 \mathrm{E}-07$ & -6.30558 & Down & $\begin{array}{l}\text { PLAG1 like zinc finger } 2 \\
\text { WD repeat and FYVE domain containing }\end{array}$ \\
\hline WDFY2 & -0.69295 & $7.76 \mathrm{E}-10$ & $1.29 \mathrm{E}-07$ & -6.30233 & Down & $\stackrel{2}{2}$ solute carrier family 14 member 1 (Kidd \\
\hline SLC14A1 & -0.82792 & $7.81 \mathrm{E}-10$ & $1.29 \mathrm{E}-07$ & -6.30132 & Down & ip) \\
\hline VIPR1 & -0.76825 & $8.51 \mathrm{E}-10$ & $1.37 \mathrm{E}-07$ & -6.28656 & Down & vasoactive intestinal peptide receptor 1 \\
\hline
\end{tabular}


medRxiv preprint doi: https://doi.org/10.1101/2020.12.20.20248601; this version posted December 23, 2020. The copyright holder for this preprint (which was not certified by peer review) is the author/funder, who has granted medRxiv a license to display the preprint in perpetuity.

All rights reserved. No reuse allowed without permission.

\begin{tabular}{|c|c|c|c|c|c|c|}
\hline AGPAT4 & -0.80086 & $8.7 \mathrm{E}-10$ & $1.39 \mathrm{E}-07$ & $\begin{array}{l}-6.28281 \\
-6.27089\end{array}$ & Down & $\begin{array}{c}\text { transferrin receptor } \\
\text { 1-acylglycerol-3-phosphate O- } \\
\text { acyltransferase } 4\end{array}$ \\
\hline COBLL1 & -0.72259 & $1.01 \mathrm{E}-09$ & $1.59 \mathrm{E}-07$ & -6.25677 & Down & $\begin{array}{l}\text { cordon-bleu WH2 repeat protein like } 1 \\
\text { SPARC (osteonectin), cwcv and kazal }\end{array}$ \\
\hline SPOCK2 & -0.89285 & $1.11 \mathrm{E}-09$ & $1.74 \mathrm{E}-07$ & -6.24084 & Down & like domains proteoglycan 2 \\
\hline $\mathrm{FECH}$ & -0.79692 & $1.35 \mathrm{E}-09$ & 2.03E-07 & -6.20743 & Down & $\begin{array}{c}\text { ferrochelatase } \\
\text { major histocompatibility complex, class }\end{array}$ \\
\hline HLA-DMB & -0.71841 & $1.47 \mathrm{E}-09$ & 2.19E-07 & -6.19232 & Down & II, DM beta \\
\hline MXI1 & -0.66288 & $1.67 \mathrm{E}-09$ & 2.43E-07 & -6.17102 & Down & MAX interactor 1, dimerization protein \\
\hline TRAK2 & -0.99989 & $1.9 \mathrm{E}-09$ & 2.73E-07 & -6.14798 & Down & trafficking kinesin protein 2 \\
\hline TSPAN5 & -0.68028 & $3.29 \mathrm{E}-09$ & 4.34E-07 & -6.05219 & Down & tetraspanin 5 \\
\hline SPTA1 & -1.01751 & $4.06 \mathrm{E}-09$ & $5.21 \mathrm{E}-07$ & -6.01532 & Down & spectrin alpha, erythrocytic 1 \\
\hline SCARNA10 & -1.16787 & 4.37E-09 & $5.55 \mathrm{E}-07$ & -6.00252 & Down & small Cajal body-specific RNA 10 \\
\hline CXCR5 & -0.91719 & $5.95 \mathrm{E}-09$ & 7.25E-07 & -5.9476 & Down & $\mathrm{C}-\mathrm{X}-\mathrm{C}$ motif chemokine receptor 5 \\
\hline KLK1 & -0.94232 & $6.66 \mathrm{E}-09$ & 8.03E-07 & -5.92739 & Down & $\begin{array}{c}\text { kallikrein } 1 \\
\text { CST telomere replication complex }\end{array}$ \\
\hline CTC1 & -0.70188 & 8.37E-09 & $9.87 \mathrm{E}-07$ & -5.88644 & Down & $\begin{array}{l}\text { component } 1 \\
\text { aldehyde dehydrogenase } 5 \text { family }\end{array}$ \\
\hline ALDH5A1 & -0.71117 & $9.58 \mathrm{E}-09$ & $1.11 \mathrm{E}-06$ & -5.86216 & Down & member $\mathrm{A} 1$ \\
\hline YIPF4 & -0.68858 & $9.91 \mathrm{E}-09$ & $1.14 \mathrm{E}-06$ & -5.85599 & Down & Yip1 domain family member 4 \\
\hline SZT2 & -0.73017 & $1.03 \mathrm{E}-08$ & $1.18 \mathrm{E}-06$ & -5.84867 & Down & $\begin{array}{l}\text { SZT2 subunit of KICSTOR complex } \\
\text { myocardial infarction associated }\end{array}$ \\
\hline MIAT & -0.63403 & $1.18 \mathrm{E}-08$ & $1.33 \mathrm{E}-06$ & -5.82457 & Down & transcript \\
\hline LENG8 & -0.63693 & $1.58 \mathrm{E}-08$ & $1.72 \mathrm{E}-06$ & -5.7713 & Down & leukocyte receptor cluster member 8 \\
\hline SLC7A6 & -0.77445 & $1.83 \mathrm{E}-08$ & $1.94 \mathrm{E}-06$ & -5.74413 & Down & solute carrier family 7 member 6 \\
\hline PLBD2 & -0.83269 & $1.94 \mathrm{E}-08$ & $2.05 \mathrm{E}-06$ & -5.73332 & Down & phospholipase B domain containing 2 \\
\hline RPL13A & -0.62991 & $2.15 \mathrm{E}-08$ & $2.21 \mathrm{E}-06$ & -5.71499 & Down & ribosomal protein L13a \\
\hline TNFRSF13B & -0.94543 & $2.39 \mathrm{E}-08$ & $2.41 \mathrm{E}-06$ & -5.6953 & Down & TNF receptor superfamily member $13 \mathrm{~B}$ \\
\hline $\mathrm{CD} 22$ & -0.67168 & $2.5 \mathrm{E}-08$ & $2.49 \mathrm{E}-06$ & -5.68696 & Down & CD22 molecule \\
\hline SERINC5 & -0.73923 & $2.52 \mathrm{E}-08$ & $2.5 \mathrm{E}-06$ & -5.6859 & Down & $\begin{array}{c}\text { serine incorporator } 5 \\
\text { G protein-coupled receptor associated }\end{array}$ \\
\hline GPRASP1 & -0.81967 & $2.57 \mathrm{E}-08$ & $2.55 \mathrm{E}-06$ & -5.68227 & Down & sorting protein 1 \\
\hline ADA2 & -0.73878 & $2.61 \mathrm{E}-08$ & $2.58 \mathrm{E}-06$ & -5.67885 & Down & adenosine deaminase 2 \\
\hline CCR7 & -0.82793 & 2.73E-08 & $2.68 \mathrm{E}-06$ & -5.67111 & Down & C-C motif chemokine receptor 7 \\
\hline SCARNA6 & -0.77803 & $2.88 \mathrm{E}-08$ & $2.81 \mathrm{E}-06$ & -5.66069 & Down & $\begin{array}{l}\text { small Cajal body-specific RNA } 6 \\
\text { connector enhancer of kinase suppressor }\end{array}$ \\
\hline CNKSR2 & -0.75294 & $3.18 \mathrm{E}-08$ & $3.06 \mathrm{E}-06$ & -5.64253 & Down & of Ras 2 \\
\hline VCAN & -0.73858 & $3.74 \mathrm{E}-08$ & $3.52 \mathrm{E}-06$ & -5.61242 & Down & versican \\
\hline SLC24A4 & -0.87802 & $4.35 \mathrm{E}-08$ & 4.03E-06 & -5.58396 & Down & $\begin{array}{c}\text { solute carrier family } 24 \text { member } 4 \\
\text { long intergenic non-protein coding RNA }\end{array}$ \\
\hline LINC00926 & -0.87511 & 4.52E-08 & 4.17E-06 & -5.57692 & Down & $\begin{array}{c}926 \\
\text { acyl-CoA synthetase long chain family }\end{array}$ \\
\hline ACSL6 & -0.82878 & $4.81 \mathrm{E}-08$ & $4.39 \mathrm{E}-06$ & -5.56537 & Down & member 6 \\
\hline TTC14 & -0.89136 & 4.84E-08 & 4.41E-06 & -5.5642 & Down & tetratricopeptide repeat domain 14 \\
\hline FCRL1 & -0.86187 & $5.34 \mathrm{E}-08$ & 4.82E-06 & -5.54543 & Down & Fc receptor like 1 \\
\hline SLC25A39 & -0.68018 & $5.46 \mathrm{E}-08$ & 4.91E-06 & -5.54135 & Down & solute carrier family 25 member 39 \\
\hline LY9 & -0.76456 & $5.66 \mathrm{E}-08$ & $5.08 \mathrm{E}-06$ & -5.53456 & Down & lymphocyte antigen 9 \\
\hline GOLGA8A & -0.83441 & 7.01E-08 & $6.08 \mathrm{E}-06$ & -5.49414 & Down & $\begin{array}{l}\text { golgin A8 family member A } \\
\text { ATPase plasma membrane } \mathrm{Ca} 2+\end{array}$ \\
\hline ATP2B1 & -0.62628 & 7.37E-08 & $6.37 \mathrm{E}-06$ & -5.48451 & Down & Hansporting 1 \\
\hline
\end{tabular}


medRxiv preprint doi: https://doi.org/10.1101/2020.12.20.20248601; this version posted December 23, 2020. The copyright holder for this preprint (which was not certified by peer review) is the author/funder, who has granted medRxiv a license to display the preprint in perpetuity.

All rights reserved. No reuse allowed without permission.

\begin{tabular}{|c|c|c|c|c|c|c|}
\hline PWAR5 & -0.75691 & 8.03E-08 & $6.79 \mathrm{E}-06$ & -5.46817 & Down & PraderWilli/Angelman region RNA 5 \\
\hline MRC2 & -0.81976 & $9.06 \mathrm{E}-08$ & 7.63E-06 & -5.44524 & Down & mannose receptor $\mathrm{C}$ type 2 \\
\hline SPIB & -0.63152 & 9.37E-08 & $7.82 \mathrm{E}-06$ & -5.43865 & Down & $\begin{array}{c}\text { Spi-B transcription factor } \\
\text { glutamate ionotropic receptor NMDA }\end{array}$ \\
\hline GRINA & -0.65332 & $1.01 \mathrm{E}-07$ & $8.28 \mathrm{E}-06$ & -5.42515 & Down & type subunit associated protein 1 \\
\hline LRP1 & -0.84115 & $1.01 \mathrm{E}-07$ & $8.28 \mathrm{E}-06$ & -5.42512 & Down & LDL receptor related protein 1 \\
\hline ADAM28 & -0.81306 & $1.11 \mathrm{E}-07$ & $9.02 \mathrm{E}-06$ & -5.40656 & Down & ADAM metallopeptidase domain 28 \\
\hline TRABD2A & -0.7573 & $1.16 \mathrm{E}-07$ & $9.42 \mathrm{E}-06$ & -5.39715 & Down & $\begin{array}{l}\text { TraB domain containing } 2 \mathrm{~A} \\
\text { piezo type mechanosensitive ion channel }\end{array}$ \\
\hline PIEZO1 & -0.74385 & $1.17 \mathrm{E}-07$ & $9.44 \mathrm{E}-06$ & -5.39644 & Down & component 1 \\
\hline ADAM19 & -0.68425 & $1.47 \mathrm{E}-07$ & $1.15 \mathrm{E}-05$ & -5.35189 & Down & $\begin{array}{l}\text { ADAM metallopeptidase domain } 19 \\
\text { poly(ADP-ribose) polymerase family }\end{array}$ \\
\hline PARP15 & -0.71333 & 2.02E-07 & $1.5 \mathrm{E}-05$ & -5.29026 & Down & member 15 \\
\hline $\mathrm{CD} 27$ & -0.71993 & 2.07E-07 & $1.53 \mathrm{E}-05$ & -5.28562 & Down & CD27 molecule \\
\hline NELL2 & -0.67846 & $2.21 \mathrm{E}-07$ & $1.62 \mathrm{E}-05$ & -5.27231 & Down & neural EGFL like 2 \\
\hline CD79A & -0.74535 & $2.38 \mathrm{E}-07$ & $1.73 \mathrm{E}-05$ & -5.2578 & Down & CD79a molecule \\
\hline ANKRD52 & -0.63287 & 2.6E-07 & $1.87 \mathrm{E}-05$ & -5.24037 & Down & ankyrin repeat domain 52 \\
\hline DNHD1 & -0.7211 & $2.8 \mathrm{E}-07$ & $1.98 \mathrm{E}-05$ & -5.22571 & Down & dynein heavy chain domain 1 \\
\hline NEURL1 & -0.74572 & 2.93E-07 & $2.06 \mathrm{E}-05$ & -5.21673 & Down & $\begin{array}{l}\text { neuralized E3 ubiquitin protein ligase } 1 \\
\text { CREB regulated transcription coactivator }\end{array}$ \\
\hline CRTC1 & -0.68306 & $3.27 \mathrm{E}-07$ & $2.25 \mathrm{E}-05$ & -5.1949 & Down & 1 \\
\hline GOLGA8B & -0.84973 & $3.8 \mathrm{E}-07$ & $2.56 \mathrm{E}-05$ & -5.16529 & Down & golgin A8 family member B \\
\hline ZNF860 & -0.72407 & 3.83E-07 & $2.58 \mathrm{E}-05$ & -5.16356 & Down & zinc finger protein 860 \\
\hline P2RX5 & -0.67155 & $3.84 \mathrm{E}-07$ & $2.58 \mathrm{E}-05$ & -5.16328 & Down & purinergic receptor $\mathrm{P} 2 \mathrm{X} 5$ \\
\hline BTLA & -0.73832 & $3.96 \mathrm{E}-07$ & $2.65 \mathrm{E}-05$ & -5.15708 & Down & $\begin{array}{c}\text { B and T lymphocyte associated } \\
\text { obscurin, cytoskeletal calmodulin and }\end{array}$ \\
\hline OBSCN & -0.80054 & $4.42 \mathrm{E}-07$ & $2.91 \mathrm{E}-05$ & -5.13505 & Down & \\
\hline SEMA7A & -0.6976 & 4.47E-07 & $2.94 \mathrm{E}-05$ & -5.13259 & Down & blood group) \\
\hline IFFO1 & -0.65589 & $4.96 \mathrm{E}-07$ & $3.2 \mathrm{E}-05$ & -5.11184 & Down & intermediate filament family orphan 1 \\
\hline SLC38A5 & -0.75551 & $5.64 \mathrm{E}-07$ & $3.56 \mathrm{E}-05$ & -5.0858 & Down & $\begin{array}{c}\text { solute carrier family } 38 \text { member } 5 \\
\text { long intergenic non-protein coding RNA }\end{array}$ \\
\hline LINC02273 & -0.70556 & $5.67 \mathrm{E}-07$ & 3.57E-05 & -5.08477 & Down & 2273 \\
\hline DNAH1 & -0.7411 & $6.47 \mathrm{E}-07$ & $4.02 \mathrm{E}-05$ & -5.05819 & Down & dynein axonemal heavy chain 1 \\
\hline NEU3 & -0.70715 & 7.2E-07 & 4.4E-05 & -5.03638 & Down & neuraminidase 3 \\
\hline POLM & -0.67693 & 7.44E-07 & $4.53 \mathrm{E}-05$ & -5.02954 & Down & DNA polymerase mu \\
\hline RPS6KA5 & -0.67198 & $8.28 \mathrm{E}-07$ & $4.96 \mathrm{E}-05$ & -5.00771 & Down & ribosomal protein S6 kinase A5 \\
\hline PDE3B & -0.68318 & 8.73E-07 & $5.17 \mathrm{E}-05$ & -4.99695 & Down & phosphodiesterase 3B \\
\hline COL7A1 & -0.7674 & $9.21 \mathrm{E}-07$ & $5.42 \mathrm{E}-05$ & -4.98585 & Down & collagen type VII alpha 1 chain \\
\hline HEPACAM2 & -0.65213 & $1.02 \mathrm{E}-06$ & $5.93 \mathrm{E}-05$ & -4.96469 & Down & $\begin{array}{l}\text { HEPACAM family member } 2 \\
\text { cadherin EGF LAG seven-pass G-type }\end{array}$ \\
\hline CELSR1 & -0.64047 & $1.12 \mathrm{E}-06$ & $6.39 \mathrm{E}-05$ & -4.94638 & Down & $\begin{array}{c}\text { receptor } 1 \\
\text { zinc finger and BTB domain containing }\end{array}$ \\
\hline ZBTB39 & -0.67388 & $1.13 \mathrm{E}-06$ & $6.46 \mathrm{E}-05$ & -4.94372 & Down & 39 \\
\hline MOB3B & -0.68472 & $1.25 \mathrm{E}-06$ & 7.03E-05 & -4.92272 & Down & MOB kinase activator 3B \\
\hline RHAG & -0.8349 & $1.26 \mathrm{E}-06$ & 7.06E-05 & -4.92115 & Down & $\begin{array}{l}\text { Rh associated glycoprotein } \\
\text { complement } \mathrm{C} 3 \mathrm{~b} / \mathrm{C} 4 \mathrm{~b} \text { receptor } 1 \text { (Knops }\end{array}$ \\
\hline CR1 & -0.65192 & $1.32 \mathrm{E}-06$ & 7.32E-05 & -4.91176 & Down & $\begin{array}{c}\text { blood group) } \\
\text { D-box binding PAR bZIP transcription }\end{array}$ \\
\hline DBP & -0.65426 & $1.38 \mathrm{E}-06$ & 7.62E-05 & -4.90202 & Down & $\begin{array}{c}\text { factor } \\
\text { tubulin gamma complex associated }\end{array}$ \\
\hline TUBGCP6 & -0.66735 & $1.55 \mathrm{E}-06$ & 8.4E-05 & -4.8776 & Down & protein 6 \\
\hline
\end{tabular}




\begin{tabular}{|c|c|c|c|c|c|c|}
\hline ZNF549 & -0.69296 & $1.59 \mathrm{E}-06$ & $8.58 \mathrm{E}-05$ & -4.87232 & Down & zinc finger protein 549 \\
\hline CSF1R & -0.63553 & $1.62 \mathrm{E}-06$ & $8.71 \mathrm{E}-05$ & -4.86868 & Down & colony stimulating factor 1 receptor \\
\hline EPB42 & -0.87201 & $1.73 \mathrm{E}-06$ & $9.24 \mathrm{E}-05$ & -4.85526 & Down & erythrocyte membrane protein band 4.2 \\
\hline SCARNA7 & -0.63099 & $1.87 \mathrm{E}-06$ & $9.88 \mathrm{E}-05$ & -4.83874 & Down & small Cajal body-specific RNA 7 \\
\hline GNG7 & -0.66304 & $1.98 \mathrm{E}-06$ & 0.000104 & -4.82656 & Down & G protein subunit gamma 7 \\
\hline ZNF589 & -0.63146 & $2 \mathrm{E}-06$ & 0.000105 & -4.82428 & Down & $\begin{array}{c}\text { zinc finger protein } 589 \\
\text { glucosaminyl (N-acetyl) transferase } 2 \text { (I }\end{array}$ \\
\hline GCNT2 & -0.69581 & $2.01 \mathrm{E}-06$ & 0.000105 & -4.82357 & Down & blood group) \\
\hline GPR146 & -0.72697 & $2.04 \mathrm{E}-06$ & 0.000106 & -4.82048 & Down & G protein-coupled receptor 146 \\
\hline QSOX2 & -0.66298 & $2.14 \mathrm{E}-06$ & 0.000109 & -4.8106 & Down & quiescin sulfhydryl oxidase 2 \\
\hline SNORA53 & -0.92118 & $2.21 \mathrm{E}-06$ & 0.000113 & -4.80308 & Down & small nucleolar RNA, H/ACA box 53 \\
\hline SCARNA13 & -0.77859 & $2.26 \mathrm{E}-06$ & 0.000115 & -4.79894 & Down & small Cajal body-specific RNA 13 \\
\hline ITGB2-AS1 & -0.62011 & $3.09 \mathrm{E}-06$ & 0.000151 & -4.73185 & Down & ITGB2 antisense RNA 1 \\
\hline ESPN & -0.78256 & $3.11 \mathrm{E}-06$ & 0.000152 & -4.73085 & Down & espin \\
\hline NEAT1 & -0.72879 & $3.35 \mathrm{E}-06$ & 0.000162 & -4.71479 & Down & nuclear paraspeckle assembly transcript 1 \\
\hline FHDC1 & -0.93149 & $3.52 \mathrm{E}-06$ & 0.000169 & -4.70423 & Down & FH2 domain containing 1 \\
\hline $\mathrm{ZC} 3 \mathrm{H} 12 \mathrm{D}$ & -0.64158 & $3.53 \mathrm{E}-06$ & 0.000169 & -4.70345 & Down & $\begin{array}{l}\text { zinc finger CCCH-type containing } 12 \mathrm{D} \\
\text { ATP binding cassette subfamily D }\end{array}$ \\
\hline $\mathrm{ABCD} 2$ & -0.6691 & $3.76 \mathrm{E}-06$ & 0.000178 & -4.6898 & Down & member 2 \\
\hline MCOLN1 & -0.69108 & $3.83 \mathrm{E}-06$ & 0.000181 & -4.68576 & Down & $\begin{array}{c}\text { mucolipin } 1 \\
\text { nuclear receptor subfamily } 4 \text { group A }\end{array}$ \\
\hline NR4A1 & -0.64016 & 4.23E-06 & 0.000196 & -4.66458 & Down & member 1 \\
\hline SLC25A42 & -0.63249 & $4.54 \mathrm{E}-06$ & 0.000209 & -4.64904 & Down & solute carrier family 25 member 42 \\
\hline GYPA & -0.73764 & $5.3 \mathrm{E}-06$ & 0.000239 & -4.61504 & Down & glycophorin A (MNS blood group) \\
\hline SCARNA2 & -0.67524 & $6.79 \mathrm{E}-06$ & 0.000297 & -4.5607 & Down & $\begin{array}{l}\text { small Cajal body-specific RNA } 2 \\
\text { family with sequence similarity } 167\end{array}$ \\
\hline FAM167A & -0.65735 & 7.44E-06 & 0.000319 & -4.54065 & Down & $\begin{array}{l}\text { member A } \\
\text { aldehyde dehydrogenase } 6 \text { family }\end{array}$ \\
\hline ALDH6A1 & -0.6308 & $8.11 \mathrm{E}-06$ & 0.000345 & -4.52128 & Down & member A1 \\
\hline CD4 & -0.62279 & $8.14 \mathrm{E}-06$ & 0.000345 & -4.52057 & Down & $\begin{array}{c}\text { CD4 molecule } \\
\text { ATP binding cassette subfamily A }\end{array}$ \\
\hline ABCA2 & -0.6866 & $9.04 \mathrm{E}-06$ & 0.000378 & -4.49716 & Down & member 2 \\
\hline BEND4 & -0.64725 & $9.32 \mathrm{E}-06$ & 0.000388 & -4.49036 & Down & BEN domain containing 4 \\
\hline CENPF & -0.7335 & $1.03 \mathrm{E}-05$ & 0.000422 & -4.46818 & Down & centromere protein $\mathrm{F}$ \\
\hline CD6 & -0.65075 & $1.03 \mathrm{E}-05$ & 0.000423 & -4.46737 & Down & CD6 molecule \\
\hline KLHL3 & -0.63143 & $1.15 \mathrm{E}-05$ & 0.000465 & -4.44229 & Down & kelch like family member 3 \\
\hline GYPB & -0.73759 & $1.45 \mathrm{E}-05$ & 0.00056 & -4.39099 & Down & $\begin{array}{l}\text { glycophorin B (MNS blood group) } \\
\text { ATP binding cassette subfamily C }\end{array}$ \\
\hline $\mathrm{ABCC} 13$ & -0.70835 & $1.46 \mathrm{E}-05$ & 0.000566 & -4.38865 & Down & member 13 (pseudogene) \\
\hline ATP13A1 & -0.61946 & $1.58 \mathrm{E}-05$ & 0.000606 & -4.3702 & Down & ATPase 13A1 \\
\hline MYO15B & -0.6612 & $1.65 \mathrm{E}-05$ & 0.000624 & -4.36062 & Down & myosin XVB \\
\hline CD5 & -0.65427 & $1.89 \mathrm{E}-05$ & 0.000697 & -4.32962 & Down & CD5 molecule \\
\hline DUSP2 & -0.64467 & $1.91 \mathrm{E}-05$ & 0.000702 & -4.32778 & Down & dual specificity phosphatase 2 \\
\hline SCML4 & -0.63141 & $1.91 \mathrm{E}-05$ & 0.000702 & -4.32734 & Down & $\begin{array}{c}\text { Scmpolycomb group protein like } 4 \\
\text { phosphoinositide-3-kinase interacting }\end{array}$ \\
\hline PIK3IP1 & -0.62444 & $3.82 \mathrm{E}-05$ & 0.001247 & -4.16463 & Down & protein 1 \\
\hline ALAS2 & -0.66726 & $5.72 \mathrm{E}-05$ & 0.001735 & -4.06777 & Down & $\begin{array}{c}\text { 5'-aminolevulinate synthase } 2 \\
\text { RNA component of mitochondrial RNA }\end{array}$ \\
\hline RMRP & -0.64882 & $8.71 \mathrm{E}-05$ & 0.002461 & -3.96458 & Down & processing endoribonuclease \\
\hline RNF182 & -0.84789 & 0.000111 & 0.00298 & -3.90357 & Down & ring finger protein 182 \\
\hline
\end{tabular}


medRxiv preprint doi: https://doi.org/10.1101/2020.12.20.20248601; this version posted December 23, 2020. The copyright holder for this preprint (which was not certified by peer review) is the author/funder, who has granted medRxiv a license to display the preprint in perpetuity.

All rights reserved. No reuse allowed without permission.

\begin{tabular}{ccccccc} 
RNA5-8SN2 & -1.28453 & 0.000116 & 0.003077 & -3.89329 & Down & $\begin{array}{c}\text { RNA, 5.8S ribosomal N2 } \\
\text { selenium binding protein 1 }\end{array}$ \\
SELENBP1 & -0.63971 & 0.000122 & 0.003212 & -3.87967 & Down & $\begin{array}{c}\text { long intergenic non-protein coding RNA } \\
1857\end{array}$ \\
LINC01857 & -0.67006 & 0.000136 & 0.003506 & -3.85285 & Down & small Cajal body-specific RNA 5 \\
SCARNA5 & -0.67276 & 0.00026 & 0.005928 & -3.68493 & Down & hemoglobin subunit mu \\
HBM & -0.66252 & 0.001557 & 0.024934 & -3.18581 & Down & tubulin beta 1 class VI \\
\hline
\end{tabular}

Table 3 The enriched GO terms of the up and down regulated differentially expressed genes

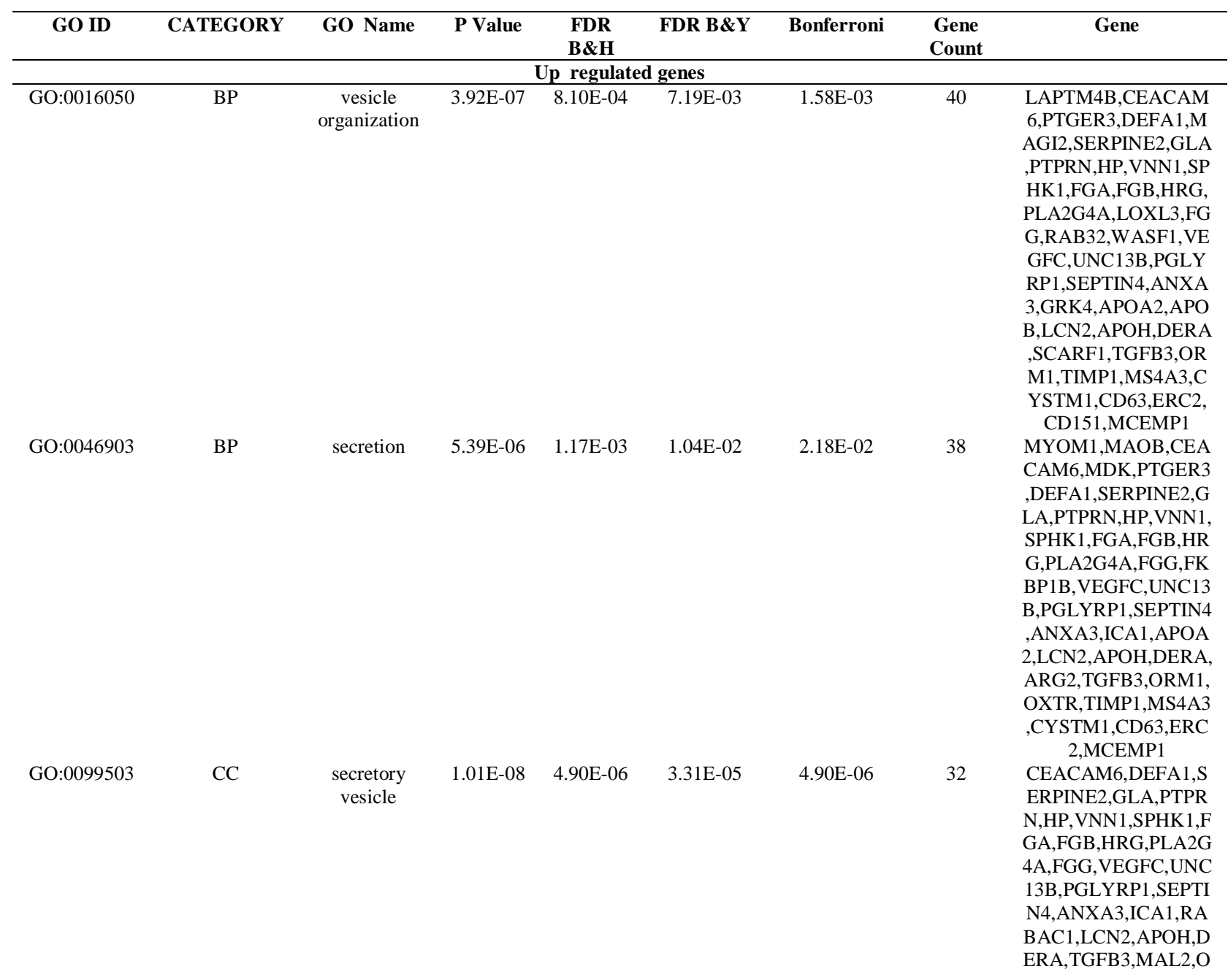


medRxiv preprint doi: https://doi.org/10.1101/2020.12.20.20248601; this version posted December 23, 2020. The copyright holder for this preprint (which was not certified by peer review) is the author/funder, who has granted medRxiv a license to display the preprint in perpetuity.

All rights reserved. No reuse allowed without permission.

\begin{tabular}{|c|c|c|c|c|c|c|c|c|}
\hline \multirow{12}{*}{ GO:0098805 } & \multirow{12}{*}{$\mathrm{CC}$} & \multirow{12}{*}{$\begin{array}{c}\text { whole } \\
\text { membrane }\end{array}$} & \multirow{12}{*}{$2.77 \mathrm{E}-03$} & \multirow{12}{*}{$3.64 \mathrm{E}-02$} & \multirow{12}{*}{$2.47 \mathrm{E}-01$} & \multirow{12}{*}{$1.00 \mathrm{E}+00$} & \multirow{12}{*}{29} & D1,MCEMP1 \\
\hline & & & & & & & & TSPAN15,MAOB,LA \\
\hline & & & & & & & & PTM4B,CEACAM6,F \\
\hline & & & & & & & & UNDC1,PTPRN,MAP \\
\hline & & & & & & & & 1LC3B2,VNN1,SPHK \\
\hline & & & & & & & & 1,GOLIM4,HRG,RAB \\
\hline & & & & & & & & 32,WASF1,UNC13B,S \\
\hline & & & & & & & & EPTIN4,ANXA3,ICA1 \\
\hline & & & & & & & & ,TOM1L1,AP1M2,GR \\
\hline & & & & & & & & B14,APOB,RET,SCA \\
\hline & & & & & & & & RF1,MAL2,MS4A3,C \\
\hline & & & & & & & & $\begin{array}{c}\text { YSTM1,CD63,CTNS, } \\
\text { MCEMP1 }\end{array}$ \\
\hline \multirow[t]{11}{*}{ GO:0046983 } & \multirow[t]{11}{*}{ MF } & \multirow{11}{*}{$\begin{array}{l}\text { protein } \\
\text { dimerization } \\
\text { activity }\end{array}$} & 4.40E-04 & $9.54 \mathrm{E}-02$ & $6.73 \mathrm{E}-01$ & $2.86 \mathrm{E}-01$ & 30 & TPM1,TPM2,PADI4, \\
\hline & & & & & & & & MYOM1,MAOB,TRP \\
\hline & & & & & & & & C6,АCOT7,CEACAM \\
\hline & & & & & & & & 6,ARNTL2,PRTFDC1, \\
\hline & & & & & & & & TYMS,H2AC13,H2BC \\
\hline & & & & & & & & 17,GLA,HP,H4C14,MI \\
\hline & & & & & & & & TF,PKD2,FGG,H2BC \\
\hline & & & & & & & & 11,TPST1,SEPTIN4,I \\
\hline & & & & & & & & CA1,H4C15,GRB14,E \\
\hline & & & & & & & & 2F1,APOA2,LCN2,TG \\
\hline & & & & & & & & $\mathrm{FB} 3, \mathrm{H} 2 \mathrm{AJ}$ \\
\hline GO:0005102 & MF & signaling & 4.71E-03 & $2.10 \mathrm{E}-01$ & $1.00 \mathrm{E}+00$ & $1.00 \mathrm{E}+00$ & 30 & MDK,MTRNR2L2,M \\
\hline & & receptor & & & & & & AGI2,SERPINE2,GLA \\
\hline & & binding & & & & & & ,PKD2,FGA,FGB,HR \\
\hline & & & & & & & & G,FGG,FHL2,FKBP1 \\
\hline & & & & & & & & B,VEGFC,PROK2,PG \\
\hline & & & & & & & & LYRP1,CMTM2,GRB \\
\hline & & & & & & & & 14,LAMB2,APOA2,A \\
\hline & & & & & & & & POB,ADAMTS5,CXC \\
\hline & & & & & & & & L3,ADAM22,CCNB1, \\
\hline & & & & & & & & TGFB1I1,TGFB3,BC \\
\hline & & & & & & & & AP31,IGFBP2,TIMP1, \\
\hline & & & & & & & & CD151 \\
\hline & & & & wn regula & genes & & & \\
\hline GO:0046649 & $\mathrm{BP}$ & lymphocyte & $1.37 \mathrm{E}-15$ & $5.40 \mathrm{E}-12$ & $4.78 \mathrm{E}-11$ & $5.40 \mathrm{E}-12$ & 40 & HLA-DMB,HLA- \\
\hline & & activation & & & & & & DPA1,SPTA1,BCL11 \\
\hline & & & & & & & & A,ITGA4,FGL2,CXC \\
\hline & & & & & & & & R5,FCRL1,PTPRC,ZC \\
\hline & & & & & & & & 3H12D,FBXO7,CCR7, \\
\hline & & & & & & & & NOTCH2,TCF7,IKZF \\
\hline & & & & & & & & 3,POLM,CAMK4,PO \\
\hline & & & & & & & & U2F2,BTLA,CR1,CBL \\
\hline & & & & & & & & B,SLC4A1,TFRC,BCL \\
\hline & & & & & & & & 11B,CD4,CD5,CD6,M \\
\hline & & & & & & & & S4A1,CD22,CD27,CD \\
\hline & & & & & & & & 44,TNFRSF13C,TNFR \\
\hline & & & & & & & & SF13B,CD79A,RORA, \\
\hline & & & & & & & & ATM,LY9,LEF1,IL7R, \\
\hline & & & & & & & & NCKAP1L \\
\hline GO:0010941 & $\mathrm{BP}$ & regulation of & $9.53 \mathrm{E}-05$ & $6.03 \mathrm{E}-03$ & $5.34 \mathrm{E}-02$ & $3.75 \mathrm{E}-01$ & 40 & STK17B,OBSCN,ITG \\
\hline & & cell death & & & & & & A4,NR4A1,STRADB, \\
\hline & & & & & & & & BNIP3L,PTPRC,BTG1 \\
\hline & & & & & & & & ,TMC8,FBX07,PLAG \\
\hline & & & & & & & & L2,CCR7,NOTCH2,T \\
\hline & & & & & & & & CF7,IKZF3,OGT,CA \\
\hline & & & & & & & & MK1D,BMF,NLRP1, \\
\hline & & & & & & & & GRINA,OPA1,EEF1A \\
\hline & & & & & & & & 1,TXNIP,BCL11B,IGF \\
\hline & & & & & & & & 2R,CSF1R,CD27,NEU \\
\hline & & & & & & & & RL1,CD44,LRP1,AT \\
\hline & & & & & & & & M,HBA1,HBA2,HBB, \\
\hline & & & & & & & & CTSB,LEF1,RPL10,IL \\
\hline & & & & & & & & 7R,SORL1,NCKAP1L \\
\hline GO:0009986 & $\mathrm{CC}$ & cell surface & 2.02E-09 & $3.10 \mathrm{E}-07$ & $2.08 \mathrm{E}-06$ & $9.30 \mathrm{E}-07$ & 35 & ADAM19,HLA- \\
\hline & & & & & & & & DPA1,HLA- \\
\hline
\end{tabular}


medRxiv preprint doi: https://doi.org/10.1101/2020.12.20.20248601; this version posted December 23, 2020. The copyright holder for this preprint (which was not certified by peer review) is the author/funder, who has granted medRxiv a license to display the preprint in perpetuity. All rights reserved. No reuse allowed without permission.

\begin{tabular}{|c|c|c|c|c|c|c|c|c|}
\hline & & & & & & & & \\
\hline & & & & & & & & $\begin{array}{l}\text { DRA,ITGA4,CXCR5, } \\
\text { FCRL1,PTPRC,CIITA }\end{array}$ \\
\hline & & & & & & & & ,MRC2,CCR7,NOTCH \\
\hline & & & & & & & & 2,SEMA7A,BTLA,CR \\
\hline & & & & & & & & 1,SLC4A1,TFRC,CD4, \\
\hline & & & & & & & & CD5,IGF2R,CD6,CSF \\
\hline & & & & & & & & 1R,MS4A1,CLEC $17 \mathrm{~A}$ \\
\hline & & & & & & & & $\mathrm{CD} 22, \mathrm{CD} 27, \mathrm{GYPA}, \mathrm{V}$ \\
\hline & & & & & & & & CAN,CD44,CLEC2D, \\
\hline & & & & & & & & TNFRSF13C,TNFRSF \\
\hline & & & & & & & & 13B,CD79A,LY9,CTS \\
\hline & & & & & & & & B,IL7R \\
\hline GO:0031226 & $\mathrm{CC}$ & intrinsic & $5.35 \mathrm{E}-07$ & $4.11 \mathrm{E}-05$ & $2.76 \mathrm{E}-04$ & $2.47 \mathrm{E}-04$ & 43 & HLA-DPA1,HLA- \\
\hline & & component & & & & & & DRA,SPTA1,SLC38A \\
\hline & & of plasma & & & & & & 5,ITGA4,SLC38A1,C \\
\hline & & membrane & & & & & & XCR5,PTPRC,SLC24 \\
\hline & & & & & & & & A4,TMC8,NOTCH2,V \\
\hline & & & & & & & & IPR1,TRABD2A,SEM \\
\hline & & & & & & & & A7A,BTLA,SLC7A6, \\
\hline & & & & & & & & CR1,MCOLN1,SLC2 \\
\hline & & & & & & & & A1,TSPAN5,RHAG,S \\
\hline & & & & & & & & LC4A1,TFRC,CELSR \\
\hline & & & & & & & & 1,CD4,CD5,IGF2R,CD \\
\hline & & & & & & & & 6,CSF1R,P2RX5,MS4 \\
\hline & & & & & & & & $\mathrm{A} 1, \mathrm{SLC} 14 \mathrm{~A} 1, \mathrm{CD} 22, \mathrm{C}$ \\
\hline & & & & & & & & D27,GYPA,GYPB,CD \\
\hline & & & & & & & & 44,CLEC2D,LRP1,TN \\
\hline & & & & & & & & FRSF13B,ATP2B1,SO \\
\hline & & & & & & & & RL1,NCKAP1L \\
\hline GO:0016772 & MF & transferase & $9.72 \mathrm{E}-04$ & 4.32E-02 & $3.09 \mathrm{E}-01$ & $6.92 \mathrm{E}-01$ & 35 & ZBTB20,RPS6KA5,ST \\
\hline & & activity, & & & & & & K17B,OBSCN,TENT5 \\
\hline & & transferring & & & & & & C,TTN,PIK3IP1,BLK, \\
\hline & & phosphorus- & & & & & & STRADB,PTPRC,CIIT \\
\hline & & containing & & & & & & A,FBXO7,CCR7,DYR \\
\hline & & groups & & & & & & K2,OGT,CAMK1D,C \\
\hline & & & & & & & & TC1,POLM,CAMK4, \\
\hline & & & & & & & & DUSP2,AAK1,CBLB, \\
\hline & & & & & & & & SLC4A1,EEF1A1,RM \\
\hline & & & & & & & & $\mathrm{RP}, \mathrm{CD} 4, \mathrm{IGF} 2 \mathrm{R}, \mathrm{CSF} 1$ \\
\hline & & & & & & & & R,NEURL1,CD44,LR \\
\hline & & & & & & & & P1,ATM,SERINC5,SO \\
\hline & & & & & & & & RL1,NCKAP1L \\
\hline GO:0008144 & MF & drug binding & $1.15 \mathrm{E}-02$ & $1.55 \mathrm{E}-01$ & $1.00 \mathrm{E}+00$ & $1.00 \mathrm{E}+00$ & 30 & ABCA2,RPS6KA5,ST \\
\hline & & & & & & & & K17B,OBSCN,TTN,B \\
\hline & & & & & & & & LK,STRADB,CIITA,A \\
\hline & & & & & & & & LAS2,ABCD2,DYRK \\
\hline & & & & & & & & 2,DNHD1,ACSL6,CA \\
\hline & & & & & & & & MK1D,EP400,ATP13 \\
\hline & & & & & & & & $\mathrm{A} 1, \mathrm{CAMK} 4, \mathrm{AAK} 1, \mathrm{~N}$ \\
\hline & & & & & & & & LRP1,EEF1A1,DNAH \\
\hline & & & & & & & & 1,CSF1R,P2RX5,ATM \\
\hline & & & & & & & & ,HBA1,HBA2,HBM,H \\
\hline & & & & & & & & BB,ATP2B1,EPB42 \\
\hline
\end{tabular}

Biological Process(BP), Cellular Component(CC) and Molecular Functions (MF)

Table 4 The enriched pathway terms of the up and down regulated differentially expressed genes

\begin{tabular}{|c|c|c|c|c|c|c|c|}
\hline Pathway ID & Pathway Name & P-value & $\begin{array}{l}\text { FDR } \\
\text { B\&H } \\
\end{array}$ & $\begin{array}{l}\text { FDR } \\
\text { B\&Y } \\
\end{array}$ & Bonferroni & $\begin{array}{c}\text { Gene } \\
\text { Count }\end{array}$ & Gene \\
\hline \multicolumn{8}{|c|}{ Up regulated genes } \\
\hline 1269340 & Hemostasis & $4.28 \mathrm{E}-06$ & $7.47 \mathrm{E}-04$ & $5.11 \mathrm{E}-03$ & $2.24 \mathrm{E}-03$ & 22 & $\begin{array}{c}\text { GNG8,TRPC6,CEACAM } \\
\text { 6,CABLES1,SERPINE2, } \\
\text { FGA,KCNMB1,FGB,HR } \\
\text { G,PLA2G4A,MMP1,FG } \\
\text { G,VEGFC,GRB14,APOB } \\
\text {,APOH,ZFPM2,TGFB3, }\end{array}$ \\
\hline
\end{tabular}


medRxiv preprint doi: https://doi.org/10.1101/2020.12.20.20248601; this version posted December 23, 2020. The copyright holder for this preprint (which was not certified by peer review) is the author/funder, who has granted medRxiv a license to display the preprint in perpetuity.

All rights reserved. No reuse allowed without permission.

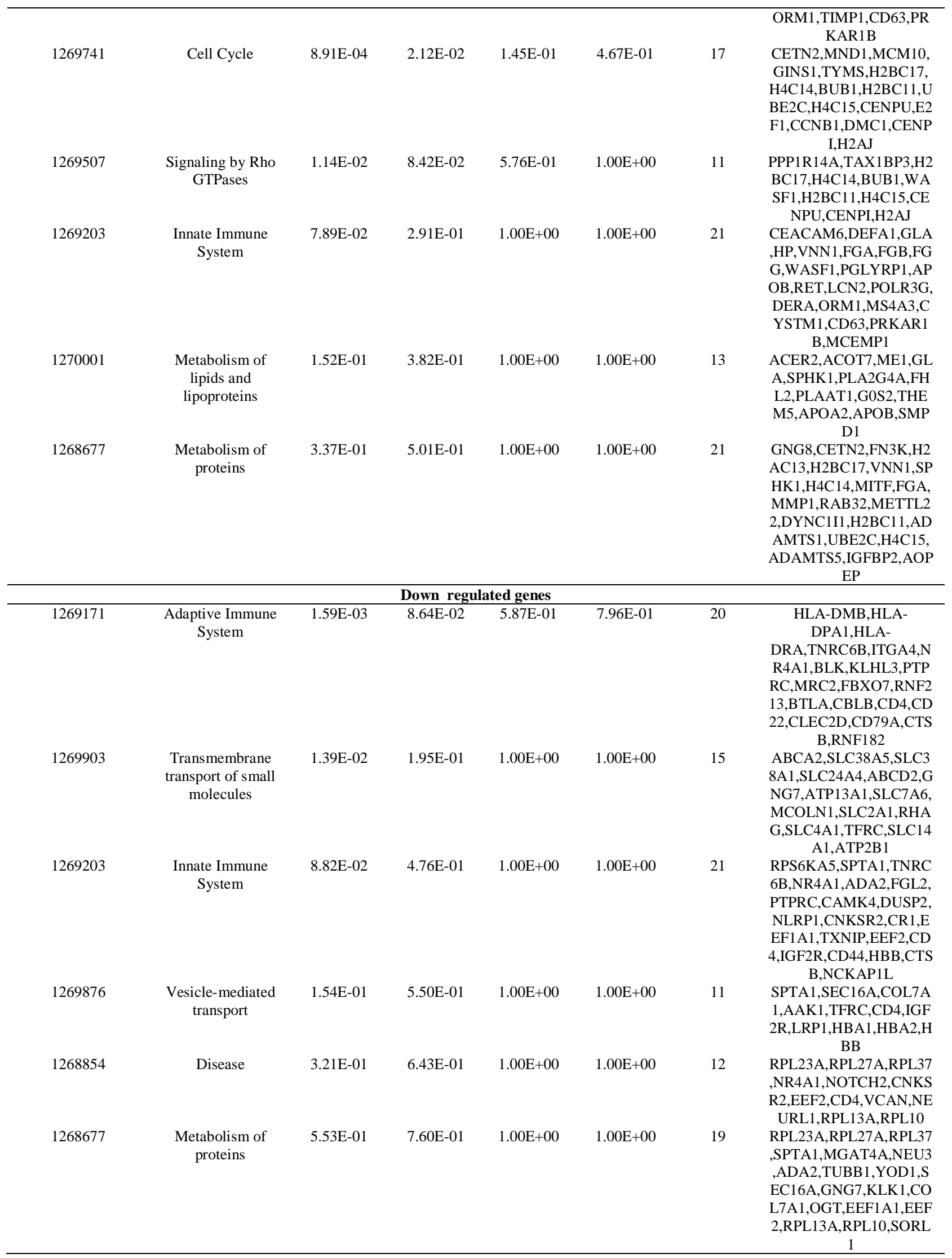


medRxiv preprint doi: https://doi.org/10.1101/2020.12.20.20248601; this version posted December 23, 2020. The copyright holder for this preprint (which was not certified by peer review) is the author/funder, who has granted medRxiv a license to display the preprint in perpetuity.

All rights reserved. No reuse allowed without permission.

Table 5 Topology table for up and down regulated genes.

\begin{tabular}{|c|c|c|c|c|c|}
\hline Regulation & Node & Degree & Betweenness & Stress & Closeness \\
\hline Up & EZH2 & 350 & 0.076224 & 81130962 & 0.349924 \\
\hline Up & DBN1 & 256 & 0.049032 & 39941040 & 0.348151 \\
\hline $\mathrm{Up}$ & CCNB1 & 158 & 0.024471 & 43653864 & 0.313488 \\
\hline Up & FHL2 & 158 & 0.031673 & 16397718 & 0.336762 \\
\hline Up & $\mathrm{E} 2 \mathrm{~F} 1$ & 151 & 0.025971 & 16601668 & 0.333208 \\
\hline Up & TPM1 & 134 & 0.022043 & 16976362 & 0.329604 \\
\hline Up & KRT18 & 132 & 0.018793 & 17362522 & 0.338383 \\
\hline Up & TPM2 & 126 & 0.021531 & 17717608 & 0.323503 \\
\hline Up & FGB & 115 & 0.021143 & 15804232 & 0.298889 \\
\hline Up & PTGER3 & 113 & 0.019531 & 25585198 & 0.284342 \\
\hline Up & SPINT2 & 108 & 0.023415 & 14310762 & 0.303448 \\
\hline Up & BUB1 & 102 & 0.018982 & 9083534 & 0.319527 \\
\hline Up & PTPRN & 93 & 0.015139 & 21217898 & 0.283912 \\
\hline Up & BCAP31 & 91 & 0.017733 & 11925460 & 0.323825 \\
\hline Up & MAP1B & 91 & 0.011535 & 22589676 & 0.310858 \\
\hline Up & KRT8 & 79 & 0.009251 & 9231600 & 0.332081 \\
\hline Up & TMEM67 & 76 & 0.014065 & 4982016 & 0.290838 \\
\hline Up & RABAC1 & 74 & 0.013172 & 9708740 & 0.293098 \\
\hline Up & APOB & 72 & 0.011818 & 15182272 & 0.302587 \\
\hline Up & UBE2C & 69 & 0.00877 & 8892764 & 0.298716 \\
\hline Up & SPHK1 & 68 & 0.011494 & 4951244 & 0.325666 \\
\hline Up & TOM1L1 & 66 & 0.00895 & 6727694 & 0.305124 \\
\hline Up & RET & 66 & 0.009723 & 10964184 & 0.305199 \\
\hline Up & WASF1 & 65 & 0.010329 & 14175172 & 0.29873 \\
\hline Up & KRT19 & 64 & 0.008418 & 5490710 & 0.32224 \\
\hline Up & CENPU & 61 & 0.011081 & 3633098 & 0.296468 \\
\hline Up & DTL & 61 & 0.006526 & 9721978 & 0.297152 \\
\hline Up & CETN2 & 60 & 0.009249 & 16418248 & 0.269586 \\
\hline Up & MCM10 & 59 & 0.007694 & 9107150 & 0.300602 \\
\hline Up & DYNC1I1 & 58 & 0.007347 & 6841812 & 0.299279 \\
\hline Up & PLA2G4A & 57 & 0.006497 & 7102868 & 0.307673 \\
\hline Up & TYMS & 55 & 0.008254 & 2898568 & 0.306378 \\
\hline Up & MDK & 54 & 0.007633 & 2641060 & 0.307322 \\
\hline Up & GOLIM4 & 45 & 0.009056 & 6535396 & 0.299091 \\
\hline Up & TGFB1I1 & 43 & 0.00576 & 2542056 & 0.317363 \\
\hline Up & PKD2 & 42 & 0.006903 & 2134988 & 0.290538 \\
\hline Up & FGA & 41 & 0.004439 & 1801264 & 0.293153 \\
\hline Up & PRKAR1B & 41 & 0.004763 & 4851900 & 0.299424 \\
\hline Up & ACOT7 & 39 & 0.00511 & 6777086 & 0.287968 \\
\hline Up & FGG & 37 & 0.002736 & 1188570 & 0.282125 \\
\hline Up & AP1M2 & 37 & 0.007088 & 9431672 & 0.281894 \\
\hline Up & MITF & 36 & 0.006067 & 5049390 & 0.308118 \\
\hline Up & SMYD3 & 35 & 0.006122 & 1971838 & 0.303776 \\
\hline Up & ACTR3B & 35 & 0.002767 & 5762182 & 0.273907 \\
\hline Up & CTPS2 & 34 & 0.004516 & 1656234 & 0.297352 \\
\hline Up & HP & 33 & 0.004002 & 2476788 & 0.299743 \\
\hline Up & MYL6B & 33 & 0.001721 & 1494552 & 0.303835 \\
\hline Up & LAMB2 & 33 & 0.003266 & 3787290 & 0.283015 \\
\hline Up & ME1 & 32 & 0.00497 & 5458746 & 0.266142 \\
\hline Up & FKBP1B & 31 & 0.002492 & 3149134 & 0.263535 \\
\hline Up & EAF2 & 31 & 0.003666 & 3614748 & 0.273181 \\
\hline Up & CD63 & 30 & 0.002963 & 1542292 & 0.278807 \\
\hline Up & TMEFF1 & 29 & 0.004306 & 1459454 & 0.277382 \\
\hline Up & PHACTR3 & 29 & 0.003235 & 6793662 & 0.273205 \\
\hline Up & MMP1 & 28 & 0.004131 & 1062610 & 0.285972 \\
\hline Up & RAB32 & 28 & 0.004125 & 3089688 & 0.273326 \\
\hline Up & NT5DC2 & 27 & 0.003149 & 4016356 & 0.290497 \\
\hline Up & LAPTM4B & 26 & 0.003861 & 1308630 & 0.280985 \\
\hline Up & LCN2 & 26 & 0.003047 & 3293226 & 0.261121 \\
\hline Up & GRB14 & 26 & 0.001737 & 2102726 & 0.272171 \\
\hline Up & PRTFDC1 & 26 & 0.003559 & 2778424 & 0.248364 \\
\hline $\mathrm{Up}$ & SERPINE2 & 25 & 0.003606 & 2767974 & 0.266199 \\
\hline Up & APOA2 & 24 & 0.003639 & 1777538 & 0.282035 \\
\hline Up & CNN1 & 24 & 0.002696 & 1398988 & 0.281984 \\
\hline
\end{tabular}


medRxiv preprint doi: https://doi.org/10.1101/2020.12.20.20248601; this version posted December 23, 2020. The copyright holder for this preprint (which was not certified by peer review) is the author/funder, who has granted medRxiv a license to display the preprint in perpetuity. All rights reserved. No reuse allowed without permission.

\begin{tabular}{|c|c|c|c|c|c|}
\hline Up & MAGI2 & 24 & 0.003636 & 4072986 & 0.273277 \\
\hline Up & PADI4 & 24 & 0.001853 & 2786250 & 0.285457 \\
\hline Up & ARNTL2 & 23 & 0.004537 & 2736046 & 0.276156 \\
\hline Up & MAL2 & 23 & 0.004035 & 3057928 & 0.266555 \\
\hline Up & TAX1BP3 & 22 & 0.00296 & 2483404 & 0.27773 \\
\hline Up & $\mathrm{APOH}$ & 22 & 0.002261 & 1011952 & 0.294759 \\
\hline Up & GLA & 22 & 0.002185 & 2812520 & 0.25131 \\
\hline Up & KRT7 & 22 & 0.002247 & 3354252 & 0.283132 \\
\hline Up & ROBO1 & 22 & 0.002997 & 2829202 & 0.285181 \\
\hline Up & ADAMTS1 & 21 & 0.003523 & 2991386 & 0.249044 \\
\hline Up & OXTR & 21 & 0.003005 & 1885024 & 0.254274 \\
\hline Up & ADAM32 & 21 & 0.002751 & 2226220 & 0.244362 \\
\hline Up & TSPAN15 & 20 & 0.002903 & 1636154 & 0.248684 \\
\hline Up & $\mathrm{DMC1}$ & 20 & 0.001518 & 1667540 & 0.255218 \\
\hline Up & EPDR1 & 20 & 0.00263 & 955076 & 0.289735 \\
\hline Up & LACTB2 & 20 & 0.003285 & 3861294 & 0.241888 \\
\hline Up & UNC13B & 19 & 0.003409 & 6715552 & 0.228252 \\
\hline Up & ERC2 & 19 & 0.002956 & 2368572 & 0.246592 \\
\hline Up & HRG & 19 & 0.002437 & 1023636 & 0.273991 \\
\hline Up & SMPD1 & 19 & 0.00236 & 2063048 & 0.275125 \\
\hline Up & ZFPM2 & 19 & 0.001198 & 1822000 & 0.266153 \\
\hline Up & METTL22 & 19 & 0.001598 & 2257038 & 0.269023 \\
\hline Up & ORM1 & 18 & 0.001349 & 1072266 & 0.255461 \\
\hline Up & ZC3HAV1L & 18 & 0.001054 & 1624786 & 0.281202 \\
\hline Up & STAC & 18 & 0.001798 & 2388538 & 0.275578 \\
\hline Up & POLR3G & 17 & 0.003237 & 9664174 & 0.229055 \\
\hline Up & DDAH1 & 17 & 0.003704 & 1699018 & 0.290824 \\
\hline Up & TIMP1 & 17 & 0.002047 & 1211820 & 0.264888 \\
\hline Up & DERA & 17 & 0.001512 & 1709944 & 0.240983 \\
\hline Up & TGFB3 & 16 & 0.001732 & 1135010 & 0.26056 \\
\hline Up & ANXA3 & 16 & 0.002306 & 3218636 & 0.263928 \\
\hline Up & ETV4 & 16 & 0.00158 & 1430402 & 0.286767 \\
\hline Up & RND3 & 16 & 0.001618 & 1798784 & 0.267963 \\
\hline Up & FUNDC1 & 16 & 0.001881 & 5031262 & 0.246033 \\
\hline Up & PPP1R14A & 16 & 0.001348 & 1468196 & 0.269398 \\
\hline Up & ADAM22 & 16 & $9.66 \mathrm{E}-04$ & 1467492 & 0.278092 \\
\hline Up & TRHDE & 16 & 0.002417 & 2718244 & 0.265571 \\
\hline Up & AOPEP & 15 & $5.09 \mathrm{E}-04$ & 455628 & 0.281778 \\
\hline Up & LOXL3 & 15 & 0.002245 & 2647672 & 0.272735 \\
\hline Up & TST & 15 & 0.002644 & 2760934 & 0.24058 \\
\hline Up & CENPI & 15 & $6.90 \mathrm{E}-04$ & 213372 & 0.26143 \\
\hline Up & TRPC6 & 15 & 0.002982 & 3195972 & 0.236597 \\
\hline Up & MSANTD3 & 14 & 0.001423 & 599870 & 0.282602 \\
\hline Up & DCBLD2 & 14 & 0.001863 & 1414006 & 0.280806 \\
\hline Up & ICA1 & 14 & 0.001837 & 1818980 & 0.253566 \\
\hline Up & CABLES1 & 14 & 4.42E-04 & 448806 & 0.275222 \\
\hline Up & GTF3C6 & 13 & 0.001446 & 393772 & 0.300413 \\
\hline Up & AVEN & 13 & $7.46 \mathrm{E}-04$ & 364352 & 0.294788 \\
\hline Up & PBLD & 13 & 0.001491 & 1062854 & 0.235839 \\
\hline Up & CD151 & 13 & 0.001883 & 1879220 & 0.264662 \\
\hline Up & YIF1B & 13 & 0.001267 & 1419634 & 0.263917 \\
\hline Up & C5orf30 & 13 & 0.001783 & 1452154 & 0.265582 \\
\hline Up & FRMD3 & 11 & $8.55 \mathrm{E}-04$ & 686546 & 0.235579 \\
\hline Up & FAH & 11 & 0.001509 & 1294972 & 0.259587 \\
\hline Up & HTATIP2 & 11 & 0.00148 & 1272602 & 0.261231 \\
\hline Up & CYSTM1 & 11 & 0.002293 & 1438306 & 0.2152 \\
\hline Up & MAP1LC3B2 & 10 & 0.001139 & 1052378 & 0.240608 \\
\hline Up & MYEOV & 2 & $5.45 \mathrm{E}-05$ & 24642 & 0.227079 \\
\hline Up & DNAH14 & 1 & 0 & 0 & 0.212349 \\
\hline Up & MYOM1 & 1 & 0 & 0 & 0.247539 \\
\hline Down & HEPACAM2 & 496 & 0.004088 & 4614336 & 0.259565 \\
\hline Down & HLA-DPA1 & 443 & 0.021345 & 6656236 & 0.294395 \\
\hline Down & DCAF12 & 359 & 0.002195 & 1838728 & 0.28738 \\
\hline Down & POLM & 259 & $6.45 \mathrm{E}-05$ & 60748 & 0.246809 \\
\hline Down & TUBB1 & 231 & 0.017014 & 13445244 & 0.31686 \\
\hline Down & KMT2D & 211 & 0.004121 & 6143304 & 0.276119 \\
\hline Down & TNFRSF13B & 208 & 0.004558 & 7473486 & 0.25441 \\
\hline Down & SEC16A & 199 & 0.024345 & 23456762 & 0.332778 \\
\hline Down & AHNAK & 158 & 0.012868 & 12992410 & 0.339572 \\
\hline Down & OGT & 151 & 0.02538 & 23785672 & 0.321486 \\
\hline
\end{tabular}


medRxiv preprint doi: https://doi.org/10.1101/2020.12.20.20248601; this version posted December 23, 2020. The copyright holder for this preprint (which was not certified by peer review) is the author/funder, who has granted medRxiv a license to display the preprint in perpetuity. All rights reserved. No reuse allowed without permission.

\begin{tabular}{|c|c|c|c|c|c|}
\hline Down & TRAK2 & 148 & 0.005447 & 1889278 & 0.291359 \\
\hline Down & PER1 & 143 & 0.007889 & 3343992 & 0.297667 \\
\hline Down & TXNIP & 142 & 0.005831 & 3723272 & 0.3011 \\
\hline Down & GPRASP1 & 140 & 0.011046 & 5269570 & 0.284316 \\
\hline Down & CTSB & 139 & 0.011516 & 5746824 & 0.316973 \\
\hline Down & ITGA4 & 132 & 0.110358 & 99169576 & 0.373747 \\
\hline Down & CBLB & 131 & 0.011859 & 9651222 & 0.31117 \\
\hline Down & LEF1 & 111 & 0.008924 & 3863000 & 0.305275 \\
\hline Down & PLEC & 110 & 0.025923 & 21209448 & 0.346999 \\
\hline Down & BNIP3L & 110 & 0.005843 & 2394548 & 0.292184 \\
\hline Down & CAMK1D & 109 & 0.007993 & 5854240 & 0.294255 \\
\hline Down & NR4A1 & 99 & 0.024611 & 10885038 & 0.333639 \\
\hline Down & OPA1 & 94 & 0.007387 & 5152054 & 0.317804 \\
\hline Down & EEF2 & 83 & 0.037887 & 47075150 & 0.354698 \\
\hline Down & SEMA7A & 82 & 0.00308 & 4153990 & 0.271146 \\
\hline Down & RPS6KA5 & 78 & 0.010004 & 5767566 & 0.321653 \\
\hline Down & STK17B & 78 & 0.00446 & 1356036 & 0.284918 \\
\hline Down & P2RX5 & 75 & 0.003754 & 3579124 & 0.255008 \\
\hline Down & SLC2A1 & 68 & 0.003791 & 2359116 & 0.318622 \\
\hline Down & GYPB & 66 & 0.007619 & 6671358 & 0.262863 \\
\hline Down & HBB & 65 & 0.01032 & 10858208 & 0.304059 \\
\hline Down & CD22 & 64 & 0.001809 & 1124092 & 0.279752 \\
\hline Down & CD4 & 64 & 0.018753 & 14195846 & 0.322845 \\
\hline Down & CD44 & 63 & 0.031474 & 16859342 & 0.344469 \\
\hline Down & TFRC & 63 & 0.019104 & 17774714 & 0.337221 \\
\hline Down & PTPRC & 62 & 0.012352 & 6796924 & 0.316681 \\
\hline Down & CD5 & 62 & 0.00189 & 1129318 & 0.283456 \\
\hline Down & HLA-DRA & 61 & 0.009348 & 4428892 & 0.287995 \\
\hline Down & HLA-DMB & 60 & 0.002503 & 1238774 & 0.277344 \\
\hline Down & CELSR1 & 60 & 0.003079 & 1745004 & 0.272928 \\
\hline Down & MS4A1 & 58 & 0.0017 & 1236694 & 0.276378 \\
\hline Down & SPTA1 & 55 & 0.007158 & 4511084 & 0.30275 \\
\hline Down & IL7R & 54 & 0.027811 & 45141856 & 0.327043 \\
\hline Down & GYPA & 53 & $8.14 \mathrm{E}-04$ & 390278 & 0.260045 \\
\hline Down & SLC4A1 & 53 & 0.002142 & 1341058 & 0.273169 \\
\hline Down & EPB42 & 52 & 0.002323 & 1787000 & 0.260879 \\
\hline Down & RHAG & 49 & 0 & 0 & 0.214566 \\
\hline Down & CD79A & 49 & 0.008789 & 4491848 & 0.293056 \\
\hline Down & CD6 & 48 & 0 & 0 & 0.220862 \\
\hline Down & CSF1R & 48 & 0.002723 & 5503564 & 0.281868 \\
\hline Down & IKZF3 & 48 & 0.021447 & 15624140 & 0.316487 \\
\hline Down & POU2F2 & 46 & 0.002814 & 4242740 & 0.262773 \\
\hline Down & IGF2R & 45 & 0.005336 & 8354606 & 0.300049 \\
\hline Down & NSUN3 & 45 & 0 & 0 & 0.226647 \\
\hline Down & BLK & 44 & 0.009001 & 4827382 & 0.309644 \\
\hline Down & VCAN & 44 & 0.00605 & 2854094 & 0.288546 \\
\hline Down & ADAM28 & 41 & 0 & 0 & 0.272076 \\
\hline Down & RPL27A & 41 & 0.009338 & 13186584 & 0.337921 \\
\hline Down & RPL23A & 39 & 0.022449 & 25286012 & 0.35326 \\
\hline Down & EEF1A1 & 37 & 0.098882 & $1.23 \mathrm{E}+08$ & 0.370457 \\
\hline Down & RPL13A & 37 & 0.009659 & 13645424 & 0.339386 \\
\hline Down & RPL10 & 35 & 0.066934 & 69760500 & 0.352275 \\
\hline Down & NOTCH2 & 35 & 0.009449 & 4095454 & 0.307291 \\
\hline Down & АТP2B1 & 35 & 0.00508 & 5650696 & 0.303835 \\
\hline Down & SLC38A1 & 35 & 0.008346 & 5880382 & 0.292709 \\
\hline Down & QSOX2 & 35 & 0.00527 & 3561792 & 0.291167 \\
\hline Down & SORL1 & 34 & 0.01017 & 6644994 & 0.299569 \\
\hline Down & LRP1 & 34 & 0.030447 & 29146796 & 0.321269 \\
\hline Down & SRRM2 & 34 & 0.044661 & 52105132 & 0.347662 \\
\hline Down & ABCC13 & 34 & 0 & 0 & 0.250182 \\
\hline Down & ATM & 33 & 0.040568 & 31808618 & 0.330997 \\
\hline Down & FECH & 33 & 0.007383 & 3340210 & 0.299511 \\
\hline Down & CD27 & 32 & 0.004882 & 2960412 & 0.278142 \\
\hline Down & VIPR1 & 32 & 0.004948 & 5472644 & 0.278694 \\
\hline Down & AGPAT4 & 32 & $1.70 \mathrm{E}-05$ & 28760 & 0.230987 \\
\hline Down & CIITA & 32 & 0.003427 & 3117716 & 0.289328 \\
\hline Down & EP400 & 31 & 0.007237 & 9601258 & 0.288196 \\
\hline Down & RORA & 31 & 0.004548 & 1396286 & 0.302558 \\
\hline Down & SOX6 & 31 & 0.001788 & 1768940 & 0.255661 \\
\hline Down & CENPF & 30 & 0.008068 & 6644598 & 0.297681 \\
\hline
\end{tabular}


medRxiv preprint doi: https://doi.org/10.1101/2020.12.20.20248601; this version posted December 23, 2020. The copyright holder for this preprint (which was not certified by peer review) is the author/funder, who has granted medRxiv a license to display the preprint in perpetuity.

All rights reserved. No reuse allowed without permission.

\begin{tabular}{|c|c|c|c|c|c|}
\hline Down & FAM167A & 29 & 0.008587 & 3540932 & 0.276168 \\
\hline Down & MXI1 & 28 & 0.001985 & 3293278 & 0.269504 \\
\hline Down & ALDH5A1 & 27 & 0.003494 & 4468018 & 0.270813 \\
\hline Down & RPL37 & 27 & 0.001913 & 3460916 & 0.29617 \\
\hline Down & TSPAN5 & 26 & 0.01221 & 9998796 & 0.2873 \\
\hline Down & PIEZO1 & 26 & 0 & 0 & 0.223188 \\
\hline Down & BTG1 & 25 & 0.002334 & 3106952 & 0.271777 \\
\hline Down & SPIB & 25 & 0.001073 & 679476 & 0.280679 \\
\hline Down & ALDH6A1 & 25 & 0.00345 & 3839804 & 0.246053 \\
\hline Down & COL7A1 & 25 & 0.003621 & 3830672 & 0.277705 \\
\hline Down & PAX5 & 25 & 0.008408 & 15230588 & 0.288317 \\
\hline Down & DUSP2 & 24 & 0.003694 & 4774362 & 0.262573 \\
\hline Down & IFFO1 & 24 & 0.004108 & 2648480 & 0.262006 \\
\hline Down & COBLL1 & 24 & 0.00318 & 3800612 & 0.267373 \\
\hline Down & DBP & 24 & 0.00207 & 2593884 & 0.258708 \\
\hline Down & SELENBP1 & 24 & 0.011965 & 15173332 & 0.275259 \\
\hline Down & DYRK2 & 23 & 0.00992 & 5736550 & 0.313918 \\
\hline Down & PDE3B & 23 & 0.005858 & 5188848 & 0.268242 \\
\hline Down & ABCA2 & 22 & 0.002246 & 1887488 & 0.270647 \\
\hline Down & TTN & 22 & 0.022803 & 22179002 & 0.328956 \\
\hline Down & AAK1 & 22 & 0.001768 & 1776702 & 0.306636 \\
\hline Down & CAMK4 & 21 & 0.001804 & 1122842 & 0.282382 \\
\hline Down & ANKRD52 & 21 & 0.004706 & 3610412 & 0.290251 \\
\hline Down & OBSCN & 21 & 0.002307 & 1424536 & 0.295125 \\
\hline Down & YOD1 & 21 & 0.003727 & 4452540 & 0.278581 \\
\hline Down & RNF213 & 21 & 0.003281 & 4225796 & 0.28073 \\
\hline Down & HBM & 21 & 0.003971 & 2893622 & 0.211891 \\
\hline Down & FAM117B & 20 & 0.002939 & 3060242 & 0.274465 \\
\hline Down & RANBP10 & 20 & 0.010162 & 16110914 & 0.263344 \\
\hline Down & RALGPS2 & 20 & 0.008034 & 10752578 & 0.280386 \\
\hline Down & CNKSR2 & 19 & 0.003716 & 4283878 & 0.253753 \\
\hline Down & MYO15B & 19 & 0.001548 & 1850770 & 0.253763 \\
\hline Down & BMF & 18 & 0.002348 & 3575424 & 0.266842 \\
\hline Down & WDFY2 & 18 & 0.004928 & 3808614 & 0.241237 \\
\hline Down & LENG8 & 18 & 0.006353 & 9944066 & 0.270896 \\
\hline Down & TUBGCP6 & 18 & 0.00405 & 3821222 & 0.278155 \\
\hline Down & NELL2 & 17 & 0.005907 & 5985122 & 0.250435 \\
\hline Down & YIPF4 & 17 & 0.002754 & 3249620 & 0.263928 \\
\hline Down & OSBPL10 & 17 & 0.002471 & 663904 & 0.287727 \\
\hline Down & BACH2 & 16 & 0.002632 & 2910574 & 0.257534 \\
\hline Down & NLRP1 & 16 & 0.003929 & 3755972 & 0.280691 \\
\hline Down & BCL11B & 2 & 0.001184 & 2467486 & 0.258362 \\
\hline Down & STRADB & 2 & 0.001267 & 1783952 & 0.276898 \\
\hline Down & BCL11A & 1 & 0.004017 & 6158386 & 0.273664 \\
\hline Down & RCAN3 & 1 & 0 & 0 & 0.233006 \\
\hline Down & KLHL3 & 1 & 0.003155 & 2811806 & 0.280551 \\
\hline Down & CLEC2D & 1 & 0.015351 & 13153684 & 0.270766 \\
\hline Down & TNRC6B & 1 & 0.010638 & 19725384 & 0.302365 \\
\hline Down & FBXO7 & 1 & 0.011435 & 14645282 & 0.298528 \\
\hline Down & MOB3B & 1 & 0 & 0 & 0.202401 \\
\hline Down & ZNF549 & 1 & 0 & 0 & 0.230523 \\
\hline Down & VSTM2A & 1 & 0 & 0 & 0.220343 \\
\hline Down & CTC1 & 1 & 0 & 0 & 0.200285 \\
\hline Down & MRC2 & 1 & 0.002911 & 3908206 & 0.26787 \\
\hline Down & TTC14 & 1 & 0 & 0 & 0.257985 \\
\hline Down & ADA2 & 1 & 0 & 0 & 0.257985 \\
\hline
\end{tabular}

Table 6 miRNA - target gene and TF - target gene interaction

\begin{tabular}{cccccccc}
\hline Regulation & Target Genes & Degree & MicroRNA & Regulation & Target Genes & Degree & TF \\
\hline Up & COL1A1 & 178 & hsa-mir-4492 & Up & IRF4 & 10 & NFATC2 \\
Up & IRF4 & 140 & hsa-mir-4319 & Up & LCK & 10 & YY1 \\
Up & MYBL2 & 83 & hsa-mir-637 & Up & RET & N & NR2C2 \\
Up & PRKCB & 81 & hsa-mir-1261 & Up & MAP1LC3C & 10 & MAX \\
Up & IL2RB & 54 & hsa-mir-4300 & Up & IL2RB & 8 & PDX1 \\
Up & CCR5 & 50 & hsa-mir-5193 & Up & GRAP2 & 8 & ELK1 \\
Up & GRAP2 & 41 & hsa-mir-3681-5p & Up & MYBPC2 & 7 & RELA
\end{tabular}


medRxiv preprint doi: https://doi.org/10.1101/2020.12.20.20248601; this version posted December 23, 2020. The copyright holder for this preprint (which was not certified by peer review) is the author/funder, who has granted medRxiv a license to display the preprint in perpetuity. All rights reserved. No reuse allowed without permission.

\begin{tabular}{|c|c|c|c|c|c|c|c|}
\hline Up & MDFI & 41 & hsa-mir-4441 & Up & MDFI & 6 & TFAP2A \\
\hline Up & RET & 17 & hsa-mir-129-2-3p & Up & MYBL2 & 6 & GATA2 \\
\hline Up & IKZF1 & 16 & hsa-mir-3607-3p & Up & CD247 & 5 & SREBF1 \\
\hline Up & BTK & 13 & hsa-mir-4667-3p & Up & COL1A1 & 5 & NFYA \\
\hline Up & LCK & 6 & hsa-mir-210-3p & Up & PRKCB & 4 & IRF2 \\
\hline Up & MYBPC2 & 6 & hsa-mir-214-3p & $\mathrm{Up}$ & IKZF1 & 4 & E2F6 \\
\hline Up & CD247 & 4 & hsa-mir-346 & Up & BTK & 2 & SOX5 \\
\hline Up & MAP1LC3C & 2 & hsa-mir-27a-3p & Up & CCR5 & 1 & EGR1 \\
\hline Down & JUN & 144 & hsa-mir-3943 & Down & ATF3 & 19 & TP53 \\
\hline Down & EGR1 & 132 & hsa-mir-548e-3p & Down & EGR1 & 16 & ARID3A \\
\hline Down & ZFP36 & 130 & hsa-mir-6077 & Down & JUNB & 15 & SRF \\
\hline Down & FOS & 105 & hsa-mir-5586-5p & Down & FOS & 13 & CREB1 \\
\hline Down & DUSP1 & 97 & hsa-mir-4458 & Down & PTPRO & 12 & $\mathrm{NR} 3 \mathrm{C} 1$ \\
\hline Down & JUNB & 85 & hsa-mir-3065-5p & Down & NR0B2 & 11 & USF1 \\
\hline Down & MME & 54 & hsa-mir-922 & Down & MME & 9 & BRCA1 \\
\hline Down & NR4A2 & 50 & hsa-mir-29b-2-5p & Down & JUN & 9 & SP1 \\
\hline Down & ATF3 & 48 & hsa-mir-5000-5p & Down & DUSP1 & 9 & STAT3 \\
\hline Down & NR4A1 & 43 & hsa-mir-107 & Down & NR4A1 & 9 & HINFP \\
\hline Down & PCK1 & 38 & hsa-mir-1185-1-3p & Down & NR4A2 & 7 & NR2E3 \\
\hline Down & PTPRO & 18 & hsa-mir-203a-3p & Down & PCK1 & 6 & NR2F1 \\
\hline Down & APOB & 17 & hsa-mir-548p & Down & ZFP36 & 5 & TFAP2C \\
\hline Down & ALB & 10 & hsa-mir-492 & Down & APOB & 4 & FOXA1 \\
\hline Down & NR0B2 & 5 & hsa-mir-141-3p & Down & ALB & 4 & STAT1 \\
\hline
\end{tabular}

Table 7. Docking results of designed molecules on CCNB1 and FHL2

\begin{tabular}{|c|c|c|c|c|c|c|c|c|c|c|c|c|}
\hline \multirow{3}{*}{$\begin{array}{c}\text { Sl. } \\
\text { No/ } \\
\text { Code }\end{array}$} & \multicolumn{6}{|c|}{ CCNB1 } & \multicolumn{6}{|c|}{ FHL2 } \\
\hline & \multicolumn{3}{|c|}{ PDB: $1 \mathrm{HOV}$} & \multicolumn{3}{|c|}{ PDB: $4 Y 72$} & \multicolumn{3}{|c|}{ PDB: 2D8Z } & \multicolumn{3}{|c|}{ PDB: 2EHE } \\
\hline & $\begin{array}{l}\text { Total } \\
\text { Score }\end{array}$ & $\begin{array}{c}\text { Crash } \\
\text { (-Ve) }\end{array}$ & Polar & $\begin{array}{l}\text { Total } \\
\text { Score }\end{array}$ & $\begin{array}{c}\text { Crash } \\
(-V e)\end{array}$ & Polar & $\begin{array}{l}\text { Total } \\
\text { Score }\end{array}$ & $\begin{array}{c}\text { Crash } \\
(-V e)\end{array}$ & Polar & $\begin{array}{l}\text { Total } \\
\text { Score }\end{array}$ & $\begin{array}{c}\text { Crash } \\
(-V e)\end{array}$ & Polar \\
\hline IM 1 & 7.239 & 0.5252 & 4.194 & 6.229 & 1.1758 & 1.3468 & 5.1488 & 1.0826 & 2.402 & 3.9597 & 1.1337 & 1.1388 \\
\hline IM 2 & 3.9559 & 3.76 & 1.2296 & 7.7753 & 1.5013 & 3.1751 & 6.8491 & 0.7865 & 3.1253 & 5.3884 & 0.7304 & 3.2443 \\
\hline IM 3 & 7.1917 & 1.469 & 4.9203 & 7.3727 & 2.1681 & 1.9271 & 5.4126 & 0.9455 & 1.6539 & 4.5339 & 0.7044 & 0.9497 \\
\hline IM 4 & 4.1974 & 3.568 & 4.3031 & 6.8188 & 2.006 & 2.4134 & 5.6181 & 0.9326 & 1.7125 & 3.5135 & 0.7458 & 1.0505 \\
\hline IM 5 & 4.5533 & 1.6492 & 2.0927 & 8.4227 & 0.344 & 2.1941 & 6.0708 & 0.8126 & 1.7745 & 5.5747 & 0.8468 & 3.3308 \\
\hline IM 6 & 6.3787 & 1.9626 & 3.3289 & 9.0333 & 1.8462 & 3.2587 & 6.6937 & 0.6986 & 1.7217 & 5.1739 & 0.7641 & 3.8671 \\
\hline IM 7 & 6.1374 & 4.1751 & 3.5386 & 9.6167 & 1.1087 & 3.9025 & 5.225 & 1.4565 & 2.041 & 4.6648 & 1.4029 & 3.3006 \\
\hline IM 8 & 8.5712 & 2.8957 & 5.1053 & 7.0482 & 1.1147 & 1.7475 & 5.8786 & 2.3548 & 4.3253 & 6.2485 & 0.9775 & 7.501 \\
\hline IM 9 & 7.2601 & 1.6697 & 4.5599 & 11.1159 & 3.4644 & 4.6657 & 7.1497 & 0.8496 & 2.7825 & 4.8018 & 1.1365 & 3.8469 \\
\hline IM 10 & 7.1162 & 1.8814 & 4.5343 & 8.442 & 3.5097 & 1.9408 & 7.7546 & 3.7166 & 5.382 & 4.9785 & 0.8538 & 3.1734 \\
\hline IM 11 & 7.8374 & 2.1808 & 5.6745 & 9.5941 & 0.7735 & 2.1344 & 5.2956 & 1.1168 & 2.1061 & 3.9556 & 1.1707 & 0.6484 \\
\hline IM 12 & 4.4123 & 3.1644 & 0.1694 & 5.6246 & 1.2211 & 5.4648 & 5.6561 & 0.5109 & 1.6096 & 3.7807 & 1.5365 & 2.3817 \\
\hline IM 13 & 4.8829 & 1.641 & 0.8781 & 8.0134 & 1.4762 & 1.0656 & 5.2993 & 1.3644 & 0.5235 & 3.7134 & 1.1631 & 2.6632 \\
\hline IM 14 & 6.0738 & 2.1599 & 1.0809 & 7.2224 & 2.4795 & 2.1333 & 6.0942 & 1.3044 & 0.9106 & 3.6364 & 0.7145 & 0 \\
\hline IM 15 & 4.1335 & 1.6663 & 0.6394 & 7.8573 & 1.0353 & 1.397 & 5.1601 & 2.6366 & 2.7824 & 4.9877 & 0.7211 & 1.2175 \\
\hline IM 16 & 4.7049 & 2.8785 & 0.8354 & 4.754 & 1.9003 & 2.3893 & 5.8987 & 3.4229 & 2.683 & 3.811 & 0.9693 & 2.5824 \\
\hline TZ17 & 4.7263 & 2.4231 & 1.618 & 7.2734 & 1.358 & 0.053 & 5.1753 & 1.1334 & 2.2964 & 2.938 & 1.0363 & 0.9651 \\
\hline TZ 18 & 2.802 & 3.145 & 0.7759 & 6.8537 & 3.0008 & 1.6321 & 7.8024 & 2.4086 & 2.4203 & 4.6169 & 1.5742 & 3.205 \\
\hline TZ 19 & 5.2455 & 4.8167 & 3.4624 & 5.6781 & 2.5738 & 1.298 & 5.1226 & 2.2316 & 1.0413 & 3.4199 & 1.0615 & 2.0714 \\
\hline TZ 20 & 4.2031 & 2.0537 & 1.495 & 6.1116 & 2.1732 & 3.8228 & 6.2266 & 0.6144 & 1.7861 & 2.938 & 1.0363 & 0.9651 \\
\hline TZ 21 & 3.0014 & 4.7503 & 2.5662 & 6.8135 & 1.9569 & 0.1433 & 6.5063 & 2.1789 & 3.6709 & 5.7655 & 1.6648 & 2.5621 \\
\hline TZ 22 & 3.7751 & 3.6506 & 1.0649 & 3.7896 & 0.9741 & 1.2645 & 6.1962 & 3.8971 & 2.3063 & 4.0152 & 1.5781 & 2.7668 \\
\hline TZ 23 & 5.1601 & 2.6366 & 2.7824 & $8.5232-$ & 1.5576 & 1.447 & 5.1729 & 0.7908 & 0.0547 & 2.6522 & 1.3858 & 1.0325 \\
\hline TZ 24 & 2.9866 & 4.5065 & 3.6118 & 3.7807 & 1.5325 & 1.1317 & 6.9491 & 1.9739 & 4.849 & 5.6246 & 1.2211 & 5.4648 \\
\hline TZ 25 & 4.8039 & 2.7509 & 4.8277 & 7.5881 & 1.5654 & 2.7715 & 6.8022 & 1.7602 & 1.3582 & 4.6179 & 0.8504 & 3.0354 \\
\hline TZ 26 & 4.6867 & 5.5789 & 4.0836 & 4.082 & 0.8257 & 1.2626 & 5.6376 & 1.0268 & 0.6945 & 6.1116 & 2.1732 & 3.8228 \\
\hline TZ 27 & 5.0617 & 0.919 & 3.0108 & 8.2356 & 5.0255 & 2.733 & 6.9041 & 1.2875 & 1.3144 & 4.0538 & 2.6973 & 2.4686 \\
\hline TZ 28 & 4.754 & 1.9003 & 2.3893 & 3.7807 & 1.5365 & 2.3817 & 6.2017 & 0.8992 & 2.0979 & 2.8957 & 2.2563 & 1.1849 \\
\hline TZ 29 & 3.8498 & 3.1807 & 2.6601 & 8.0953 & 2.9258 & 0.0118 & 5.0893 & 1.1718 & 1.9465 & 4.0316 & 1.4654 & 2.5085 \\
\hline TZ 30 & 2.1031 & 2.8504 & 0.4643 & 3.7644 & 2.6181 & 0.8861 & 4.971 & 3.1573 & 1.1485 & 2.8812 & 1.0498 & 0.0078 \\
\hline TZ 31 & 3.5097 & 3.5835 & 1.0165 & 6.7706 & 0.5308 & 0.0066 & 4.9571 & 1.2321 & 1.1728 & 2.7919 & 2.5153 & 1.8636 \\
\hline TZ 32 & 2.9901 & 3.3732 & 1.7976 & 2.041 & 4.6648 & 1.4029 & 6.2178 & 0.9615 & 1.6287 & 3.6108 & 1.261 & 2.2254 \\
\hline
\end{tabular}


medRxiv preprint doi: https://doi.org/10.1101/2020.12.20.20248601; this version posted December 23, 2020. The copyright holder for this preprint (which was not certified by peer review) is the author/funder, who has granted medRxiv a license to display the preprint in perpetuity.

All rights reserved. No reuse allowed without permission.

\begin{tabular}{|c|c|c|c|c|c|c|c|c|c|c|c|c|}
\hline PU33 & 5.0124 & 2.6209 & 1.6596 & 8.3705 & 2.4455 & 1.8383 & 5.1058 & 2.8533 & 2.1314 & 4.082 & 0.8257 & 1.2626 \\
\hline PU 34 & 1.8876 & 3.1575 & 1.8876 & 2.9186 & 1.7769 & 0.7803 & 6.2293 & 0.79 & 4.1623 & 5.7541 & 0.8169 & 2.2649 \\
\hline PU 35 & 4.2415 & 0.9639 & 1.4337 & 8.5453 & 0.7988 & 0.3678 & 5.993 & 1.1302 & 1.6123 & 3.7896 & 0.9741 & 1.2645 \\
\hline PU 36 & 3.7644 & 2.6181 & 0.8861 & 3.4946 & 1.6854 & 2.8474 & 5.5186 & 0.8034 & 1.7233 & 4.2415 & 0.9639 & 1.4337 \\
\hline PU 37 & 2.2051 & 3.0552 & 1.6443 & 8.8008 & 1.667 & 3.5679 & 6.3895 & 1.7399 & 2.0389 & 5.0617 & 0.919 & 3.0108 \\
\hline PU 38 & 5.2735 & 4.1465 & 2.4599 & 4.754 & 1.9003 & 2.3893 & 4.2415 & 0.9639 & 1.4337 & 3.4946 & 1.6854 & 2.8474 \\
\hline PU 39 & 5.0617 & 0.919 & 3.0108 & 7.8157 & 1.3292 & 0.2824 & 5.0617 & 0.919 & 3.0108 & 4.2155 & 0.823 & 3.9682 \\
\hline PU 40 & 4.8638 & 5.448 & 1.8878 & 4.2415 & 0.9639 & 1.4337 & 3.2316 & 1.6854 & 2.8474 & 4.7646 & 1.6643 & 4.7161 \\
\hline PU 41 & 7.1661 & 3.1588 & 5.0991 & 10.3389 & 4.9022 & 4.0552 & 3.2121 & 0.823 & 3.9682 & 5.2192 & 1.3596 & 1.3065 \\
\hline PU 42 & 5.278 & 1.1462 & 3.3261 & 4.754 & 1.9003 & 2.3893 & 5.4326 & 1.6643 & 4.7161 & 4.9542 & 3.6876 & 3.8272 \\
\hline PU 43 & 5.2192 & 1.3596 & 1.3065 & 10.8916 & 2.8239 & 2.464 & 4.0152 & 1.5781 & 2.7668 & 3.9964 & 1.1219 & 0.8063 \\
\hline PU 44 & 4.8815 & 3.9606 & 2.9386 & 6.5063 & 2.1789 & 3.6709 & 3.9964 & 1.1219 & 0.8063 & 4.3649 & 0.7553 & 3.4696 \\
\hline PU 45 & 3.4541 & 3.3428 & 1.9008 & 8.3081 & 0.3422 & 2.9369 & 3.9597 & 1.1337 & 1.1388 & 4.2415 & 0.9639 & 1.4337 \\
\hline PU 46 & 3.5097 & 3.5835 & 1.0165 & 6.0942 & 1.3044 & 0.9106 & 3.9556 & 1.1707 & 0.6484 & 5.0617 & 0.919 & 3.0108 \\
\hline PU 47 & 3.7807 & 1.5365 & 2.3817 & 7.5477 & 2.2832 & 2.7503 & 4.0152 & 1.5781 & 2.7668 & 3.4946 & 1.6854 & 2.8474 \\
\hline PU 48 & 3.6402 & 3.5929 & 1.2563 & 4.2415 & 0.9639 & 1.4337 & 3.9964 & 1.1219 & 0.8063 & 4.2155 & 0.823 & 3.9682 \\
\hline
\end{tabular}

\section{Figures}

\section{Volcano plot}

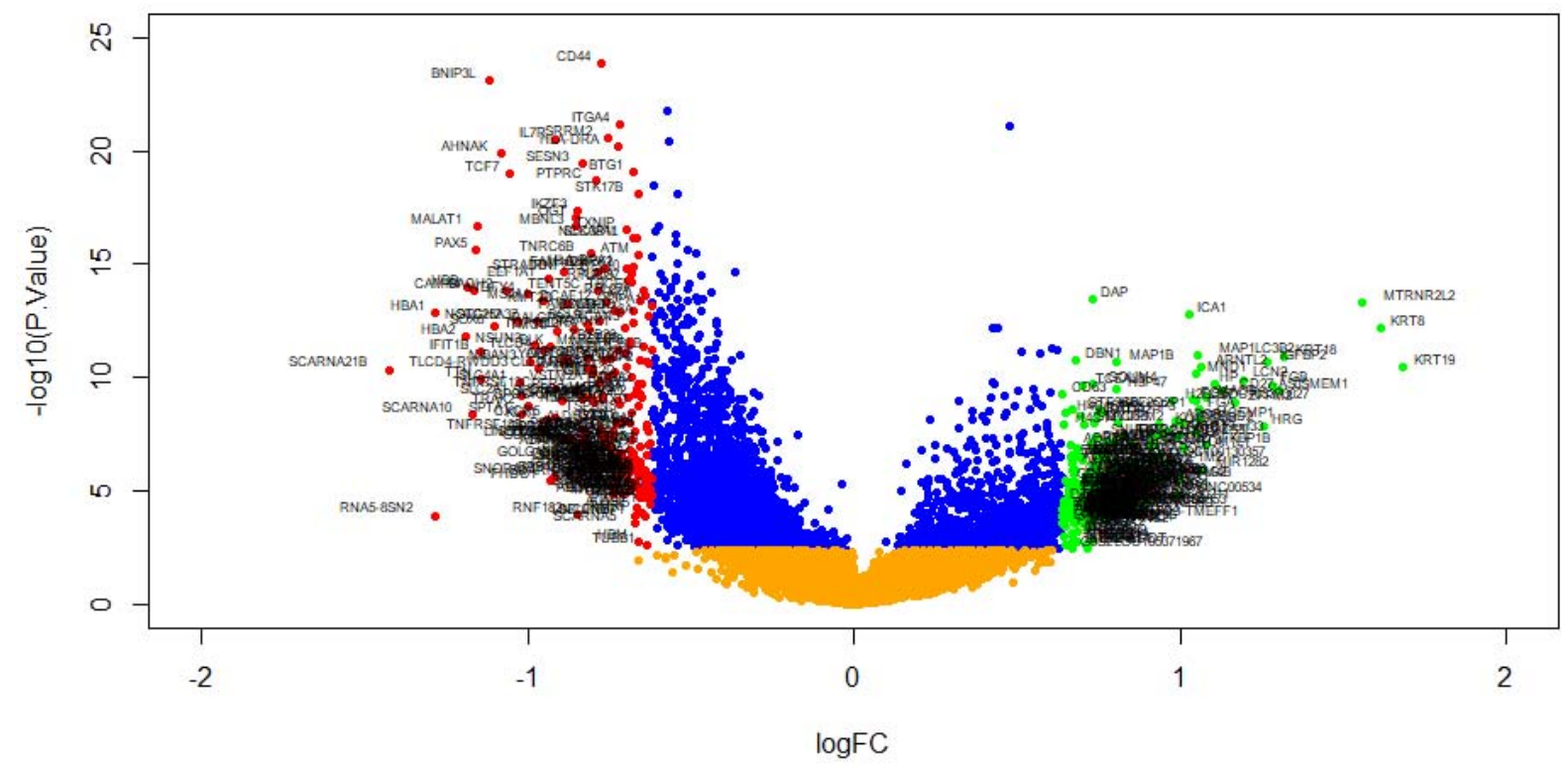

Fig. 1. Volcano plot of differentially expressed genes. Genes with a significant change of more than two-fold were selected. Green dot represented up regulated significant genes and red dot represented down regulated significant genes. 
medRxiv preprint doi: https://doi.org/10.1101/2020.12.20.20248601; this version posted December 23, 2020. The copyright holder for this preprint (which was not certified by peer review) is the author/funder, who has granted medRxiv a license to display the preprint in perpetuity. All rights reserved. No reuse allowed without permission.

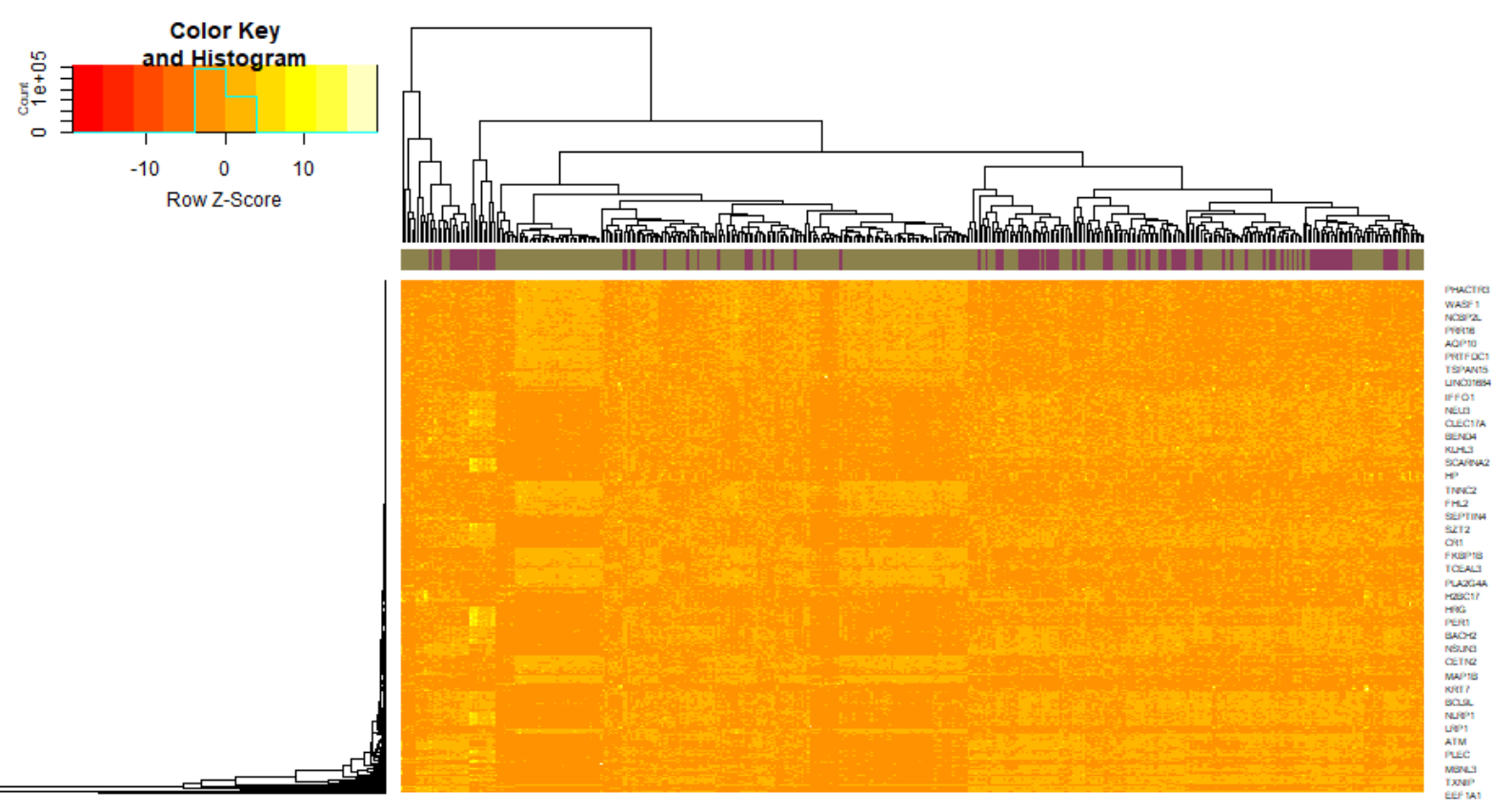

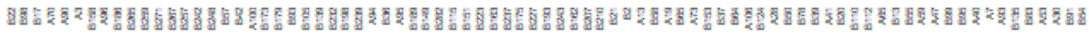

Fig. 2. Heat map of differentially expressed genes. Legend on the top left indicate log fold change of genes. (A1 A114 = normal control samples; B1 - B284 = PDAC samples)

A

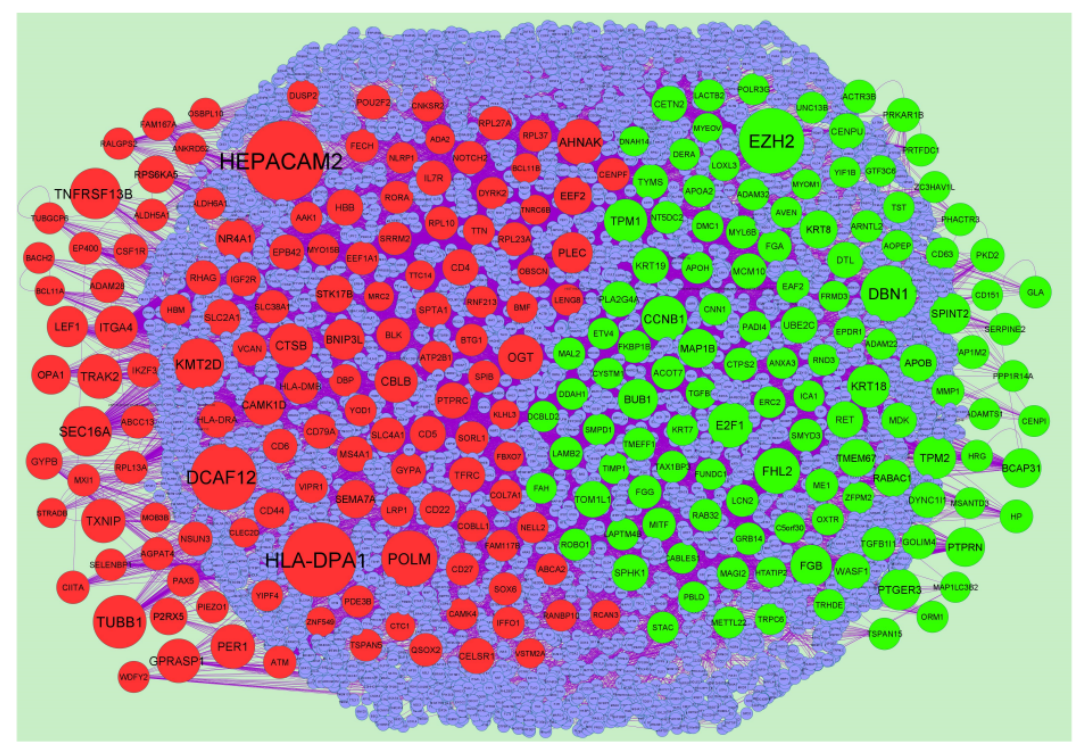

B

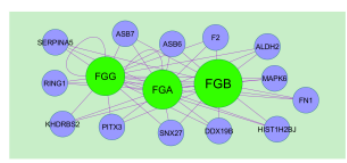

C

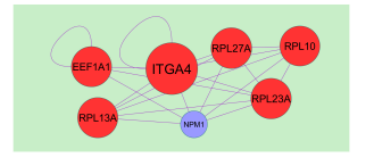

Fig. 3. PPI network and the most significant modules of DEGs. (A) The PPI network of DEGs was constructed using Cytoscape (B) The most significant module was obtained from PPI network with 16 nodes and 44 edges for 
medRxiv preprint doi: https://doi.org/10.1101/2020.12.20.20248601; this version posted December 23, 2020. The copyright holder for this preprint (which was not certified by peer review) is the author/funder, who has granted medRxiv a license to display the preprint in perpetuity. All rights reserved. No reuse allowed without permission.

up regulated genes $(\mathrm{C})$ The most significant module was obtained from PPI network with 6 nodes and 20 edges for up regulated genes. Up regulated genes are marked in green; down regulated genes are marked in red

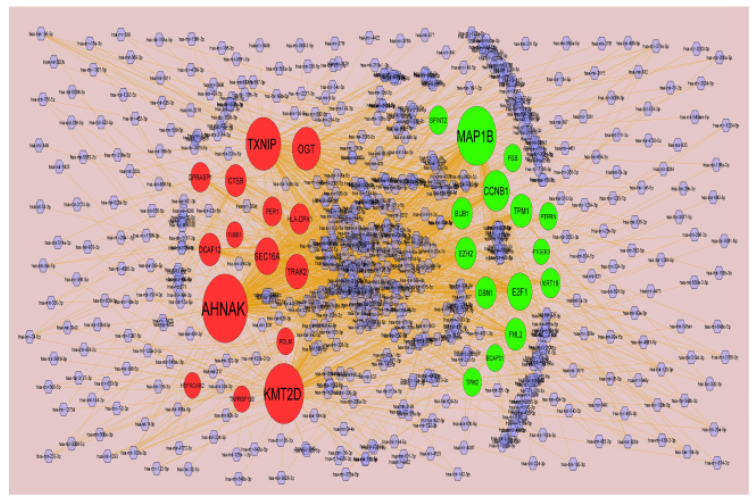

B

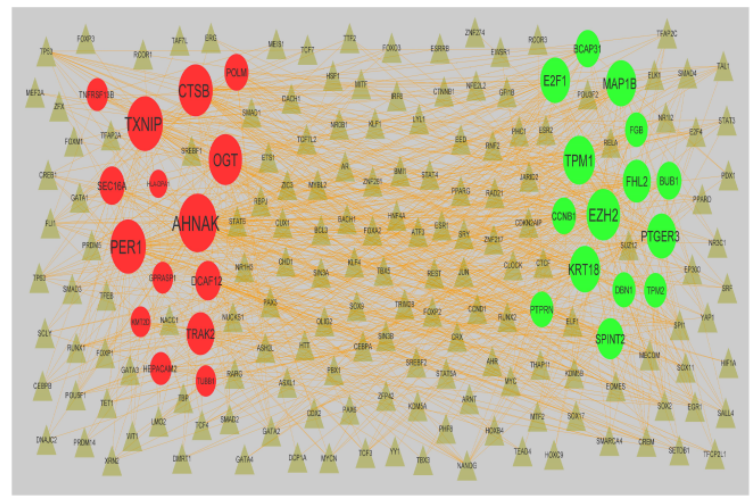

Fig. 4. (A) Target gene - miRNA regulatory network between target genes and miRNAs (B) Target gene - TF regulatory network between target genes and TFs. Up regulated genes are marked in green; down regulated genes are marked in red; The blue color diamond nodes represent the key miRNAs; the gray color triangle nodes represent the key TFs
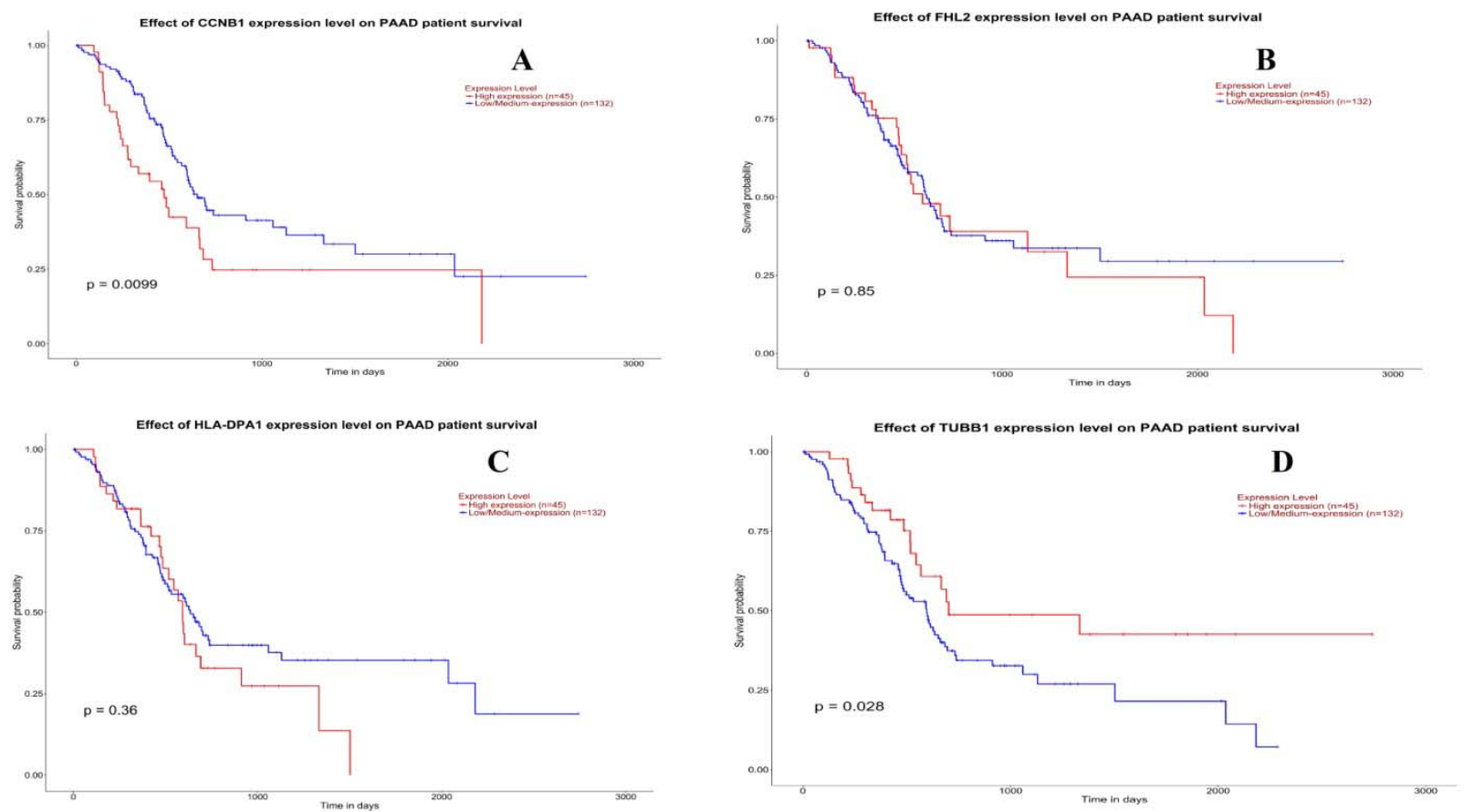

Fig. 5. Overall survival analysis of hub genes. Overall survival analyses were performed using the UALCAN online platform. Red line denotes - high expression; Blur line denotes - low expression. A) CCNB1 B) FHL2 C) HLADPA1 D) TUBB1 
medRxiv preprint doi: https://doi.org/10.1101/2020.12.20.20248601; this version posted December 23, 2020. The copyright holder for this preprint (which was not certified by peer review) is the author/funder, who has granted medRxiv a license to display the preprint in perpetuity.

All rights reserved. No reuse allowed without permission.

A

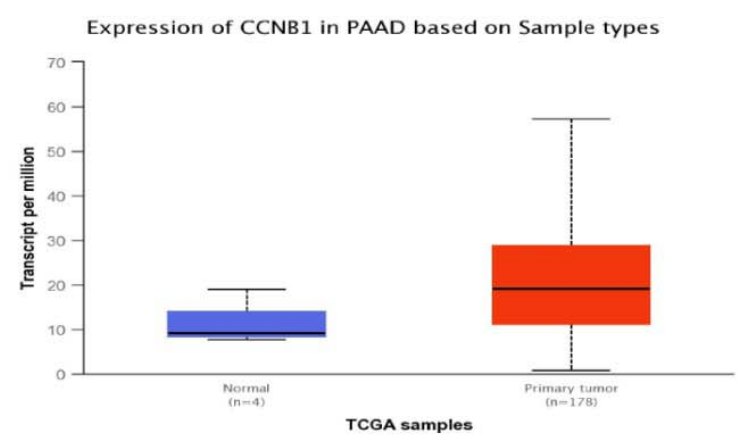

C

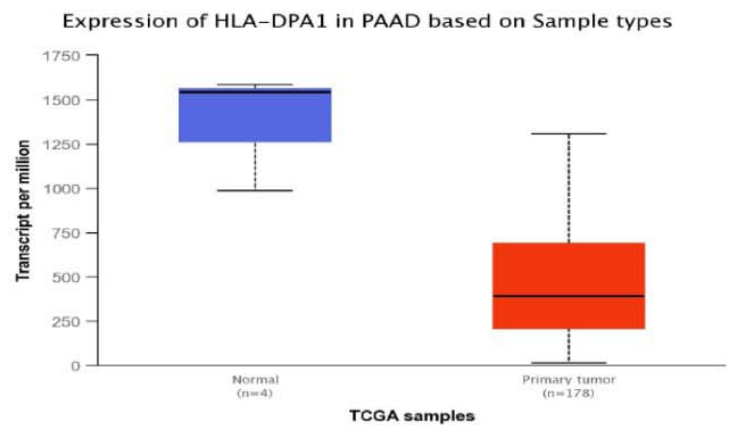

B

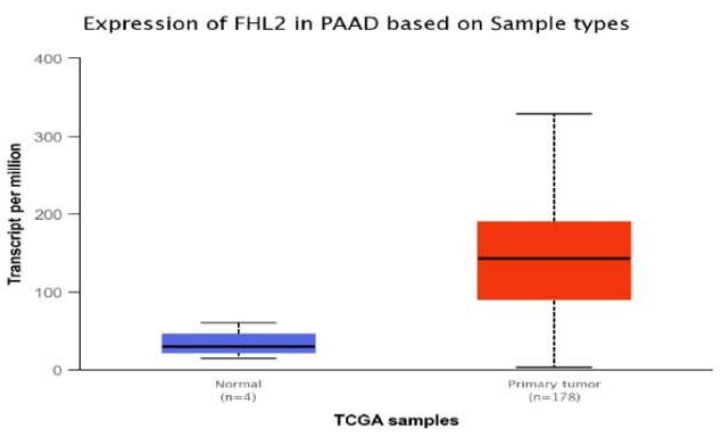

D

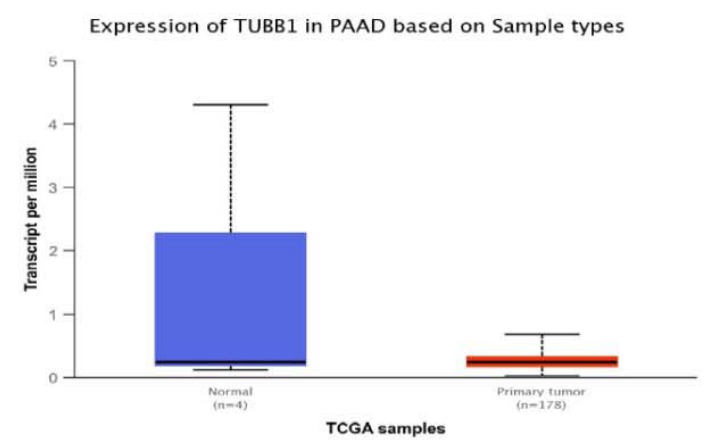

Fig. 6. Box plots (expression analysis) hub genes were produced using the UALCAN platform. A) CCNB1 B) FHL2 C) HLA-DPA1 D) TUBB1 
medRxiv preprint doi: https://doi.org/10.1101/2020.12.20.20248601; this version posted December 23, 2020. The copyright holder for this preprint (which was not certified by peer review) is the author/funder, who has granted medRxiv a license to display the preprint in perpetuity. All rights reserved. No reuse allowed without permission.

A

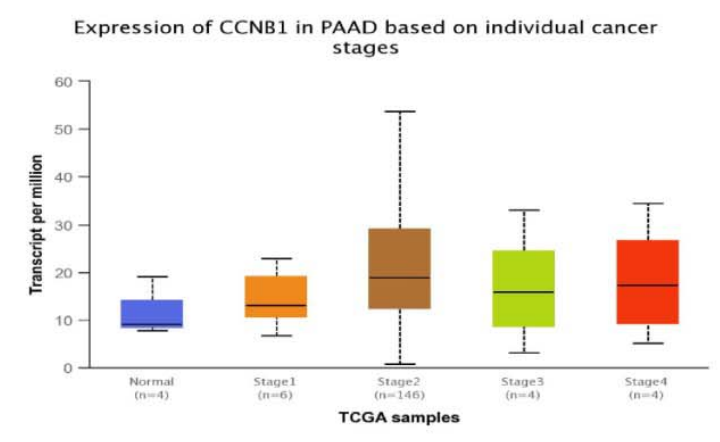

C

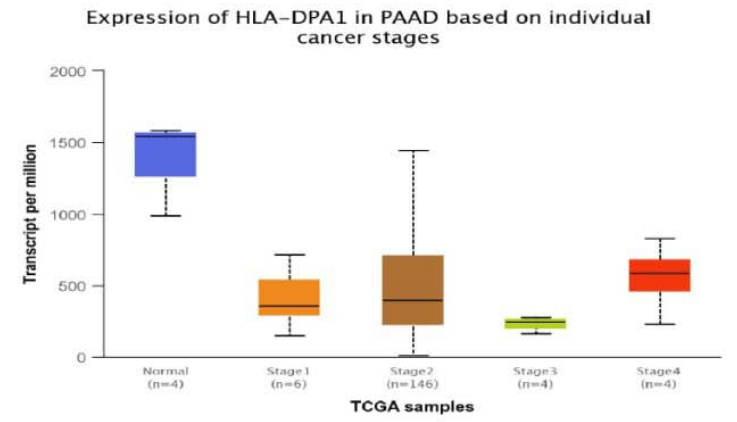

B

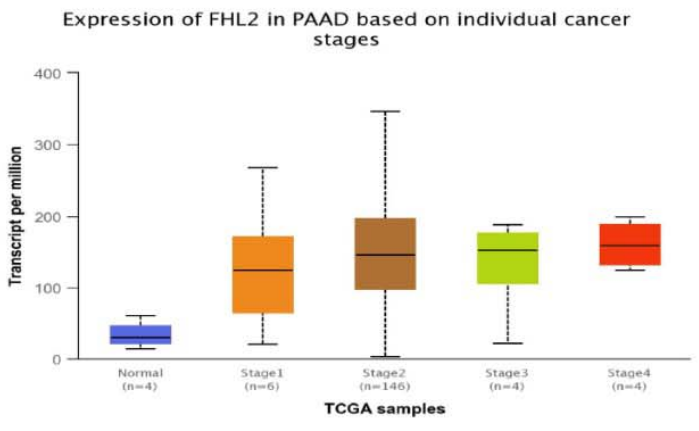

D

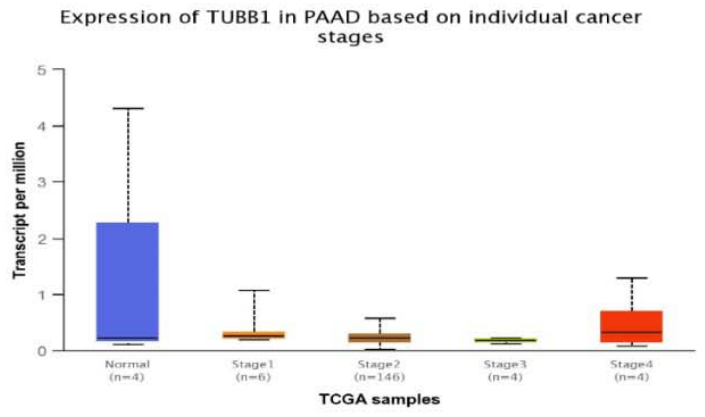

Fig. 7. Box plots (clinical stage analysis) hub genes were produced using the UALCAN platform. A) CCNB1 B) FHL2 C) HLA-DPA1 D) TUBB1
A CONB1 On
B FHL2 $0 . \%$
C HLADPAI $230|\|||||||||-|$
D TUBB1 $23 \% \|||||||$

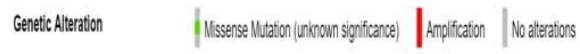

Fig. 8. Mutation analyses of hub genes were produced using the CbioPortal online platform. A) CCNB1 B) FHL2 C) HLA-DPA1 D) TUBB1 
medRxiv preprint doi: https://doi.org/10.1101/2020.12.20.20248601; this version posted December 23, 2020. The copyright holder for this preprint (which was not certified by peer review) is the author/funder, who has granted medRxiv a license to display the preprint in perpetuity. All rights reserved. No reuse allowed without permission.

A

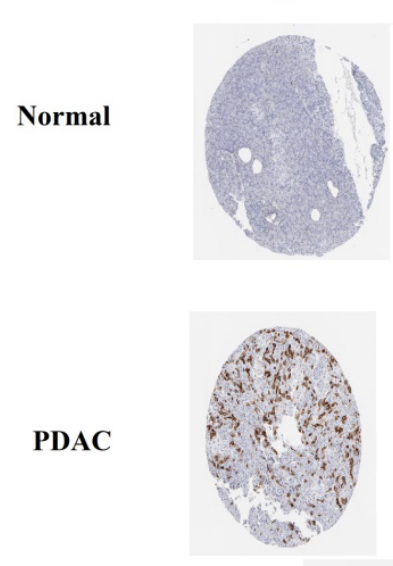

B
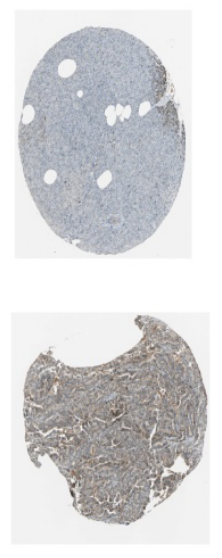

C

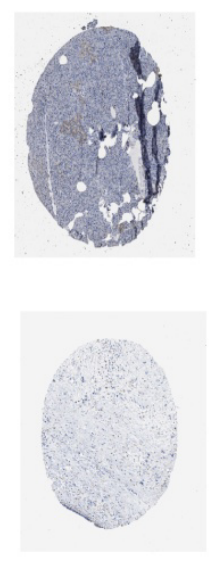

D
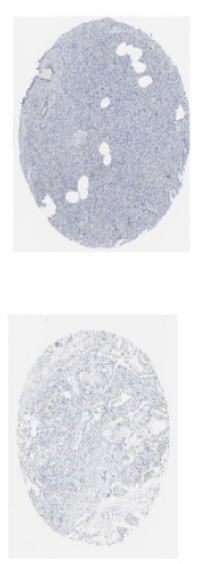

Fig. 9. Immunohisto chemical (IHC) analyses of hub genes were produced using the human protein atlas (HPA) online platform. A) CCNB1 B) FHL2 C) HLA-DPA1 D) TUBB1

A
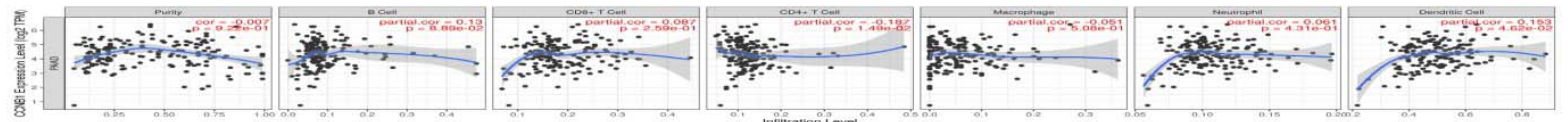

в
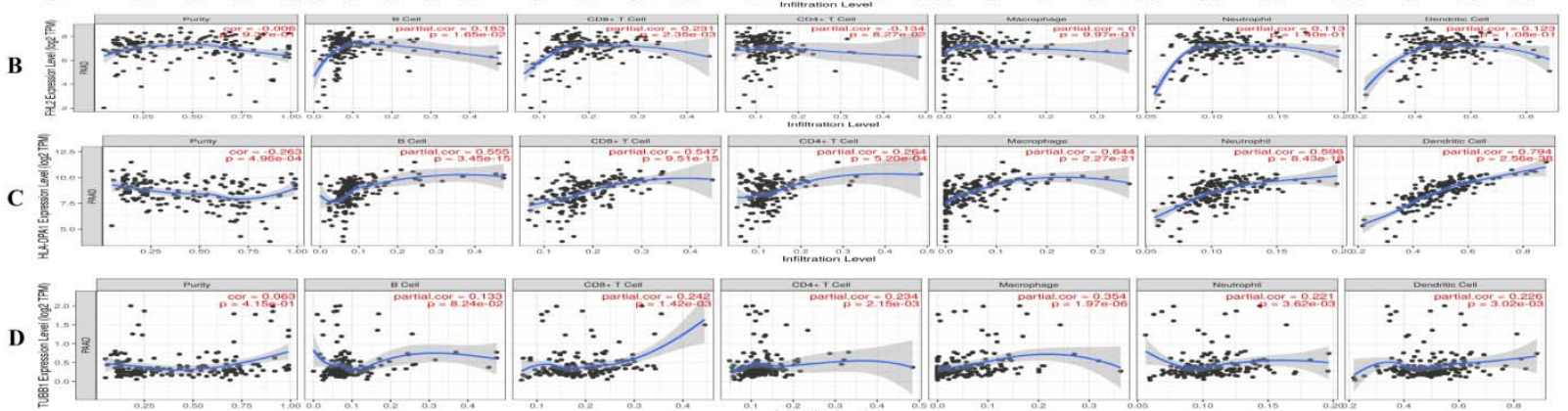

Fig. 10. Scatter plot for immune infiltration for hub genes. A) CCNB1 B) FHL2 C) HLA-DPA1 D) TUBB1 

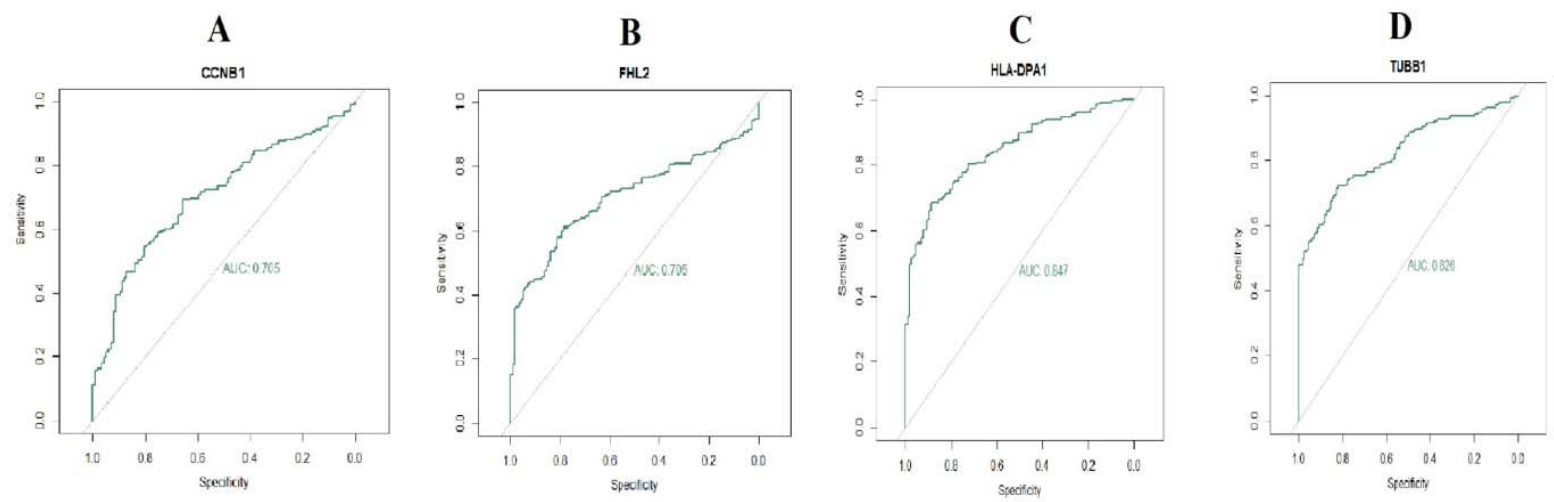

Fig. 11. ROC curve validated the sensitivity, specificity of hub genes as a predictive biomarker for PDAC prognosis. A) CCNB1 B) FHL2 C) HLA-DPA1 D) TUBB1
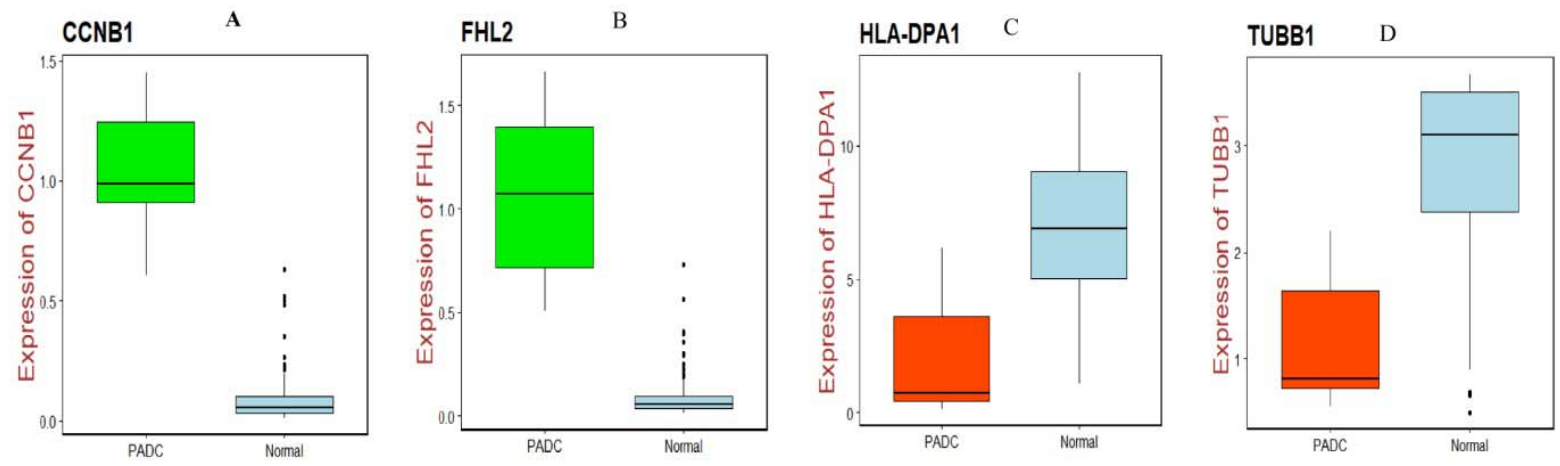

PDAC (Up regulated)

PDAC (Down regulated)

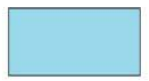

Normal control

Fig. 12. Validation of hub genes by RT- PCR. A) CCNB1 B) FHL2 C) HLA-DPA1 D) TUBB1 
medRxiv preprint doi: https://doi.org/10.1101/2020.12.20.20248601; this version posted December 23, 2020. The copyright holder for this preprint (which was not certified by peer review) is the author/funder, who has granted medRxiv a license to display the preprint in perpetuity.

All rights reserved. No reuse allowed without permission.

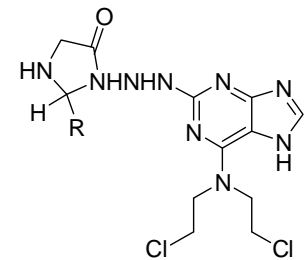

Imidazolidine derivatives (IM)

$\mathrm{R}$<smiles>COc1cncc(C)c1</smiles><smiles>[R]C1NC(=O)CS1</smiles>

Thiazolidine derivatives (TZ)<smiles>[R]C=NNc1nc(N(CCCl)CCCl)c2[nH]cnc2n1</smiles>

Purine derivetives (PU)<smiles>C/C=C/c1ccccc1</smiles><smiles>COc1cc(C)ccc1O</smiles>

Fig. 13. Structures of Designed Molecules

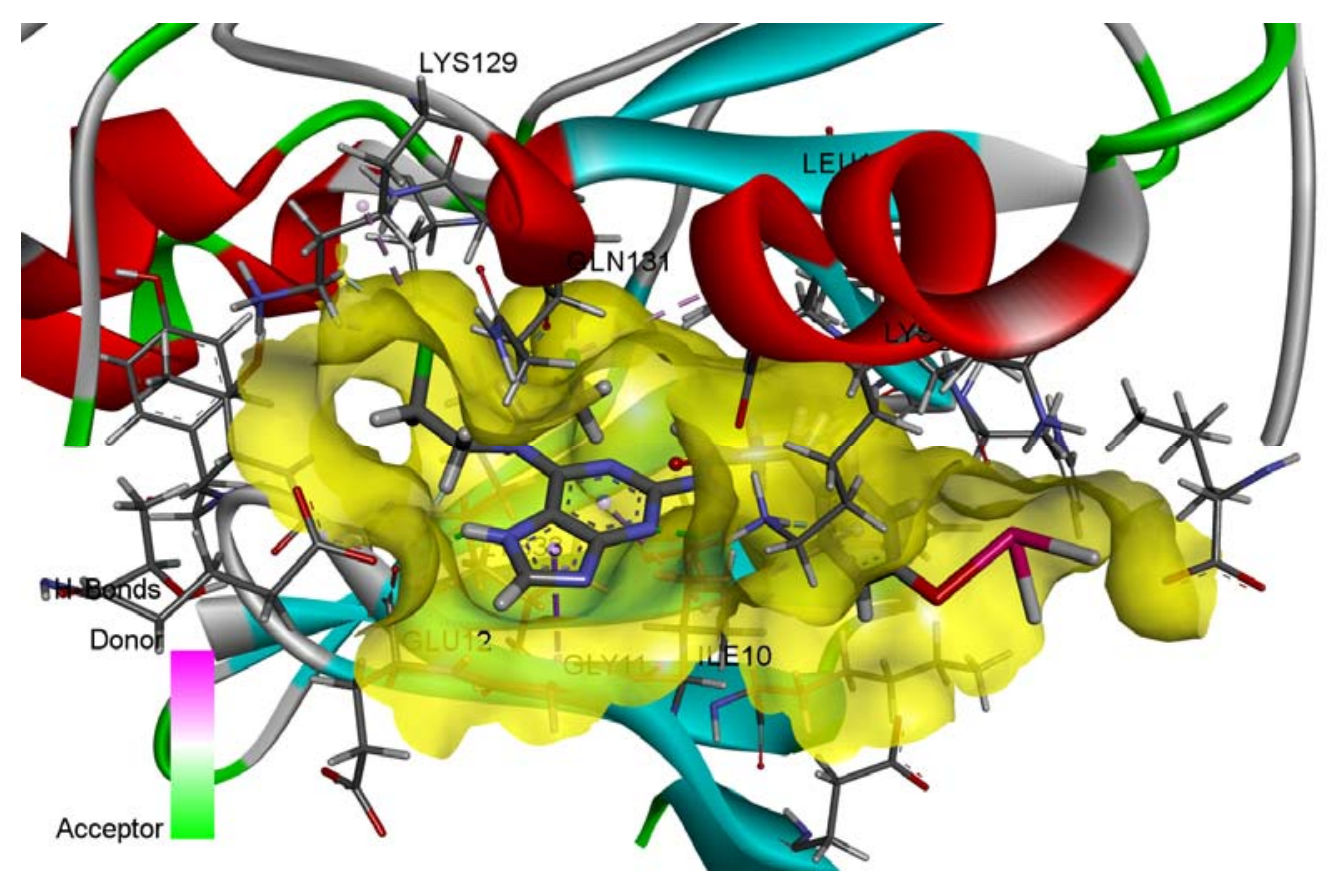

Fig.14. 3D Binding of Molecule IM 8 with $1 \mathrm{H} 0 \mathrm{~V}$ 
medRxiv preprint doi: https://doi.org/10.1101/2020.12.20.20248601; this version posted December 23, 2020. The copyright holder for this preprint (which was not certified by peer review) is the author/funder, who has granted medRxiv a license to display the preprint in perpetuity. All rights reserved. No reuse allowed without permission.

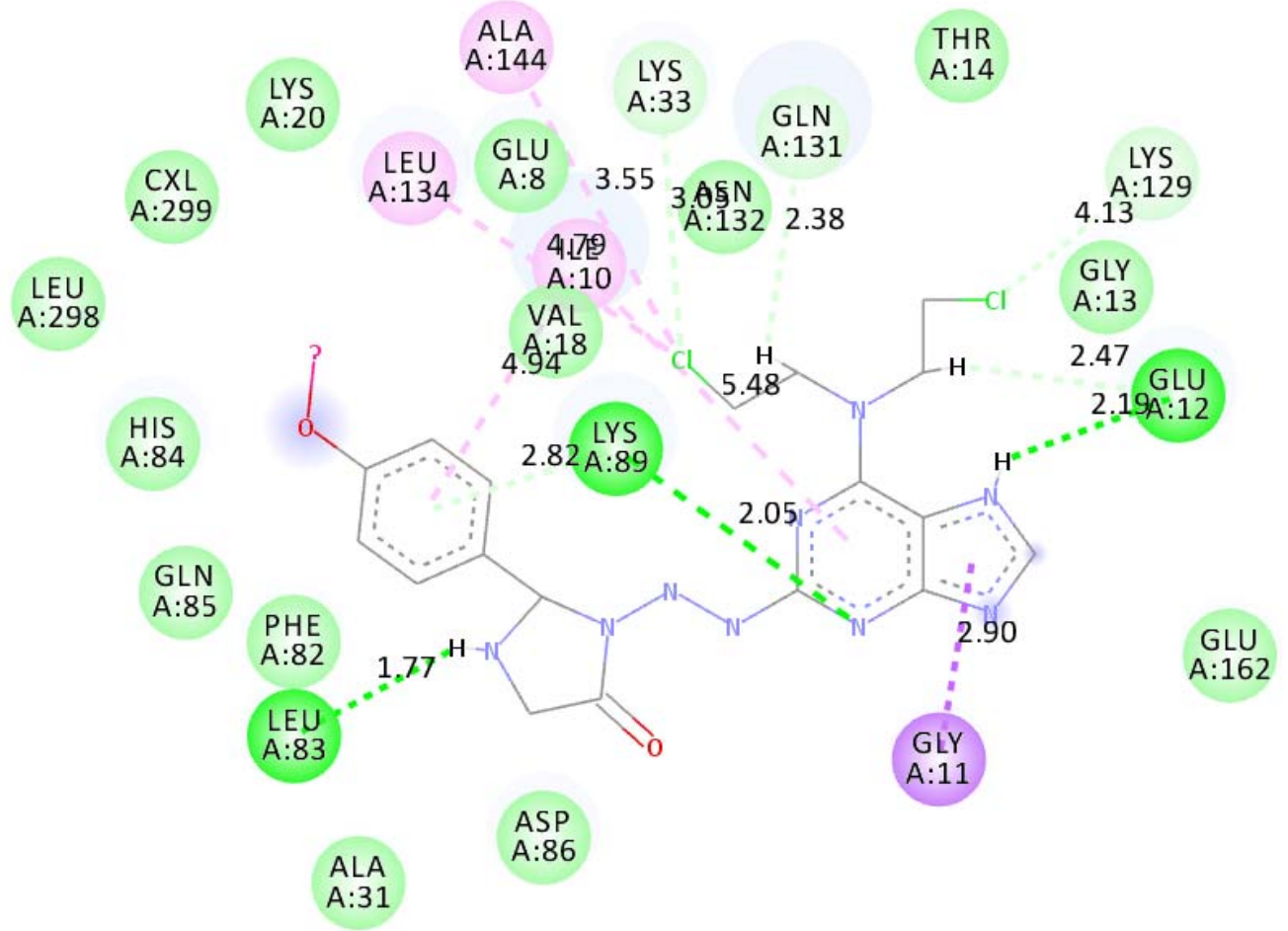

Fig. 15. 2D Binding of Molecule IM 8 with 1HOV 
medRxiv preprint doi: https://doi.org/10.1101/2020.12.20.20248601; this version posted December 23, 2020. The copyright holder for this preprint (which was not certified by peer review) is the author/funder, who has granted medRxiv a license to display the preprint in perpetuity.

All rights reserved. No reuse allowed without permission. 